\title{
Synthesis and Antitumor Activity of C-7-Alkynylated and Arylated Pyrrolotriazine C-Ribonucleosides
}

Qingfeng Li, $\uparrow$ Elisabetta Groaz, $\uparrow$ Leentje Persoons,§ Dirk Daelemans,§ and Piet Herdewijn†**

$†$ Medicinal Chemistry, KU Leuven, Rega Institute for Medical Research, Herestraat 49-box 1041, 3000 Leuven, Belgium

§Laboratory of Virology and Chemotherapy, KU Leuven, Rega Institute for Medical Research, Herestraat 49box 1043, 3000 Leuven, Belgium

\section{Table of Contents}

Experimental Section

Compound 11a ${ }^{1} \mathrm{H}$ NMR

Compound 11a ${ }^{13} \mathrm{C}\left\{{ }^{1} \mathrm{H}\right\}$ NMR

Compound 11b ${ }^{1} \mathrm{H}$ NMR

Compound 11b ${ }^{13} \mathrm{C}\left\{{ }^{1} \mathrm{H}\right\}$ NMR

Compound 11c ${ }^{1} \mathrm{H}$ NMR

Compound 11c ${ }^{13} \mathrm{C}\left\{{ }^{1} \mathrm{H}\right\}$ NMR

Compound 11d ${ }^{1} \mathrm{H}$ NMR

Compound 11d ${ }^{13} \mathrm{C}\left\{{ }^{1} \mathrm{H}\right\}$ NMR

Compound 11e ${ }^{1} \mathrm{H}$ NMR

Compound 11e ${ }^{13} \mathrm{C}\left\{{ }^{1} \mathrm{H}\right\}$ NMR

Compound 11f ${ }^{1} \mathrm{H}$ NMR

Compound 11f ${ }^{13} \mathrm{C}\left\{{ }^{1} \mathrm{H}\right\}$ NMR

Compound 11g ${ }^{1} \mathrm{H}$ NMR

Compound 11g ${ }^{13} \mathrm{C}\left\{{ }^{1} \mathrm{H}\right\}$ NMR 
Compound 12a ${ }^{13} \mathrm{C}\left\{{ }^{1} \mathrm{H}\right\}$ NMR $\quad$ S33

Compound 12b ${ }^{1} \mathrm{H}$ NMR $\quad$ S34

Compound 12b ${ }^{13} \mathrm{C}\left\{{ }^{1} \mathrm{H}\right\}$ NMR $\quad$ S35

Compound 12b ${ }^{1} \mathrm{H}$ NMR $\quad$ S36

Compound 12c ${ }^{13} \mathrm{C}\left\{{ }^{1} \mathrm{H}\right\}$ NMR $\quad$ S37

Compound 12d ${ }^{1} \mathrm{H}$ NMR $\quad$ S38

Compound 12d ${ }^{13} \mathrm{C}\left\{{ }^{1} \mathrm{H}\right\}$ NMR $\quad$ S39

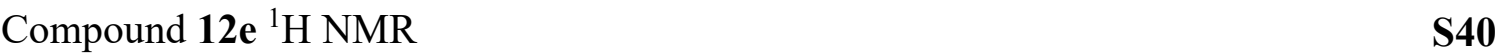

Compound 12e ${ }^{13} \mathrm{C}\left\{{ }^{1} \mathrm{H}\right\}$ NMR

Compound 12f ${ }^{1} \mathrm{H}$ NMR $\quad$ S42

Compound 12f ${ }^{13} \mathrm{C}\left\{{ }^{1} \mathrm{H}\right\}$ NMR $\quad \mathbf{S 4 3}$

Compound 12g ${ }^{1} \mathrm{H}$ NMR $\quad \mathbf{S 4 4}$

Compound 12g ${ }^{13} \mathrm{C}\left\{{ }^{1} \mathrm{H}\right\}$ NMR $\quad$ S45

Compound 12h ${ }^{1} \mathrm{H}$ NMR $\quad$ S46

Compound 12h ${ }^{13} \mathrm{C}\left\{{ }^{1} \mathrm{H}\right\}$ NMR $\quad$ S47

Compound $12 \mathbf{i}^{1} \mathrm{H}$ NMR $\quad \mathbf{S 4 8}$

Compound 12i ${ }^{13} \mathrm{C}\left\{{ }^{1} \mathrm{H}\right\}$ NMR

Compound 12j ${ }^{1} \mathrm{H}$ NMR $\quad$ S50

Compound $\mathbf{1 2} \mathbf{j}{ }^{13} \mathrm{C}\left\{{ }^{1} \mathrm{H}\right\}$ NMR

Compound 12k ${ }^{1} \mathrm{H}$ NMR

Compound 12k ${ }^{13} \mathrm{C}\left\{{ }^{1} \mathrm{H}\right\}$ NMR

Compound 11a HRMS $\quad$ S54

Compound 11b HRMS

Compound 11c HRMS $\quad$ S56

Compound 11d HRMS

Compound 11e HRMS $\quad$ S58

Compound 11f HRMS

Compound 11g HRMS $\quad$ S60

Compound 12a HRMS

Compound 12b HRMS

Compound 12c HRMS $\quad$ S63

Compound 12d HRMS $\quad$ S64

Compound 12e HRMS $\quad$ S65

Compound 12f HRMS $\quad$ S66

Compound 12g HRMS $\quad$ S67

Compound 12h HRMS $\quad$ S68

Compound 12i HRMS $\quad$ S69

Compound 12j HRMS $\quad$ S70

$\begin{array}{ll}\text { Compound 12k HRMS } & \text { S71 }\end{array}$ 


\section{Experimental section}

\subsection{General chemical information}

All reagents and solvents were purchased from commercial sources and used as obtained. Moisture sensitive reactions were carried out using oven-dried glassware under a nitrogen or argon atmosphere. ${ }^{1} \mathrm{H}$ NMR, ${ }^{13} \mathrm{C}$ NMR, and ${ }^{31} \mathrm{P}$ NMR spectra were recorded on a Bruker Avance 300 or $600 \mathrm{MHz}$ spectrometer using tetramethylsilane as internal standard or referenced to the residual solvent signal. The following abbreviations were used to indicate multiplicities: s (singlet), $d$ (doublet), t (triplet), q (quartet), m (multiplet), br (broad), and dd (doublet of doublets). Coupling constants are expressed in hertz (Hz). High-resolution mass spectra (HRMS) were obtained on a quadrupole orthogonal acceleration time-of-flight mass spectrometer (Synapt G2 HDMS, Waters, Milford, MA). Samples were infused at $3 \mu \mathrm{L} / \mathrm{min}$ and spectra were obtained in positive ionization mode with a resolution of 15000 (fwhm) using leucine enkephalin as lock mass. Pre-coated aluminum sheets $(254 \mathrm{~nm})$ were used for thin layer chromatography (TLC), and spots were visualized with UV light. All intermediate products were purified by flash silica gel column chromatography (40-60 $\mu, 60 \AA)$. Final compounds were purified by preparative RP-HPLC (C18 Phenomenex Gemini column, $110 \AA, 10 \mu \mathrm{m}, 21.2 \mathrm{~mm} \times 250 \mathrm{~mm}$ ) using a linear gradient of $\mathrm{CH}_{3} \mathrm{CN}$ or $\mathrm{MeOH}$ and $\mathrm{H}_{2} \mathrm{O}$.

\subsection{Synthetic procedures}

7-(Iodo)-4-aza-7,9-dideazaadenosine (13). Compound 13 was obtained according to a previously reported procedure. ${ }^{1}$

7-(Pent-1-yn-1-yl)-4-aza-7,9-dideazaadenosine (11a). An argon purged mixture of 13 (100.0 mg, $0.255 \mathrm{mmol}), \mathrm{PdCl}_{2}\left(\mathrm{PPh}_{3}\right)_{2}(9.00 \mathrm{mg}, 0.013 \mathrm{mmol}), \mathrm{CuI}$ (24.0 mg, $\left.0.127 \mathrm{mmol}\right)$, pent-1-yne $(0.25 \mathrm{~mL}, 2.55 \mathrm{mmol})$, and triethylamine $(0.1 \mathrm{~mL})$ in dry DMF $(5 \mathrm{~mL})$ was stirred at room temperature for $16 \mathrm{~h}$. After removal of all the volatiles in vacuo, the remaining residue was coevaporated twice with $\mathrm{EtOH}$, then redissolved in a minimal amount of $\mathrm{EtOH}$ and further loaded on silica gel by coevaporation until complete drying. The mixture was then purified by flash 
column chromatography $\left(\mathrm{CH}_{2} \mathrm{Cl}_{2} / \mathrm{MeOH}=10: 1, \mathrm{v} / \mathrm{v}\right)$, followed by further purification by preparative TLC $\left(\mathrm{CH}_{2} \mathrm{Cl}_{2} / \mathrm{MeOH}=20: 1, \mathrm{v} / \mathrm{v}\right)$ and reversed-phase HPLC (5-60\% MeCN in water) to afford $11 \mathrm{a}$ as a white solid (7.00 mg, 8\%). ${ }^{1} \mathrm{H}$ NMR (300 MHz, CD $\left.\mathrm{OD}_{3} \mathrm{~d}_{4}\right) \delta 7.79\left(\mathrm{~s}, 1 \mathrm{H}, \mathrm{H}_{2}\right)$,

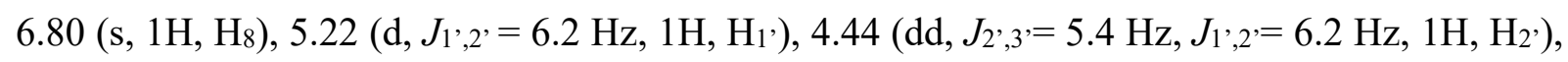
$4.16\left(\mathrm{dd}, J_{3^{\prime}, 4^{\prime}}=4.3 \mathrm{~Hz}, J_{3^{\prime}, 2^{\prime}}=5.3 \mathrm{~Hz}, 1 \mathrm{H}, \mathrm{H}_{3}{ }^{\prime}\right), 4.02\left(\mathrm{ddd}, J^{\prime}, 5^{\prime}\right.$ " = $3.2 \mathrm{~Hz}, J_{4^{\prime}, 5^{\prime}}=4.0 \mathrm{~Hz}, J_{4^{\prime}, 3^{\prime}}=$ $\left.4.2 \mathrm{~Hz}, 1 \mathrm{H}, \mathrm{H}_{4}{ }^{\prime}\right), 3.83-3.66\left(2 \times \mathrm{dd}, J_{5}{ }^{\prime}, 4^{\prime}=4.0 \mathrm{~Hz}, J_{5^{\prime}, 4^{\prime}}=3.2 \mathrm{~Hz}, J_{\mathrm{gem}}=12.3 \mathrm{~Hz}, \mathrm{H}_{5}, \mathrm{H}_{5}{ }^{\prime}\right), 2.49$ (t, $\left.J=7.1 \mathrm{~Hz}, 2 \mathrm{H}, \mathrm{CH}_{2} \mathrm{CH}_{2} \mathrm{CH}_{3}\right), 1.70-1.69$ (m, 2H, $\left.\mathrm{CH}_{2} \mathrm{CH}_{2} \mathrm{CH}_{3}\right), 1.08$ (t, $J=7.1 \mathrm{~Hz}, 3 \mathrm{H}$, $\mathrm{CH}_{2} \mathrm{CH}_{2} \mathrm{CH}_{3}$ ); ${ }^{13} \mathrm{C}$ NMR (75 MHz, CD $\left.{ }_{3} \mathrm{OD}-\mathrm{d}_{4}\right) \delta 155.7$ (C-2), 147.3 (C-5), 128.5 (C-6), 115.5 (C9), 113.4 (C-7), 97.7 (C-8), 93.2, 84.5 (C-1'), 76.4 (C-4'), 73.5 (C-2'), 71.3 (C-3'), 61.9 (C-5'), 28.9, 21.5, 20.4, 12.0; HRMS (ESI-TOF) m/z: calcd for $\mathrm{C}_{16} \mathrm{H}_{21} \mathrm{~N}_{4} \mathrm{O}_{4}\left([\mathrm{M}+\mathrm{H}]^{+}\right), 333.1563$, found 333.1559 .

7-(Hex-1-yn-1-yl)-4-aza-7,9-dideazaadenosine (11b). Following a similar procedure as that used for the synthesis of $\mathbf{1 1 a}$, compound $\mathbf{1 1 b}$ was obtained as a white solid ( $6 \mathrm{mg}, 7 \%)$ starting from $\mathbf{1 3}$ (100.0 mg, $0.255 \mathrm{mmol}), \mathrm{PdCl}_{2}\left(\mathrm{PPh}_{3}\right)_{2}(9.00 \mathrm{mg}, 0.013 \mathrm{mmol}), \mathrm{CuI}$ (24 mg, $\left.0.127 \mathrm{mmol}\right)$, hex-1yne $(0.30 \mathrm{~mL}, 2.55 \mathrm{mmol})$, and triethylamine $(0.1 \mathrm{~mL})$ in dry DMF $(5.0 \mathrm{~mL})$ after purification by silica gel column chromatography $\left(\mathrm{CH}_{2} \mathrm{Cl}_{2} / \mathrm{MeOH}=10: 1\right.$, v/v), preparative TLC $\left(\mathrm{CH}_{2} \mathrm{Cl}_{2} / \mathrm{MeOH}\right.$ $=20: 1, \mathrm{v} / \mathrm{v})$, and reversed-phase HPLC (5-60\% MeCN in water). ${ }^{1} \mathrm{H}$ NMR (300 $\left.\mathrm{MHz}, \mathrm{CD}_{3} \mathrm{OD}-\mathrm{d}_{4}\right)$ $\delta 7.79\left(\mathrm{~s}, 1 \mathrm{H}, \mathrm{H}_{2}\right), 6.79(\mathrm{~s}, 1 \mathrm{H}, \mathrm{H} 8), 5.22\left(\mathrm{~d}, J_{1^{\prime}, 2^{\prime}}=6.3 \mathrm{~Hz}, 1 \mathrm{H}, \mathrm{H}_{1}{ }^{\prime}\right), 4.44\left(\mathrm{dd}, J_{2}{ }^{\prime}, 3^{\prime}=5.3 \mathrm{~Hz}, J_{2}{ }^{\prime}, 1^{\prime}=\right.$ $\left.6.3 \mathrm{~Hz}, 1 \mathrm{H}, \mathrm{H}_{2}{ }^{\prime}\right), 4.16\left(\mathrm{dd}, J_{3^{\prime}, 4^{\prime}}=4.3 \mathrm{~Hz}, J_{3^{\prime}, 2^{\prime}}=5.3 \mathrm{~Hz}, 1 \mathrm{H}, \mathrm{H}_{3}{ }^{\prime}\right), 4.02\left(\mathrm{ddd}, J^{\prime}, 3^{\prime}=4.3 \mathrm{~Hz}, J_{4}{ }^{\prime}, 5^{\prime}=\right.$ $\left.4.0 \mathrm{~Hz}, J_{4}, 5^{\prime}=3.3 \mathrm{~Hz}, 1 \mathrm{H}, \mathrm{H}_{4}{ }^{\prime}\right), 3.79-3.66\left(2 \times \mathrm{dd}, J_{\mathrm{gem}}=12.1 \mathrm{~Hz}, J_{5}, 4^{\prime}=4.0 \mathrm{~Hz}, J_{5}{ }^{\prime}, 4^{\prime}=3.3 \mathrm{~Hz}\right.$, $2 \mathrm{H}, \mathrm{H}_{5}, \mathrm{H}_{5}$ "), 2.49 (t, $\left.J=7.0 \mathrm{~Hz}, 2 \mathrm{H}, \mathrm{CH}_{2} \mathrm{CH}_{2} \mathrm{CH}_{2} \mathrm{CH}_{3}\right), 1.66-1.50$ (m, 4H, $\left.\mathrm{CH}_{2}\left(\mathrm{CH}_{2}\right)_{2} \mathrm{CH}_{3}\right), 0.99$ (t, $\left.J=7.3 \mathrm{~Hz}, 3 \mathrm{H}, \mathrm{CH}_{2} \mathrm{CH}_{2} \mathrm{CH}_{2} \mathrm{CH}_{3}\right) ;{ }^{13} \mathrm{C} \mathrm{NMR}\left(75 \mathrm{MHz}, \mathrm{CD}_{3} \mathrm{OD}-\mathrm{d}_{4}\right) \delta 155.7$ (C-2), 147.3 (C-5), 128.5 (C-6), 115.5 (C-9), 113.4 (C-7), 97.7 (C-8), 93.3, 84.5 (C-1'), 76.4 (C-4'), 73.5 (C-2'), 71.3 (C-3'), 61.9 (C-5'), 30.2, 28.9, 21.3, 18.1, 12.1; HRMS (ESI-TOF) m/z: calcd for $\mathrm{C}_{17} \mathrm{H}_{22} \mathrm{~N}_{4} \mathrm{O}_{4}$ $\left([\mathrm{M}+\mathrm{H}]^{+}\right), 347.1719$, found 347.1709.

7-(Cyclopropylethynyl)-4-aza-7,9-dideazaadenosine (11c). Following a similar procedure as that used for the synthesis of 11a, compound 11c was obtained as a white solid (7.00 $\mathrm{mg}, 8 \%)$ starting from $13(100.0 \mathrm{mg}, 0.255 \mathrm{mmol}), \mathrm{PdCl}_{2}\left(\mathrm{PPh}_{3}\right)_{2}(9.00 \mathrm{mg}, 0.013 \mathrm{mmol}), \mathrm{CuI}(24.0 \mathrm{mg}$, $0.127 \mathrm{mmol})$, ethynylcyclopropane $(0.50 \mathrm{~mL}, 2.55 \mathrm{mmol})$, and triethylamine $(0.1 \mathrm{~mL})$ in dry DMF $(5.0 \mathrm{~mL})$ after purification by silica gel column chromatography $\left(\mathrm{CH}_{2} \mathrm{Cl}_{2} / \mathrm{MeOH}=10: 1, \mathrm{v} / \mathrm{v}\right)$, preparative TLC $\left(\mathrm{CH}_{2} \mathrm{Cl}_{2} / \mathrm{MeOH}=20: 1, \mathrm{v} / \mathrm{v}\right)$, and reversed-phase HPLC (5-60\% MeCN in water). 
${ }^{1} \mathrm{H}$ NMR (300 MHz, CD $\left.{ }_{3} \mathrm{OD}-\mathrm{d}_{4}\right) \delta 7.79\left(\mathrm{~s}, 1 \mathrm{H}, \mathrm{H}_{2}\right), 6.78\left(\mathrm{~s}, 1 \mathrm{H}, \mathrm{H}_{8}\right), 5.20\left(\mathrm{~d}, J_{1^{\prime}, 2^{\prime}}=6.2 \mathrm{~Hz}, 1 \mathrm{H}\right.$, $\left.\mathrm{H}_{1^{\prime}}\right)^{\prime}, 4.44\left(\mathrm{dd}, J_{2^{\prime}, 3^{\prime}}=5.4 \mathrm{~Hz}, J_{1^{\prime}, 2^{\prime}}=6.2 \mathrm{~Hz}, 1 \mathrm{H}, \mathrm{H}_{2^{\prime}}\right), 4.16\left(\mathrm{dd}, J_{3^{\prime}, 4^{\prime}}=4.6 \mathrm{~Hz}, J_{3^{\prime}, 2^{\prime}}=5.4 \mathrm{~Hz}, 1 \mathrm{H}\right.$, $\left.\mathrm{H}_{3}{ }^{\prime}\right), 4.02\left(\mathrm{ddd}, J_{4^{\prime}, 5^{\prime}}=4.0 \mathrm{~Hz}, J_{4^{\prime}, 5^{\prime}}=3.2 \mathrm{~Hz} J_{4^{\prime}, 3^{\prime}}=4.6 \mathrm{~Hz}, 1 \mathrm{H}, \mathrm{H}_{4}{ }^{\prime}\right), 3.82-3.66\left(2 \times \mathrm{dd}, J_{\mathrm{gem}}=\right.$ $\left.12.1 \mathrm{~Hz}, J_{5}, 4^{\prime}=4.0 \mathrm{~Hz}, J_{5}{ }^{\prime}, 4^{\prime}=3.2 \mathrm{~Hz}, 2 \mathrm{H}, \mathrm{H}_{5}{ }^{\prime}, \mathrm{H}_{5}{ }^{\prime}\right), 1.60-1.54\left(\mathrm{~m}, 1 \mathrm{H}, \mathrm{CH}\left(\mathrm{CH}_{2} \mathrm{CH}_{2}\right)\right), 0.96-0.91$ (m, 2H, CH(CH2 $\left.\left.\mathrm{CH}_{2}\right)\right)$, 0.81-0.76 (m, 2H, CH( $\left.\left.\mathrm{CH}_{2} \mathrm{CH}_{2}\right)\right) ;{ }^{13} \mathrm{C} \mathrm{NMR}\left(75 \mathrm{MHz}, \mathrm{CD}_{3} \mathrm{OD}-\mathrm{d}_{4}\right) \delta 157.2$ (C-2), 148.8 (C-5), 130.0 (C-6), 117.2 (C-9), 115.1 (C-7), 99.1 (C-8), 98.0, 86.0 (C-1'), 77.9 (C4'), 74.9 (C-2'), 72.8 (C-3'), 69.8 (C-3'), 63.4 (C-5'), 8.8, 0.5; HRMS (ESI-TOF) m/z: calcd for $\mathrm{C}_{16} \mathrm{H}_{18} \mathrm{~N}_{4} \mathrm{O}_{4}\left([\mathrm{M}+\mathrm{H}]^{+}\right), 331.1406$, found 331.1397 .

7-((4-Fluorophenyl)ethynyl)-4-aza-7,9-dideazaadenosine (11d). Following a similar procedure as that used for the synthesis of 11a, compound 11d was obtained as a white solid (12.0 $\mathrm{mg}, 12 \%)$ starting from 13 (100.0 mg, $0.255 \mathrm{mmol}), \mathrm{PdCl}_{2}\left(\mathrm{PPh}_{3}\right)_{2}(9.00 \mathrm{mg}, 0.013 \mathrm{mmol}), \mathrm{CuI}(24.0 \mathrm{mg}$, $0.127 \mathrm{mmol})$, 1-ethynyl-4-fluorobenzene $(0.50 \mathrm{~mL}, 2.55 \mathrm{mmol})$, and triethylamine $(0.1 \mathrm{~mL})$ in dry DMF $(5.0 \mathrm{~mL})$ after purification by silica gel column chromatography $\left(\mathrm{CH}_{2} \mathrm{Cl}_{2} / \mathrm{MeOH}=10: 1\right.$, $\mathrm{v} / \mathrm{v})$, preparative TLC $\left(\mathrm{CH}_{2} \mathrm{Cl}_{2} / \mathrm{MeOH}=20: 1, \mathrm{v} / \mathrm{v}\right)$, and reversed-phase HPLC $(5-60 \% \mathrm{MeCN}$ in water). ${ }^{1} \mathrm{H}$ NMR (300 MHz, DMSO-d $) ~ \delta 7.96\left(\mathrm{~s}, 1 \mathrm{H}, \mathrm{H}_{2}\right), 7.66$ (t, $\left.J=7.6 \mathrm{~Hz}, 2 \mathrm{H}, \mathrm{Ar}-H\right), 7.47$ (t, $J=8.0 \mathrm{~Hz}, 2 \mathrm{H}, \operatorname{Ar}-H), 7.01\left(\mathrm{~s}, 1 \mathrm{H}, \mathrm{H}_{8}\right), 5.13\left(\mathrm{~d}, J=6.1 \mathrm{~Hz}, 1 \mathrm{H}, \mathrm{H}_{1^{\circ}}\right), 5.10\left(\mathrm{~d}, J_{\mathrm{OH}, 2^{\prime}}=6.2 \mathrm{~Hz}, 1 \mathrm{H}\right.$, OH-2'), $4.95\left(\mathrm{~d}, J_{\mathrm{OH}, 3^{\prime}}=4.9 \mathrm{~Hz}, 1 \mathrm{H}, \mathrm{OH}-3^{\prime}\right), 4.82\left(\mathrm{dd}, J_{\mathrm{OH}, 5^{\prime}}=5.5 \mathrm{~Hz}, J_{\mathrm{OH}, 5^{\prime}}=5.5 \mathrm{~Hz}, 1 \mathrm{H}, \mathrm{OH}-\right.$ 5'), $4.21\left(\mathrm{ddd}, J_{2}{ }^{\prime}, 3^{\prime}=5.5 \mathrm{~Hz}, J_{2^{\prime}, 1^{\prime}}=6.1 \mathrm{~Hz}, J_{2}{ }^{\prime}, \mathrm{OH}=6.2 \mathrm{~Hz}, 1 \mathrm{H}, \mathrm{H}_{2}{ }^{\prime}\right), 3.96\left(\mathrm{~m}, 1 \mathrm{H}, \mathrm{H}_{3^{\prime}}\right.$ ), 3.81 (m, 1H, $\mathrm{H}_{4}$ ) $), 3.55-3.45$ (m, 2H, $\left.\mathrm{H}_{5}{ }^{\prime}, \mathrm{H}_{5}{ }^{\prime}\right) ;{ }^{13} \mathrm{C}$ NMR (75 MHz, DMSO-d 6 ) $\delta 163.7,160.4,155.7,148.8$, 133.6, 133.5 (d, $J=7.7 \mathrm{~Hz}), 130.2,119.0$ (d, $J=3.3 \mathrm{~Hz}), 116.1,115.8,115.7,113.7,95.2,91.2$, 84.6 (C-1'), 83.3, 75.2 (C-4'), 74.1 (C-2'), 71.2 (C-3'), 61.9 (C-5'); HRMS (ESI-TOF) m/z: calcd for $\mathrm{C}_{19} \mathrm{H}_{17} \mathrm{~F}_{1} \mathrm{~N}_{4} \mathrm{O}_{4}\left([\mathrm{M}+\mathrm{H}]^{+}\right), 385.1312$, found 385.1304 .

7-(Thiophen-2-ylethynyl)-4-aza-7,9-dideazaadenosine (11e). Following a similar procedure as that used for the synthesis of 11a, compound 11e was obtained as a white solid (8.00 $\mathrm{mg}, 9 \%)$ starting from 13 (100.0 mg, $0.255 \mathrm{mmol}), \mathrm{PdCl}_{2}\left(\mathrm{PPh}_{3}\right)_{2}$ (9.00 mg, $\left.0.013 \mathrm{mmol}\right), \mathrm{CuI}$ (24.0 mg, $0.127 \mathrm{mmol})$, 2-ethynylthiophene $(0.5 \mathrm{~mL}, 2.55 \mathrm{mmol})$, and triethylamine $(0.1 \mathrm{~mL})$ in dry DMF $(5.0 \mathrm{~mL})$ after purification by silica gel column chromatography $\left(\mathrm{CH}_{2} \mathrm{Cl}_{2} / \mathrm{MeOH}=10: 1, \mathrm{v} / \mathrm{v}\right)$, preparative TLC $\left(\mathrm{CH}_{2} \mathrm{Cl}_{2} / \mathrm{MeOH}=20: 1, \mathrm{v} / \mathrm{v}\right)$, and reversed-phase HPLC (5-60\% MeCN in water). ${ }^{1} \mathrm{H}$ NMR (300 MHz, DMSO-d6) $\delta 7.96\left(\mathrm{~s}, 1 \mathrm{H}, \mathrm{H}_{2}\right), 7.66$ (d, $\left.J=4.0 \mathrm{~Hz}, 1 \mathrm{H}, \mathrm{Ar}-H\right), 7.47$ (d, $J=4.0$ $\mathrm{Hz}, 1 \mathrm{H}, \mathrm{Ar}-H), 7.13(\mathrm{t}, J=4.2 \mathrm{~Hz}, 1 \mathrm{H}, \mathrm{Ar}-H), 7.02(\mathrm{~s}, 1 \mathrm{H}, \mathrm{H} 8), 5.12\left(\mathrm{~d}, J_{1^{\prime}, 2^{\prime}}=6.1 \mathrm{~Hz}, 1 \mathrm{H}, \mathrm{H}_{1}{ }^{\prime}\right)$, $5.09\left(\mathrm{~d}, J_{\mathrm{OH}, 2^{\prime}}=6.3 \mathrm{~Hz}, 1 \mathrm{H}, \mathrm{OH}-2^{\prime}\right), 4.94\left(\mathrm{~d}, J_{\mathrm{OH}, 3^{\prime}}=4.8 \mathrm{~Hz}, 1 \mathrm{H}, \mathrm{OH}-3^{\prime}\right), 4.80\left(\mathrm{dd}, J_{\mathrm{OH}, 5^{\prime}}=6.1\right.$ 
$\left.\mathrm{Hz}, J_{\mathrm{OH}, 5^{\prime}}=5.5 \mathrm{~Hz}, 1 \mathrm{H}, \mathrm{OH}-5^{\prime}\right), 4.80\left(\mathrm{ddd}, J_{2^{\prime}, 3^{\prime}}=5.5 \mathrm{~Hz}, J_{2^{\prime}, 1^{\prime}}=6.1 \mathrm{~Hz}, J_{2^{\prime}, \mathrm{OH}}=6.3 \mathrm{~Hz}, 1 \mathrm{H}, \mathrm{H}_{2}{ }^{\prime}\right)$, $3.96\left(\mathrm{ddd}, J_{3^{\prime}, 4^{\prime}}=4.5 \mathrm{~Hz}, J_{3^{\prime}, 2^{\prime}}=5.5 \mathrm{~Hz}, J_{3^{\prime}, \mathrm{OH}}=4.8 \mathrm{~Hz}, 1 \mathrm{H}, \mathrm{H}_{3^{\prime}}\right), 3.80\left(\mathrm{ddd}, J_{4^{\prime}, 5^{\prime}}=4.7 \mathrm{~Hz}, J_{4^{\prime}, 3^{\prime}}=\right.$ $\left.4.5 \mathrm{~Hz}, J_{4}{ }^{\prime}, \mathrm{OH}=4.5 \mathrm{~Hz}, 1 \mathrm{H}, \mathrm{H}_{4}{ }^{\prime}\right), 3.60-3.53\left(\mathrm{ddd}, J_{\mathrm{gem}}=11.9 \mathrm{~Hz}, J_{5}{ }^{\prime}, 4^{\prime}=3.9 \mathrm{~Hz}, J_{5}{ }^{\prime}, \mathrm{OH}=5.2 \mathrm{~Hz}\right.$, $\left.1 \mathrm{H}, \mathrm{H}_{5}{ }^{\prime}\right), 3.50-3.43\left(\mathrm{ddd}, J_{\mathrm{gem}}=11.9 \mathrm{~Hz}, J_{5}{ }^{\prime}, 4^{\prime}=4.7 \mathrm{~Hz}, J_{5}, \mathrm{OH}=6.1 \mathrm{~Hz}, 1 \mathrm{H}, \mathrm{H}_{5}{ }^{\prime}\right){ }^{13} \mathrm{C} \mathrm{NMR}(75$ MHz, DMSO-d6) $\delta 155.7,148.9,132.6,130.4,128.8,127.8,122.1,115.8,113.7,94.9,87.0,85.5$, 84.6 (C-1'), 75.2 (C-4'), 74.1 (C-2'), 71.2 (C-3'), 61.9 (C-5'); HRMS (ESI-TOF) m/z: calcd for $\mathrm{C}_{17} \mathrm{H}_{16} \mathrm{~N}_{4} \mathrm{O}_{4} \mathrm{~S}_{1}\left([\mathrm{M}+\mathrm{H}]^{+}\right), 373.0971$, found 373.0957.

7-(Phenylethynyl)-4-aza-7,9-dideazaadenosine (11f). Following a similar procedure as that used for the synthesis of 11a, compound $11 \mathbf{f}$ was obtained as a white solid (12.0 mg, 13\%) starting from 13 (100.0 mg, $0.255 \mathrm{mmol}), \mathrm{PdCl}_{2}\left(\mathrm{PPh}_{3}\right)_{2}(9.00 \mathrm{mg}, 0.013 \mathrm{mmol}), \mathrm{CuI}(24.0 \mathrm{mg}, 0.127 \mathrm{mmol})$, ethynylbenzene $(39.0 \mathrm{mg}, 2.55 \mathrm{mmol})$, and triethylamine $(0.1 \mathrm{~mL})$ in dry DMF $(5.0 \mathrm{~mL})$ after purification by silica gel column chromatography $\left(\mathrm{CH}_{2} \mathrm{Cl}_{2} / \mathrm{MeOH}=10: 1, \mathrm{v} / \mathrm{v}\right)$, preparative TLC $\left(\mathrm{CH}_{2} \mathrm{Cl}_{2} / \mathrm{MeOH}=20: 1, \mathrm{v} / \mathrm{v}\right)$, and reversed-phase HPLC (5-60\% MeCN in water). ${ }^{1} \mathrm{H}$ NMR (300 MHz, DMSO-d6) $\delta 7.96$ (s, 1H, H2), 7.61-7.58 (m, 2H, Ar- H), 7.44-7.41 (m, 3H, Ar- H), 7.02 (s, $1 \mathrm{H}, \mathrm{H} 8), 5.13\left(\mathrm{~d}, J_{1^{\prime}, 2^{\prime}}=6.1 \mathrm{~Hz}, 1 \mathrm{H}, \mathrm{H}_{1^{\prime}}\right), 5.08\left(\mathrm{~d}, J_{\mathrm{OH}, 2^{\prime}}=6.0 \mathrm{~Hz}, 1 \mathrm{H}, \mathrm{OH}-2^{\prime}\right), 4.93\left(\mathrm{~d}, J_{\mathrm{OH}, 3^{\prime}}=5.2\right.$ $\mathrm{Hz}, 1 \mathrm{H}, \mathrm{OH}), 4.80\left(\mathrm{dd}, J_{\mathrm{OH}, 5^{\prime}}=5.9 \mathrm{~Hz}, J_{\mathrm{OH}, 5^{\prime}}=4.6 \mathrm{~Hz}, 1 \mathrm{H}, \mathrm{OH}-5^{\prime}\right.$ ), $4.21\left(\mathrm{ddd}, J_{2}{ }^{\prime} 1^{\prime}=6.0 \mathrm{~Hz}, J_{2}{ }^{\prime}{ }^{\prime}\right.$ ' $\left.=5.4 \mathrm{~Hz}, J_{2}{ }^{\prime} \mathrm{OH}=5.8 \mathrm{~Hz}, 1 \mathrm{H}, \mathrm{H}_{2}{ }^{\prime}\right), 3.97\left(\mathrm{ddd}, J_{3^{\prime}, 4^{\prime}}=5.0 \mathrm{~Hz}, J_{3^{\prime}, 2^{\prime}}=5.4 \mathrm{~Hz}, J_{3^{\prime}, \mathrm{OH}}=5.1 \mathrm{~Hz}, 1 \mathrm{H}\right.$, $\left.\mathrm{H}_{3}{ }^{\prime}\right), 3.80\left(\mathrm{ddd}, J_{4^{\prime}, 3^{\prime}}=4.9 \mathrm{~Hz}, J_{4^{\prime}, 5^{\prime}}=4.7 \mathrm{~Hz}, J_{4^{\prime}, 5^{\prime}}=4.0 \mathrm{~Hz}, 1 \mathrm{H}, \mathrm{H}_{4}{ }^{\prime}\right), 3.61-3.54\left(\mathrm{ddd}, J_{\mathrm{gem}}=11.7\right.$ $\left.\mathrm{Hz}, J_{5}{ }^{\prime}, 4^{\prime}=4.0 \mathrm{~Hz}, J_{5}{ }^{\prime}, \mathrm{OH}=4.6 \mathrm{~Hz}, 1 \mathrm{H}, \mathrm{H}_{5}{ }^{\prime}\right), 3.50-3.43\left(\mathrm{ddd}, J_{\mathrm{gem}}=11.7 \mathrm{~Hz}, J_{5}, 4^{\prime}=4.7 \mathrm{~Hz}, J_{5}{ }^{\prime}, \mathrm{OH}\right.$ $\left.=5.9 \mathrm{~Hz}, 1 \mathrm{H}, \mathrm{H}_{5}{ }^{\prime \prime}\right) ;{ }^{13} \mathrm{C}$ NMR (75 MHz, DMSO-d6) $\delta 155.8,148.8,131.2,130.3,128.8,128.7$, 122.5, 115.7, 113.7, 95.2, 92.3, 84.6 (C-1'), 83.7, 75.2 (C-4'), 74.1 (C-2'), 71.2 (C-3'), 61.9 (C-5'); HRMS (ESI-TOF) m/z: calcd for $\mathrm{C}_{19} \mathrm{H}_{18} \mathrm{~N}_{4} \mathrm{O}_{4}\left([\mathrm{M}+\mathrm{H}]^{+}\right), 367.1401$, found 367.1399 .

7-Ethynyl-4-aza-7,9-dideazaadenosine (11g). An argon purged mixture of 13 (130.0 mg, 0.331 $\mathrm{mmol}), \mathrm{PdCl}_{2}\left(\mathrm{PPh}_{3}\right)_{2}(12.0 \mathrm{mg}, 0.017 \mathrm{mmol}), \mathrm{CuI}(24.0 \mathrm{mg}, 0.165 \mathrm{mmol})$, trimethylsilylacetylene $(0.5 \mathrm{~mL}, 3.32 \mathrm{mmol})$, and triethylamine $(0.14 \mathrm{~mL})$ was stirred in dry DMF $(5 \mathrm{~mL})$ at room temperature for $16 \mathrm{~h}$. After removal of all the volatiles in vacuo, the remaining residue was coevaporated twice with $\mathrm{EtOH}$, then redissolved in a minimal amount of $\mathrm{EtOH}$ and further loaded on silica gel by coevaporation until complete drying. The mixture was purified by flash column chromatography $\left(\mathrm{CH}_{2} \mathrm{Cl}_{2} / \mathrm{MeOH}=10: 1, \mathrm{v} / \mathrm{v}\right)$ to afford a residue $(20 \mathrm{mg})$, which was further dissolved in $\mathrm{MeOH}(5.0 \mathrm{~mL})$, followed by addition of $\mathrm{K}_{2} \mathrm{CO}_{3}(30.0 \mathrm{mg})$. The mixture was stirred at room temperature for $1 \mathrm{~h}$, followed by dry loading on silica gel. The mixture was purified by 
silica gel column chromatography $\left(\mathrm{CH}_{2} \mathrm{Cl}_{2} / \mathrm{MeOH}=10: 1\right.$, v/v), followed by further purification by preparative TLC $\left(\mathrm{CH}_{2} \mathrm{Cl}_{2} / \mathrm{MeOH}=20: 1, \mathrm{v} / \mathrm{v}\right)$ and reversed-phase HPLC (5-60\% MeCN in water) afforded title compound $\mathbf{1 1 g}$ as white solid (10 mg, 11\%). ${ }^{1} \mathrm{H}$ NMR (300 MHz, DMSO-d 6 ) $\delta 7.92\left(\mathrm{~s}, 1 \mathrm{H}, \mathrm{H}_{2}\right), 6.93$ (s, 1H, H8), 5.09 (d, $\left.J_{1^{\prime}, 2^{\prime}}=6.1 \mathrm{~Hz}, 1 \mathrm{H}, \mathrm{H}_{1}{ }^{\prime}\right), 5.08$ (br, OH-2'), 4.90 (br, 1H, OH-3'), 4.79 (br, $1 \mathrm{H}, \mathrm{OH}-5^{\prime}$ ), 4.41 (s, $\left.1 \mathrm{H}, \mathrm{C} \equiv C \mathrm{H}\right), 4.19$ (dd, $J_{2^{\prime}, 3^{\prime}}=4.4 \mathrm{~Hz}, J_{2^{\prime}} 3^{\prime}=6.1 \mathrm{~Hz}, 1 \mathrm{H}$, $\left.\mathrm{H}_{2}{ }^{\prime}\right), 3.93\left(\mathrm{dd}, J_{3^{\prime}, 2^{\prime}}=4.4 \mathrm{~Hz}, J_{3^{\prime}, 4^{\prime}}=4.2 \mathrm{H}, 1 \mathrm{H}, \mathrm{H}_{3^{\prime}}\right.$ ), $3.78\left(\mathrm{ddd}, J_{4^{\prime}, 3^{\prime}}=4.2 \mathrm{~Hz}, J_{4^{\prime}, 5^{\prime}}=4.5 \mathrm{~Hz}, J_{4^{\prime}, 5^{\prime}}\right.$, $\left.=4.0 \mathrm{~Hz}, 1 \mathrm{H}, \mathrm{H}_{4}{ }^{\prime}\right), 3.57-3.44\left(\mathrm{~m}, 2 \mathrm{H}, \mathrm{H}_{5}, \mathrm{H}_{5}{ }^{\prime}\right) ;{ }^{13} \mathrm{C}$ NMR $\left(75 \mathrm{MHz}, \mathrm{DMSO}-\mathrm{d}_{6}\right) \delta 155.7$ (C-2), 148.8 (C-5), 129.9 (C-6), 116.4 (C-9), 113.7 (C-7), 94.5 (C-8), 84.6 (C-1'), 84.1, 78.0, 75.1 (C4'), 74.0 (C-2'), 71.1(C-3'), 61.8 (C-5'); HRMS (ESI-TOF) m/z: calcd for $\mathrm{C}_{13} \mathrm{H}_{14} \mathrm{~N}_{4} \mathrm{O}_{4}\left([\mathrm{M}+\mathrm{H}]^{+}\right)$, 291.1093, found 291.1088.

7-Phenyl-4-aza-7,9-dideazaadenosine (12a). An argon purged mixture of 13 (100.0 mg, 0.255 mmol), phenylboronic acid (93.0 mg, $0.76 \mathrm{mmol}), \mathrm{Na}_{2} \mathrm{CO}_{3}(243 \mathrm{mg}, 2.3 \mathrm{mmol}), \mathrm{Pd}(\mathrm{OAc}) 2(3.50$ $\mathrm{mg}, 0.015 \mathrm{mmol})$, and TPPTS (20.0 $\mathrm{mg}, 0.035 \mathrm{mmol})$ in water/MeCN $(2: 1,3.0 \mathrm{~mL})$ was stirred at $100{ }^{\circ} \mathrm{C}$ for $1 \mathrm{~h}$. After removal of all the volatiles in vacuo, the resulting residue was purified by silica gel column chromatography $\left(\mathrm{CH}_{2} \mathrm{Cl}_{2} / \mathrm{MeOH}=10: 1\right.$, v/v), preparative TLC $\left(\mathrm{CH}_{2} \mathrm{Cl}_{2} / \mathrm{MeOH}\right.$ $=20: 1, \mathrm{v} / \mathrm{v})$, and reversed-phase HPLC $(5-80 \% \mathrm{MeOH}$ in water) to afford title compound 12a as a white solid (20.0 mg, 23\%). ${ }^{1} \mathrm{H}$ NMR (300 MHz, DMSO-d 6 ) $\delta 7.92\left(\mathrm{~s}, 1 \mathrm{H}, \mathrm{H}_{2}\right)$, 7.54-7.37 (m, $5 \mathrm{H}, \mathrm{Ar}-H), 6.82\left(\mathrm{~s}, 1 \mathrm{H}, \mathrm{H}_{8}\right), 5.09\left(\mathrm{~d}, J_{1^{\prime}, 2^{\prime}}=6.1 \mathrm{~Hz}, 1 \mathrm{H}, \mathrm{H}_{1^{\prime}}\right), 5.05\left(\mathrm{~d}, J_{\mathrm{OH}, 2^{\prime}}=6.1 \mathrm{~Hz}, 1 \mathrm{H}, \mathrm{OH}-2^{\prime}\right)$, $4.92\left(\mathrm{~d}, J_{\mathrm{OH}, 3^{\prime}}=5.0 \mathrm{~Hz}, 1 \mathrm{H}, \mathrm{OH}-3^{\prime}\right), 4.78\left(\mathrm{dd}, J_{\mathrm{OH}, 5^{\prime}}=5.0 \mathrm{~Hz}, J_{\mathrm{OH}, 5^{\prime}}=5.8 \mathrm{~Hz}, 1 \mathrm{H}, \mathrm{OH}-5^{\prime}\right), 4.27$ $\left(\mathrm{ddd}, J_{2}{ }^{\prime}{ }^{\prime}=6.1 \mathrm{~Hz}, J_{2}{ }^{\prime} 3^{\prime}=5.4 \mathrm{~Hz}, J_{2}{ }^{\prime} \mathrm{OH}=6.0 \mathrm{~Hz}, 1 \mathrm{H}, \mathrm{H}_{2}{ }^{\prime}\right), 3.97\left(\mathrm{ddd}, J_{3^{\prime}, \mathrm{OH}}=5.0 \mathrm{~Hz}, J_{3^{\prime}, 2^{\prime}}=5.4\right.$ $\left.\mathrm{Hz}, J_{3^{\prime}, 4^{\prime}}=4.3 \mathrm{~Hz}, 1 \mathrm{H}, \mathrm{H}_{3^{\prime}}\right), 3.81\left(\mathrm{ddd}, J_{4^{\prime}, 3^{\prime}}=4.3 \mathrm{~Hz}, J_{4^{\prime}, 5^{\prime}}=3.7 \mathrm{~Hz}, J_{4^{\prime}, 5^{\prime}}=4.3 \mathrm{~Hz}, 1 \mathrm{H}, \mathrm{H}_{4}{ }^{\prime}\right), 3.57$ $\left(\mathrm{ddd}, J_{5^{\prime}, 4^{\prime}}=3.7 \mathrm{~Hz}, J_{5^{\prime}, \mathrm{OH}}=5.0 \mathrm{~Hz}, J_{\mathrm{gem}}=11.9 \mathrm{~Hz}, 1 \mathrm{H}, \mathrm{H}_{5}{ }^{\prime}\right)$ ), 3.50-3.43 (ddd, $J_{5}{ }^{\prime}, 4^{\prime}=4.2 \mathrm{~Hz}$, $\left.J_{5}, \mathrm{OH}=5.6 \mathrm{~Hz}, J_{\mathrm{gem}}=11.9 \mathrm{~Hz}, 1 \mathrm{H}, \mathrm{H}_{5},\right) ;{ }^{13} \mathrm{C} \mathrm{NMR}(75 \mathrm{MHz}, \mathrm{DMSO}-\mathrm{d} 6) \delta 155.8,147.5,135.3$, 129.6, 129.3, 129.0, 127.3, 118.0, 111.4, 110.4, 84.6 (C-1'), 75.4 (C-4'), 74.1 (C-2'), 71.3 (C-3'), 62.0 (C-5'); HRMS (ESI-TOF) m/z: calcd for $\mathrm{C}_{17} \mathrm{H}_{19} \mathrm{~N}_{4} \mathrm{O}_{4}\left([\mathrm{M}+\mathrm{H}]^{+}\right), 343.1406$, found 343.1394. 7-(4-Fluorophenyl)-4-aza-7,9-dideazaadenosine (12b). Following a similar procedure as that used for the synthesis of 12a, compound 12b was obtained as a white solid ( $9 \mathrm{mg}, 18 \%$ ) starting from 13 (50.0 mg, $0.127 \mathrm{mmol})$, (4-fluorophenyl)boronic acid (27.0 mg, $0.191 \mathrm{mmol}), \mathrm{Pd}(\mathrm{OAc})_{2}$ (2.00 mg, $0.008 \mathrm{mmol}), \mathrm{Na}_{2} \mathrm{CO}_{3}(121.0 \mathrm{mg}, 1.15 \mathrm{mmol})$, and TPPTS (10.0 mg, $\left.0.018 \mathrm{mmol}\right)$ in water/MeCN $(2: 1,3.0 \mathrm{~mL})$ after purification by silica gel column chromatography $\left(\mathrm{CH}_{2} \mathrm{Cl}_{2} / \mathrm{MeOH}\right.$ $=10: 1, \mathrm{v} / \mathrm{v})$, preparative TLC $\left(\mathrm{CH}_{2} \mathrm{Cl}_{2} / \mathrm{MeOH}=20: 1, \mathrm{v} / \mathrm{v}\right)$, and reversed-phase HPLC $(5-80 \%$ 
$\mathrm{MeOH}$ in water). ${ }^{1} \mathrm{H}$ NMR (300 MHz, DMSO-d 6$) \delta 7.91\left(\mathrm{~s}, 1 \mathrm{H}, \mathrm{H}_{2}\right), 7.50-7.45(\mathrm{~m}, 2 \mathrm{H}, \mathrm{Ar}-H)$, $7.31(\mathrm{t}, J=8.8 \mathrm{~Hz}, 1 \mathrm{H}, \mathrm{Ar}-H), 6.81\left(\mathrm{~s}, 1 \mathrm{H}, \mathrm{H}_{8}\right), 5.18$ (d, $J=6.2 \mathrm{~Hz}, 1 \mathrm{H}, \mathrm{H}_{1}$ ), $5.06-4.95$ (br, 2H, OH-2', OH-3'), 4.78 (br, 1H, OH-5'), 4.26 (dd, $\left.J_{2}{ }^{\prime}, 3^{\prime}=5.2 \mathrm{~Hz}, J_{2}{ }^{\prime}, 1^{\prime}=6.2 \mathrm{~Hz}, 1 \mathrm{H}, \mathrm{H}_{2}{ }^{\prime}\right), 3.96$ (dd, $\left.J_{3^{\prime}, 2^{\prime}}=5.2 \mathrm{~Hz}, J_{3^{\prime}, 4^{\prime}}=4.3 \mathrm{~Hz}, 1 \mathrm{H}, \mathrm{H}_{3^{\prime}}{ }^{\prime}\right), 3.80\left(\mathrm{ddd}, J_{4^{\prime}, 3^{\prime}}=4.3 \mathrm{~Hz}, J^{\prime}, 5^{\prime}=4.7 \mathrm{~Hz}, J^{\prime}, 5^{\prime}=4.0 \mathrm{~Hz}, 1 \mathrm{H}\right.$, $\left.\mathrm{H}_{4}{ }^{\prime}\right), 3.57-3.41$ (m, 2H, H5, $\left.\mathrm{H}_{5}{ }^{\prime}\right)$ ) ${ }^{13} \mathrm{C}$ NMR (75 MHz, DMSO-d6) $\delta 163.3,160.0,155.7,147.5$, $131.5(\mathrm{~d}, J=3.2 \mathrm{~Hz}), 131.3,131.2$ (d, $J=7.7 \mathrm{~Hz}), 129.5,116.9,115.9,115.6,111.5,110.5,84.6$ (C-1'), 75.4 (C-4'), 74.0 (C-2'), 71.3 (C-3'), 62.0 (C-5'); HRMS (ESI-TOF) m/z: calcd for $\mathrm{C}_{17} \mathrm{H}_{17} \mathrm{~F}_{1} \mathrm{~N}_{4} \mathrm{O}_{4}\left([\mathrm{M}+\mathrm{H}]^{+}\right), 361.1312$, found 361.1310 .

7-(4-Chlorophenyl)-4-aza-7,9-dideazaadenosine (12c). Following a similar procedure as that used for the synthesis of 12a, compound $\mathbf{1 2 c}$ was obtained as a white solid (16 $\mathrm{mg}, 16 \%)$ starting from 13 (50.0 mg, $0.127 \mathrm{mmol}$ ), (4-chlorophenyl)boronic acid (30.0 mg, $0.191 \mathrm{mmol}), \mathrm{Pd}(\mathrm{OAc})_{2}$ (2.00 mg, $0.00765 \mathrm{mmol}), \mathrm{Na}_{2} \mathrm{CO}_{3}(121.0 \mathrm{mg}, 1.15 \mathrm{mmol})$, and TPPTS (10.0 mg, $\left.0.018 \mathrm{mmol}\right)$ in water/MeCN $(2: 1,3.0 \mathrm{~mL})$ after purification by silica gel column chromatography $\left(\mathrm{CH}_{2} \mathrm{Cl}_{2} / \mathrm{MeOH}\right.$ $=10: 1, \mathrm{v} / \mathrm{v})$, preparative TLC $\left(\mathrm{CH}_{2} \mathrm{Cl}_{2} / \mathrm{MeOH}=20: 1, \mathrm{v} / \mathrm{v}\right)$, and reversed-phase HPLC $(5-80 \%$ $\mathrm{MeOH}$ in water). ${ }^{1} \mathrm{H}$ NMR (300 MHz, DMSO-d6) $\delta 7.92$ (s, $1 \mathrm{H}, \mathrm{H}_{2}$ ), 7.49 (q, $J=8.4 \mathrm{~Hz}, 4 \mathrm{H}, \mathrm{Ar}-$

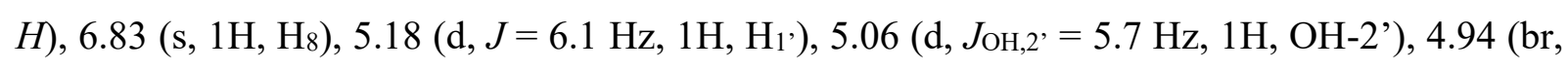
$1 \mathrm{H}, \mathrm{OH}-3^{\prime}$ ), $4.78\left(\mathrm{dd}, J_{\mathrm{OH}, 5^{\prime}}=6.0 \mathrm{~Hz}, J_{\mathrm{OH}, 5^{\prime}}=5.1 \mathrm{~Hz}, 1 \mathrm{H}, \mathrm{OH}-5^{\prime}\right.$ '), 4.25 (ddd, $J_{2^{\prime}, 3^{\prime}}=5.0 \mathrm{~Hz}, J_{2^{\prime}, 1^{\prime}}$ $\left.=6.0 \mathrm{~Hz}, J_{2^{\prime}, \mathrm{OH}}=5.7 \mathrm{~Hz}, 1 \mathrm{H}, \mathrm{H}_{2}{ }^{\prime}\right), 3.96\left(\mathrm{dd}, J_{3^{\prime}, 2^{\prime}}=4.9 \mathrm{~Hz}, J_{3^{\prime}, 4^{\prime}}=4.6 \mathrm{~Hz}, 1 \mathrm{H}, \mathrm{H}_{3}{ }^{\prime}\right), 3.80$ (ddd, $\left.J_{4}, 3^{\prime}=4.6 \mathrm{~Hz}, J^{\prime}, 5^{\prime}=4.7 \mathrm{~Hz}, J_{4}{ }^{,}, 5^{\prime}=4.0 \mathrm{~Hz}, 1 \mathrm{H}, \mathrm{H}_{4}{ }^{\prime}\right), 3.59-3.52\left(\mathrm{ddd}, J_{5}{ }^{\prime}, 4^{\prime}=3.9 \mathrm{~Hz}, J_{5}{ }^{\prime}, \mathrm{OH}=5.1\right.$ $\left.\mathrm{Hz}, J_{\text {gem }}=11.8 \mathrm{~Hz}, 1 \mathrm{H}, \mathrm{H} 5^{\prime}\right), 3.45\left(\mathrm{ddd}, J_{5^{\prime}, 4^{\prime}}=4.7 \mathrm{~Hz}, J_{5^{\prime}, \mathrm{OH}}=6.0 \mathrm{~Hz}, J_{\mathrm{gem}}=11.8 \mathrm{~Hz}, 1 \mathrm{H}, \mathrm{H}_{5}{ }^{\prime}\right)$; ${ }^{13} \mathrm{C}$ NMR (75 MHz, DMSO-d6) $\delta$ 155.6, 147.6, 133.9, 131.9, 131.0, 129.6, 128.9, 116.6, 111.4, 110.4, 84.5 (C-1'), 75.2 (C-4'), 73.9 (C-2'), 71.2 (C-3'), 61.9(C-5'); HRMS (ESI-TOF) m/z: calcd for $\mathrm{C}_{17} \mathrm{H}_{17} \mathrm{Cl}_{1} \mathrm{~N}_{4} \mathrm{O}_{4}\left([\mathrm{M}+\mathrm{H}]^{+}\right), 377.1017$, found 377.1006 .

7-(2-Fluorophenyl)-4-aza-7,9-dideazaadenosine (12d). Following a similar procedure as that used for the synthesis of 12a, compound $\mathbf{1 2 d}$ was obtained as a white solid (11 $\mathrm{mg}, 23 \%)$ starting from 13 (50.0 mg, $0.127 \mathrm{mmol}$ ), (4-chlorophenyl)boronic acid (27.0 mg, $0.191 \mathrm{mmol}), \mathrm{Pd}(\mathrm{OAc})_{2}$ (2.00 mg, $0.008 \mathrm{mmol}), \mathrm{Na}_{2} \mathrm{CO}_{3}(121.0 \mathrm{mg}, 1.15 \mathrm{mmol})$, and TPPTS (10.0 mg, $\left.0.018 \mathrm{mmol}\right)$ in water/MeCN $(2: 1,3.0 \mathrm{~mL})$ after purification by silica gel column chromatography $\left(\mathrm{CH}_{2} \mathrm{Cl}_{2} / \mathrm{MeOH}\right.$ $=10: 1, \mathrm{v} / \mathrm{v})$, preparative TLC $\left(\mathrm{CH}_{2} \mathrm{Cl}_{2} / \mathrm{MeOH}=20: 1, \mathrm{v} / \mathrm{v}\right)$, and reversed-phase HPLC $(5-80 \%$ $\mathrm{MeOH}$ in water). ${ }^{1} \mathrm{H}$ NMR (300 MHz, DMSO-d 6$) \delta 7.93\left(\mathrm{~s}, 1 \mathrm{H}, \mathrm{H}_{2}\right), 7.47-7.28(\mathrm{~m}, 3 \mathrm{H}, \mathrm{Ar}-H)$, $6.82(\mathrm{~s}, 1 \mathrm{H}, \mathrm{H} 8), 5.18\left(\mathrm{~d}, J=6.3 \mathrm{~Hz}, 1 \mathrm{H}, \mathrm{H}_{1}{ }^{\prime}\right), 5.07$ (d, $\left.J_{\mathrm{OH}, 2^{\prime}}=6.1 \mathrm{~Hz}, 1 \mathrm{H}, \mathrm{OH}-2^{\prime}\right), 4.94$ (d, J $J_{\mathrm{OH}, 3^{\prime}}$ 
$\left.=4.8 \mathrm{~Hz}, 1 \mathrm{H}, \mathrm{OH}-3^{\prime}\right), 4.79\left(\mathrm{dd}, J_{\mathrm{OH}, 5^{\prime}}=5.8 \mathrm{~Hz}, J_{\mathrm{OH}, 5}{ }^{\prime}=5.2 \mathrm{~Hz}, 1 \mathrm{H}, \mathrm{OH}-5\right.$ '), $4.26\left(\mathrm{ddd}, J_{2}{ }^{\prime}, 1^{\prime}=6.0\right.$ $\left.\mathrm{Hz}, J_{2^{\prime}, 3^{\prime}}=5.0 \mathrm{~Hz}, J_{2^{\prime}, \mathrm{OH}}=6.1 \mathrm{~Hz}, 1 \mathrm{H}, \mathrm{H}_{2}{ }^{\prime}\right), 3.96\left(\mathrm{ddd}, J_{3^{\prime}, 2^{\prime}}=5.5 \mathrm{~Hz}, J_{3^{\prime}, 4^{\prime}}=4.6 \mathrm{~Hz}, J_{3^{\prime}, \mathrm{OH}^{\prime}}=4.8\right.$ $\left.\mathrm{Hz}, 1 \mathrm{H}, \mathrm{H}_{3}{ }^{\prime}\right), 3.81\left(\mathrm{ddd}, J_{4}{ }^{,},{ }^{\prime}=4.7 \mathrm{~Hz}, J_{4^{\prime}, 5^{\prime}}=4.0 \mathrm{~Hz}, J_{4}{ }^{\prime}, 3^{\prime}=4.5 \mathrm{~Hz}, 1 \mathrm{H}, \mathrm{H}_{4}{ }^{\prime}\right), 3.59-3.52\left(\mathrm{ddd}, J_{5}{ }^{\prime}, 4^{\prime}=\right.$

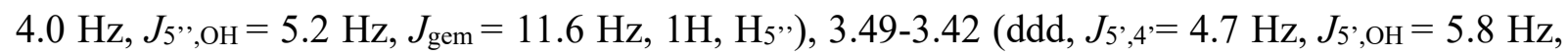
$\left.J_{\mathrm{gem}}=11.5 \mathrm{~Hz}, 1 \mathrm{H}, \mathrm{H}_{5}\right) ;{ }^{13} \mathrm{C} \mathrm{NMR}(75 \mathrm{MHz}$, DMSO-d6) $\delta 161.1,157.9,155.7,147.2,132.4,130.0$, $129.9(\mathrm{~d}, J=8.5 \mathrm{~Hz}), 129.5,124.9,124.8$ (d, $J=3.8 \mathrm{~Hz}), 122.6,122.4(\mathrm{~d}, J=15.2 \mathrm{~Hz}), 116.4$, 116.2 (d, $J=21.9 \mathrm{~Hz}), 112.1,111.6,110.1,84.7$ (C-1'), 75.4 (C-4'), 74.0 (C-2'), 71.3 (C-3'), 62.0 (C-5'); HRMS (ESI-TOF) m/z: calcd for $\mathrm{C}_{17} \mathrm{H}_{17} \mathrm{~F}_{1} \mathrm{~N}_{4} \mathrm{O}_{4}\left([\mathrm{M}+\mathrm{H}]^{+}\right), 361.1312$, found 361.1310 .

7-(2,4-Difluorophenyl)-4-aza-7,9-dideazaadenosine (12e). Following a similar procedure as that used for the synthesis of 12a, compound 12e was obtained as a white solid (10 $\mathrm{mg}, 20 \%)$ starting from 13 (50.0 mg, $0.127 \mathrm{mmol}$ ), (2,4-difluorophenyl)boronic acid (30.0 mg, $0.191 \mathrm{mmol}$ ), $\mathrm{Pd}(\mathrm{OAc})_{2}$ (2.00 mg, $\left.0.008 \mathrm{mmol}\right), \mathrm{Na}_{2} \mathrm{CO}_{3}(121.0 \mathrm{mg}, 1.15 \mathrm{mmol})$, and TPPTS (10.0 mg, 0.018 $\mathrm{mmol})$ in water/MeCN $(2: 1,3.0 \mathrm{~mL})$ after purification by silica gel column chromatography $\left(\mathrm{CH}_{2} \mathrm{Cl}_{2} / \mathrm{MeOH}=10: 1, \mathrm{v} / \mathrm{v}\right)$, preparative TLC $\left(\mathrm{CH}_{2} \mathrm{Cl}_{2} / \mathrm{MeOH}=20: 1, \mathrm{v} / \mathrm{v}\right)$, and reversed-phase HPLC (5-80\% MeOH in water). ${ }^{1} \mathrm{H}$ NMR (300 MHz, DMSO-d6) $\delta 7.92$ (s, 1H, H2), 7.48-7.33 (m,

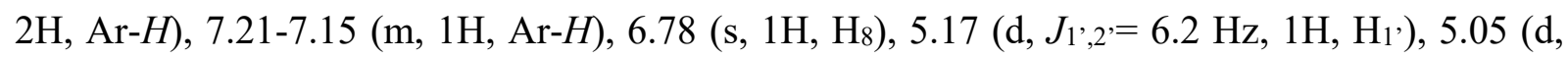
$\left.J_{\mathrm{OH}, 2^{\prime}}=6.1 \mathrm{~Hz}, 1 \mathrm{H}, \mathrm{OH}-2^{\prime}\right), 4.93\left(\mathrm{~d}, J_{\mathrm{OH}, 3^{\prime}}=5.2 \mathrm{~Hz}, 1 \mathrm{H}, \mathrm{OH}-3^{\prime}\right), 4.78\left(\mathrm{dd}, J_{\mathrm{OH}, 5^{\prime}}=6.1 \mathrm{~Hz}, J_{\mathrm{OH}, 5^{\prime}}\right.$ $\left.=5.1 \mathrm{~Hz}, 1 \mathrm{H}, \mathrm{OH}-5^{\prime}\right), 4.25\left(\mathrm{ddd}, J_{2}{ }^{\prime}, 1^{\prime}=6.2 \mathrm{~Hz}, J_{2}{ }^{\prime}, 3^{\prime}=5.6 \mathrm{~Hz}, J_{2}{ }^{\prime}, \mathrm{OH}=6.1 \mathrm{~Hz}, 1 \mathrm{H}, \mathrm{H}_{2}{ }^{\prime}\right), 3.95$ (ddd, $\left.J_{3^{\prime}, 4^{\prime}}=4.8 \mathrm{~Hz}, J_{3^{\prime}, \mathrm{OH}^{\prime}}=5.2 \mathrm{~Hz}, J_{3^{\prime}, 2^{\prime}}=5.5 \mathrm{~Hz}\right), 3.80\left(\mathrm{ddd}, J_{4^{\prime}, 3^{\prime}}=4.8 \mathrm{~Hz}, J_{4^{\prime}, 5^{\prime}}=4.2 \mathrm{~Hz}, J_{4^{\prime}, 5^{\prime}}=3.5\right.$ $\left.\mathrm{Hz} 1 \mathrm{H}, \mathrm{H}_{4}{ }^{\prime}\right), 3.59-3.52\left(\mathrm{ddd}, J_{5}{ }^{\prime}, 4^{\prime}=4.1 \mathrm{~Hz}, J_{5}{ }^{\prime}, \mathrm{OH}=5.1 \mathrm{~Hz}, J_{\mathrm{gem}}=11.6 \mathrm{~Hz}, 1 \mathrm{H}, \mathrm{H}_{5}{ }^{\prime}\right), 3.49-3.42$ $\left(\mathrm{ddd}, J_{5^{\prime}, 4^{\prime}}=4.7 \mathrm{~Hz}, J_{5^{\prime}, \mathrm{OH}}=6.1 \mathrm{~Hz}, J_{\mathrm{gem}}=11.5 \mathrm{~Hz}, 1 \mathrm{H}, \mathrm{H}_{5}{ }^{\prime}\right) ;{ }^{13} \mathrm{C} \mathrm{NMR}\left(75 \mathrm{MHz}, \mathrm{DMSO}-\mathrm{d}_{6}\right) \delta$ $163.8(\mathrm{~d}, J=10.5 \mathrm{~Hz}), 161.4,161.2(\mathrm{~d}, J=11.7 \mathrm{~Hz}), 157.9,155.7,147.7,133.5$ (q, $J=3.9 \mathrm{~Hz})$, 129.4, 118.9 (q, $J=3.2 \mathrm{~Hz}), 112.1,111.8$ (t, $J=3.6 \mathrm{~Hz}), 109.2,104.7$ (t, $J=25.3 \mathrm{~Hz}), 84.7$ (C1'), 75.4 (C-4'), 74.0 (C-2'), 71.3 (C-3'), 62.0 (C-5'); HRMS (ESI-TOF) m/z: calcd for $\mathrm{C}_{17} \mathrm{H}_{16} \mathrm{~F}_{2} \mathrm{~N}_{4} \mathrm{O}_{4}\left([\mathrm{M}+\mathrm{H}]^{+}\right), 379.1218$, found 379.1215 .

7-(4-Methoxyphenyl)-4-aza-7,9-dideazaadenosine (12f). Following a similar procedure as that used for the synthesis of 12a, compound $\mathbf{1 2 f}$ was obtained as a white solid (4 $\mathrm{mg}, 8.5 \%$ ) starting from 13 (50.0 mg, $0.127 \mathrm{mmol}$ ), (4-methoxyphenyl)boronic acid (30.0 mg, $0.191 \mathrm{mmol}$ ), $\mathrm{Pd}(\mathrm{OAc})_{2}$ (2.00 mg, $\left.0.008 \mathrm{mmol}\right), \mathrm{Na}_{2} \mathrm{CO}_{3}(121.0 \mathrm{mg}, 1.15 \mathrm{mmol})$, and TPPTS (10.0 mg, 0.018 $\mathrm{mmol})$ in water/MeCN $(2: 1,3.0 \mathrm{~mL})$ after purification by silica gel column chromatography $\left(\mathrm{CH}_{2} \mathrm{Cl}_{2} / \mathrm{MeOH}=10: 1, \mathrm{v} / \mathrm{v}\right)$, preparative TLC $\left(\mathrm{CH}_{2} \mathrm{Cl}_{2} / \mathrm{MeOH}=20: 1, \mathrm{v} / \mathrm{v}\right)$, and reversed-phase 
HPLC (5-80\% MeOH in water). ${ }^{1} \mathrm{H}$ NMR (300 MHz, DMSO-d 6$) \delta 7.89\left(\mathrm{~s}, 1 \mathrm{H}, \mathrm{H}_{2}\right), 7.37$ (d, $J=$ $8.8 \mathrm{~Hz}, 2 \mathrm{H}, \mathrm{Ar}-H), 7.37$ (d, $J=8.8 \mathrm{~Hz}, 2 \mathrm{H}, \operatorname{Ar}-H), 6.76(\mathrm{~s}, 1 \mathrm{H}, \mathrm{H} 8), 5.18\left(\mathrm{~d}, J_{1^{\prime}, 2}{ }^{\prime}=6.2 \mathrm{~Hz}, 1 \mathrm{H}\right.$, $\mathrm{H}_{1}$ '), 5.05 (br, 1H, OH-2'), 4.95 (br, 1H, OH-3'), 4.79 (br, 1H, OH-5'), 4.25 (dd, $J_{2}{ }^{\prime}, 3^{\prime}=5.2 \mathrm{~Hz}$, $\left.J_{2^{\prime}, 1^{\prime}}=6.2 \mathrm{~Hz}, 1 \mathrm{H}, \mathrm{H}_{2}{ }^{\prime}\right), 3.97\left(\mathrm{dd}, J_{3^{\prime}, 4^{\prime}}=4.7 \mathrm{~Hz}, J_{3^{\prime}, 2^{\prime}}=5.2 \mathrm{~Hz}, 1 \mathrm{H}, \mathrm{H}_{3}{ }^{\prime}\right), 3.82-3.79$ (m, 1H, H4' $)$, 3.80 (s, 3H, -OCH3), 3.60-3.41 (m, 2H, $\left.\mathrm{H}_{5}, \mathrm{H}_{5}{ }^{\prime}\right)$ ) ${ }^{13} \mathrm{C}$ NMR (75 MHz, DMSO-d6) $\delta 158.7,155.8$, 147.5, 130.5, 129.3, 127.3, 117.8, 114.5, 111.3, 110.4, 84.6 (C-1'), 75.4 (C-4'), 74.0 (C-2'), 71.3 (C-3'), 62.1 (C-5'), 55.3; HRMS (ESI-TOF) m/z: calcd for $\mathrm{C}_{18} \mathrm{H}_{20} \mathrm{~N}_{4} \mathrm{O}_{5}\left([\mathrm{M}+\mathrm{H}]^{+}\right), 373.1512$, found 373.1511 .

7-(o-Tolyl)-4-aza-7,9-dideazaadenosine (12g). Following a similar procedure as that used for the synthesis of 12a, compound $\mathbf{1 2} \mathbf{g}$ was obtained as a white solid (15 mg, 15\%) starting from $\mathbf{1 3}$ (50.0 $\mathrm{mg}, 0.127 \mathrm{mmol}$ ), $o$-tolylboronic acid (26.0 mg, $0.191 \mathrm{mmol}), \mathrm{Pd}(\mathrm{OAc})_{2}(2.00 \mathrm{mg}, 0.008 \mathrm{mmol})$, $\mathrm{Na}_{2} \mathrm{CO}_{3}(121.0 \mathrm{mg}, 1.15 \mathrm{mmol})$, and TPPTS $(10 \mathrm{mg}, 0.018 \mathrm{mmol})$ in water/MeCN $(2: 1,3.0 \mathrm{~mL})$ after purification by silica gel column chromatography $\left(\mathrm{CH}_{2} \mathrm{Cl}_{2} / \mathrm{MeOH}=10: 1, \mathrm{v} / \mathrm{v}\right)$, preparative TLC $\left(\mathrm{CH}_{2} \mathrm{Cl}_{2} / \mathrm{MeOH}=20: 1, \mathrm{v} / \mathrm{v}\right)$, and reversed-phase HPLC $\left(5-80 \% \mathrm{MeOH}\right.$ in water). ${ }^{1} \mathrm{H}$ NMR (300 MHz, DMSO-d6) $\delta 7.91$ (s, 1H, H2), 7.40-7.20 (m, 4H, Ar-H), 7.37 (d, J=8.8 Hz, 2H, Ar$H), 6.81(\mathrm{~s}, 1 \mathrm{H}, \mathrm{H} 8), 5.18\left(\mathrm{~d}, J=6.1 \mathrm{~Hz}, 1 \mathrm{H}, \mathrm{H}_{1}{ }^{\prime}\right), 5.06\left(\mathrm{~d}, J_{1^{\prime}, 2^{\prime}}=6.0 \mathrm{~Hz}, 1 \mathrm{H}, \mathrm{OH}\right), 4.93\left(\mathrm{~d}, J_{\mathrm{OH}, 3^{\prime}}\right.$ $\left.=5.0 \mathrm{~Hz}, 1 \mathrm{H}, \mathrm{OH}-3^{\prime}\right), 4.79\left(\mathrm{dd}, J_{5}, \mathrm{OH}=5.8 \mathrm{~Hz}, J_{5}{ }^{\prime}, \mathrm{OH}=5.1 \mathrm{~Hz}, 1 \mathrm{H}, \mathrm{OH}-5^{\prime}\right), 4.26\left(\mathrm{ddd}, J_{2}{ }^{\prime}, 3^{\prime}=5.5\right.$ $\left.\mathrm{Hz}, J_{2}{ }^{\prime}, 1^{\prime}=6.1 \mathrm{~Hz}, J_{2}{ }^{\prime}, \mathrm{OH}=6.0 \mathrm{~Hz} 1 \mathrm{H}, \mathrm{H}_{2^{\prime}}\right), 3.97\left(\mathrm{ddd}, J_{3^{\prime}, 2^{\prime}}=5.5 \mathrm{~Hz}, J_{3^{\prime}, 4^{\prime}}=4.5 \mathrm{~Hz}, J_{3^{\prime}, \mathrm{OH}}=5.0\right.$ $\mathrm{Hz}, 1 \mathrm{H}, \mathrm{H}_{3^{\prime}}$ ), 3.81 (ddd, $J_{4^{\prime}, 5^{\prime}}=3.8 \mathrm{~Hz}, J_{4^{\prime}, 3^{\prime}}=4.5 \mathrm{~Hz}, J_{4^{\prime}, 5^{\prime}}=3.5 \mathrm{~Hz}, 1 \mathrm{H}, \mathrm{H}_{4}{ }^{\prime}$ ), 3.60-3.53 (ddd, $J_{5}{ }^{\prime}, 4^{\prime}=4.3 \mathrm{~Hz}, J_{5}$ ", $\left.\mathrm{OH}=5.1 \mathrm{~Hz}, J_{\mathrm{gem}}=11.8 \mathrm{~Hz}, 1 \mathrm{H}, \mathrm{H}_{5}{ }^{\prime}\right), 3.60-3.53\left(\mathrm{ddd}, J_{5}{ }^{\prime}, 4^{\prime}=4.7 \mathrm{~Hz}, J_{5}{ }^{\prime}, \mathrm{OH}=\right.$ $\left.5.8 \mathrm{~Hz}, J_{\mathrm{gem}}=11.8 \mathrm{~Hz}, 1 \mathrm{H}, \mathrm{H}_{5}\right)$; ${ }^{13} \mathrm{C} \mathrm{NMR}\left(75 \mathrm{MHz}, \mathrm{DMSO}-\mathrm{d}_{6}\right) \delta 155.7,147.5,138.3,135.2$, 130.0, 129.5, 128.9, 128.0, 126.3, 118.1, 111.3, 110.4, 84.6 (C-1'), 75.4 (C-4'), 74.1 (C-2'), 71.3 (C-3'), 62.1 (C-5'), 21.1; HRMS (ESI-TOF) m/z: calcd for $\mathrm{C}_{18} \mathrm{H}_{20} \mathrm{~N}_{4} \mathrm{O}_{4}\left([\mathrm{M}+\mathrm{H}]^{+}\right), 357.1563$, found 357.1554 .

7-(Furan-3-yl)-4-aza-7,9-dideazaadenosine (12h). Following a similar procedure as that used for the synthesis of $\mathbf{1 2 a}$, compound $\mathbf{1 2 h}$ was obtained as a white solid (10 $\mathrm{mg}, 22 \%)$ starting from 13 (50.0 mg, $0.127 \mathrm{mmol}$ ), furan-3-ylboronic acid (28.0 mg, $0.191 \mathrm{mmol}), \mathrm{Pd}(\mathrm{OAc})_{2}$ (2.00 mg, $0.008 \mathrm{mmol}$ ), $\mathrm{Na}_{2} \mathrm{CO}_{3}(121.0 \mathrm{mg}, 1.15 \mathrm{mmol})$, and TPPTS (10.0 mg, $\left.0.018 \mathrm{mmol}\right)$ in water/MeCN $(2: 1,3.0 \mathrm{~mL})$ after purification by silica gel column chromatography $\left(\mathrm{CH}_{2} \mathrm{Cl}_{2} / \mathrm{MeOH}=10: 1, \mathrm{v} / \mathrm{v}\right)$, preparative TLC $\left(\mathrm{CH}_{2} \mathrm{Cl}_{2} / \mathrm{MeOH}=20: 1, \mathrm{v} / \mathrm{v}\right)$, and reversed-phase HPLC (5-80\% $\mathrm{MeOH}$ in water). ${ }^{1} \mathrm{H}$ NMR (300 MHz, DMSO-d6) $\delta 7.88\left(\mathrm{~s}, 1 \mathrm{H}, \mathrm{H}_{2}\right), 7.83(\mathrm{t}, J=1.6 \mathrm{~Hz}, 1 \mathrm{H}, \mathrm{Ar}-H), 7.81(\mathrm{t}, J=1.6$ 
$\mathrm{Hz}, 1 \mathrm{H}, \mathrm{Ar}-H), 6.76(\mathrm{~s}, 1 \mathrm{H}, \mathrm{Ar}-H), 6.68(\mathrm{~s}, 1 \mathrm{H}, \mathrm{H} 8), 5.16$ (d, $\left.J_{1^{\prime}, 2^{\prime}}=6.0 \mathrm{~Hz}, 1 \mathrm{H}, \mathrm{H}_{1^{\prime}}\right), 5.02\left(\mathrm{~d}, J_{\mathrm{OH}, 2^{\prime}}\right.$ $=6.0 \mathrm{~Hz}, 1 \mathrm{H}, \mathrm{OH}), 4.90$ (br, 1H, OH-3'), 4.76 (dd, $J_{\mathrm{OH}, 5}$ ' = $5.8 \mathrm{~Hz}, J_{\mathrm{OH}, 5^{\prime}}=5.0 \mathrm{~Hz} 1 \mathrm{H}, \mathrm{OH}-5^{\prime}$ ), $4.23\left(\mathrm{ddd}, J_{2^{\prime}, 3^{\prime}}=5.4 \mathrm{~Hz}, J_{2^{\prime}, 1^{\prime}}=6.0 \mathrm{~Hz}, J_{2^{\prime}, \mathrm{OH}}=6.0 \mathrm{~Hz}, 1 \mathrm{H}, \mathrm{H}_{2^{\prime}}\right), 3.95\left(\mathrm{dd}, J_{3^{\prime}, 4^{\prime}}=4.7 \mathrm{~Hz}, J_{3^{\prime}, 2^{\prime}}=\right.$ $\left.5.3 \mathrm{~Hz}, 1 \mathrm{H}, \mathrm{H}_{3}{ }^{\prime}\right), 3.80\left(\mathrm{ddd}, J_{4}{ }^{\prime},{ }^{\prime}=4.7 \mathrm{~Hz}, J_{4}{ }^{\prime},{ }^{\prime}=4.0 \mathrm{~Hz}, J_{4}{ }^{\prime}, 3^{\prime}=4.5 \mathrm{~Hz}, 1 \mathrm{H}, \mathrm{H}_{4}{ }^{\prime}\right.$ ), 3.57-3.53 (ddd, $\left.J_{5}{ }^{\prime}, 4^{\prime}=4.0 \mathrm{~Hz}, J_{5}{ }^{\prime}, \mathrm{OH}=5.2 \mathrm{~Hz}, J_{\mathrm{gem}}=11.7 \mathrm{~Hz}, 1 \mathrm{H}, \mathrm{H}_{5}{ }^{\prime}\right), 3.48-3.44\left(\mathrm{ddd}, J_{5}{ }^{\prime}, 4^{\prime}=4.7 \mathrm{~Hz}, J_{5}{ }^{\prime}, \mathrm{OH}=\right.$ $\left.5.8 \mathrm{~Hz}, J_{\mathrm{gem}}=11.7 \mathrm{~Hz}, 1 \mathrm{H}, \mathrm{H}_{5}\right) ;{ }^{13} \mathrm{C} \mathrm{NMR}\left(75 \mathrm{MHz}, \mathrm{DMSO}-\mathrm{d}_{6}\right) \delta 155.9,147.6,144.3,140.3$, 129.5, 119.4, 112.0, 111.4, 111.0, 107.8, 84.6 (C-1'), 75.3 (C-4'), 74.1 (C-2'), 71.3 (C-3'), 62.1(C5'); HRMS (ESI-TOF) m/z: calcd for $\mathrm{C}_{15} \mathrm{H}_{16} \mathrm{~N}_{4} \mathrm{O}_{5}\left([\mathrm{M}+\mathrm{H}]^{+}\right), 333.1199$, found 333.1192.

7-((E)-Styryl)-4-aza-7,9-dideazaadenosine (12i). Following a similar procedure as that used for the synthesis of 12a, compound $\mathbf{1 2} \mathbf{i}$ was obtained as a yellow solid (29 $\mathrm{mg}, 40 \%)$ starting from 13 (76.0 mg, $0.193 \mathrm{mmol}),(E)$-2-phenylvinylboronic acid (43.0 mg, $0.290 \mathrm{mmol}), \mathrm{Pd}(\mathrm{OAc})_{2}$ (3.00 $\mathrm{mg}, 0.011 \mathrm{mmol}), \mathrm{Na}_{2} \mathrm{CO}_{3}(184 \mathrm{mg}, 1.74 \mathrm{mmol})$, and TPPTS (15.0 mg, $\left.0.027 \mathrm{mmol}\right)$ in water/MeCN $(2: 1,3.0 \mathrm{~mL})$ after purification by silica gel column chromatography $\left(\mathrm{CH}_{2} \mathrm{Cl}_{2} / \mathrm{MeOH}\right.$ $=10: 1, \mathrm{v} / \mathrm{v})$, preparative TLC $\left(\mathrm{CH}_{2} \mathrm{Cl}_{2} / \mathrm{MeOH}=20: 1, \mathrm{v} / \mathrm{v}\right)$, and reversed-phase HPLC $(5-80 \%$ $\mathrm{MeOH}$ in water). ${ }^{1} \mathrm{H}$ NMR (300 MHz, DMSO-d6) $\delta 7.83\left(\mathrm{~s}, 1 \mathrm{H}, \mathrm{H}_{2}\right), 7.71(\mathrm{~d}, J=7.8 \mathrm{~Hz}, 1 \mathrm{H}, \mathrm{Ar}-$ $H$ ), 7.60 (d, $J=15.7 \mathrm{~Hz}, 2 \mathrm{H}, \operatorname{Ar}-H), 7.35$ (t, $J=7.4 \mathrm{~Hz}, 1 \mathrm{H}, \operatorname{Ar}-H), 7.24$ (d, $J=7.4 \mathrm{~Hz}, 1 \mathrm{H}), 7.20$ $\left(\mathrm{s}, 1 \mathrm{H}, \mathrm{H}_{8}\right), 7.10(\mathrm{~d}, J=15.8 \mathrm{~Hz}, 1 \mathrm{H}), 5.13\left(\mathrm{~d}, J_{1^{\prime}, 2^{\prime}}=6.3 \mathrm{~Hz}, 1 \mathrm{H}, \mathrm{H}_{1^{\prime}}\right), 5.06\left(\mathrm{~d}, J_{\mathrm{OH}, 2^{\prime}}=6.3 \mathrm{~Hz}, 1 \mathrm{H}\right.$, OH-2'), $4.94\left(\mathrm{~d}, J_{\mathrm{OH}, 3^{\prime}}=5.3 \mathrm{~Hz}, 1 \mathrm{H}, \mathrm{OH}-3^{\prime}\right), 4.82\left(\mathrm{dd}, J_{\mathrm{OH}, 5^{\prime}}=5.8 \mathrm{~Hz}, J_{\mathrm{OH}, 5^{\prime}}=5.1 \mathrm{~Hz}, 1 \mathrm{H}, \mathrm{OH}-\right.$ 5'), $4.24\left(\mathrm{ddd}, J_{2}{ }^{\prime}, 3^{\prime}=5.6 \mathrm{~Hz}, J_{2}{ }^{\prime}, 1^{\prime}=6.2 \mathrm{~Hz}, J_{2}{ }^{\prime}, \mathrm{OH}=6.3 \mathrm{~Hz}, 1 \mathrm{H}, \mathrm{H}_{2}{ }^{\prime}\right), 3.97$ (ddd, $J_{3^{\prime}, 4^{\prime}}=4.5 \mathrm{~Hz}$, $\left.J_{3^{\prime}, 2^{\prime}}=5.6 \mathrm{~Hz}, J_{3^{\prime}, \mathrm{OH}}=5.3 \mathrm{~Hz}, 1 \mathrm{H}, \mathrm{H}_{3}{ }^{\prime}\right), 3.80\left(\mathrm{ddd}, J_{4^{\prime}, 3^{\prime}}=4.6 \mathrm{~Hz}, J_{4^{\prime}, 5^{\prime}}=4.5 \mathrm{~Hz}, J_{4}, 5^{\prime}=4.3 \mathrm{~Hz}, 1 \mathrm{H}\right.$, $\mathrm{H}_{4}{ }^{\prime}$ ), 3.60-3.53 (ddd, $J_{5}{ }^{\prime}, 4^{\prime}=4.3 \mathrm{~Hz}, J_{5}{ }^{\prime}, \mathrm{OH}=5.2 \mathrm{~Hz}, J_{\mathrm{gem}}=11.5 \mathrm{~Hz}, 1 \mathrm{H}, \mathrm{H}_{5}{ }^{\prime}$ ), 3.62-3.55 (ddd, $\left.J_{5}, 4^{\prime}=4.5 \mathrm{~Hz}, J_{5}, \mathrm{OH}=5.8 \mathrm{~Hz}, J_{\mathrm{gem}}=11.5 \mathrm{~Hz}, 1 \mathrm{H}, \mathrm{H}_{5}{ }^{\prime}\right) ;{ }^{13} \mathrm{C}$ NMR $\left(75 \mathrm{MHz}, \mathrm{DMSO}-\mathrm{d}_{6}\right) \delta 165.5$, $156.8,146.9,139.7,137.9,137.5,136.4,136.0,129.5,124.7,121.1,116.5,93.9$ (C-1'), 84.6 (C4'), 83.3 (C-2'), 80.6 (C-3'), 71.4 (C-5'); HRMS (ESI-TOF) m/z: calcd for $\mathrm{C}_{19} \mathrm{H}_{20} \mathrm{~N}_{4} \mathrm{O}_{4}\left([\mathrm{M}+\mathrm{H}]^{+}\right)$, 369.1563 , found 369.1553 .

7-(Thiophen-3-yl)-4-aza-7,9-dideazaadenosine (12j). Following a similar procedure as that used for the synthesis of $\mathbf{1 2 a}$, compound $\mathbf{1 2} \mathbf{j}$ was obtained as a white solid (10 $\mathrm{mg}, 21 \%)$ starting from 13 (50.0 mg, $0.127 \mathrm{mmol}$ ), thiophen-3-ylboronic acid (28 mg, $0.191 \mathrm{mmol}), \mathrm{Pd}(\mathrm{OAc}) 2$ (2.00 mg, $0.008 \mathrm{mmol}), \mathrm{Na}_{2} \mathrm{CO}_{3}(121.0 \mathrm{mg}, 1.15 \mathrm{mmol})$, and TPPTS (10.0 mg, $\left.0.018 \mathrm{mmol}\right)$ in water/MeCN $(2: 1,3.0 \mathrm{~mL})$ after purification by silica gel column chromatography $\left(\mathrm{CH}_{2} \mathrm{Cl}_{2} / \mathrm{MeOH}=10: 1, \mathrm{v} / \mathrm{v}\right)$, preparative TLC $\left(\mathrm{CH}_{2} \mathrm{Cl}_{2} / \mathrm{MeOH}=20: 1, \mathrm{v} / \mathrm{v}\right)$, and reversed-phase HPLC (5-80\% MeOH in water). 
${ }^{1} \mathrm{H}$ NMR (300 MHz, DMSO-d6) $\delta 7.90\left(\mathrm{~s}, 1 \mathrm{H}, \mathrm{H}_{2}\right), 7.31\left(\mathrm{dd}, J_{1}=2.9 \mathrm{~Hz}, J_{2}=4.9 \mathrm{~Hz}, 1 \mathrm{H}, \mathrm{Ar}-H\right)$, $7.55\left(\mathrm{dd}, J_{1}=1.3 \mathrm{~Hz}, J_{2}=3.0 \mathrm{~Hz}, 1 \mathrm{H}, \mathrm{Ar}-H\right), 7.25\left(\mathrm{dd}, J_{1}=1.2 \mathrm{~Hz}, J_{2}=4.9 \mathrm{~Hz}, 1 \mathrm{H}, \mathrm{Ar}-H\right), 6.80$ $\left(\mathrm{s}, 1 \mathrm{H}, \mathrm{H}_{8}\right), 5.17\left(\mathrm{~d}, J_{1^{\prime}, 2^{\prime}}=6.1 \mathrm{~Hz}, 1 \mathrm{H}, \mathrm{H}_{1^{\prime}}\right), 5.05\left(\mathrm{~d}, J_{\mathrm{OH}, 2^{\prime}}=6.0 \mathrm{~Hz}, 1 \mathrm{H}, \mathrm{OH}-2^{\prime}\right), 4.92\left(\mathrm{~d}, J_{\mathrm{OH}, 3^{\prime}}=\right.$ $5.3 \mathrm{~Hz}, 1 \mathrm{H}, \mathrm{OH}-3^{\prime}$ ), 4.78 (dd, $J_{\mathrm{OH}, 5^{\prime}}=5.0 \mathrm{~Hz}, J_{\mathrm{OH}, 5^{\prime}}=6.1 \mathrm{~Hz}, 1 \mathrm{H}, \mathrm{OH}-5$ '), 4.24 (ddd, $J_{2}{ }^{\prime}, 3^{\prime}=5.5$ $\left.\mathrm{Hz}, J_{2}{ }^{\prime}, 1^{\prime}=6.1 \mathrm{~Hz}, J_{2}{ }^{\prime}, \mathrm{OH}=6.0 \mathrm{~Hz}, 1 \mathrm{H}, \mathrm{H}_{2}{ }^{\prime}\right), 3.96\left(\mathrm{ddd}, J_{3^{\prime}, 4^{\prime}}=4.8 \mathrm{~Hz}, J_{3^{\prime}, 2^{\prime}}=5.5 \mathrm{~Hz}, J^{\prime}, \mathrm{OH}=5.3\right.$ $\mathrm{Hz}, 1 \mathrm{H}, \mathrm{H}_{3^{\prime}}$ ), 3.80 (ddd, $J_{4^{\prime}, 3^{\prime}}=4.8 \mathrm{~Hz}, J_{4}{ }^{\prime}, 5^{\prime}=4.7 \mathrm{~Hz}, J_{4^{\prime}, 5^{\prime}}=4.2 \mathrm{~Hz}, 1 \mathrm{H}, \mathrm{H}_{4}{ }^{\prime}$ ), 3.57-3.54 (ddd, $\left.J_{5}{ }^{\prime}, 4^{\prime}=4.2 \mathrm{~Hz}, J_{5}{ }^{\prime}, \mathrm{OH}=5.0 \mathrm{~Hz}, J_{\mathrm{gem}}=11.7 \mathrm{~Hz}, 1 \mathrm{H}, \mathrm{H}_{5}{ }^{\prime}\right), 3.48-3.44\left(\mathrm{ddd}, J_{5^{\prime}, 4^{\prime}}=4.8 \mathrm{~Hz}, J_{5}{ }^{\prime}, \mathrm{OH}=\right.$ $\left.6.1 \mathrm{~Hz}, J_{\mathrm{gem}}=11.7 \mathrm{~Hz}, 1 \mathrm{H}, \mathrm{H}_{5}\right)$; ${ }^{13} \mathrm{C} \mathrm{NMR}\left(75 \mathrm{MHz}, \mathrm{DMSO}-\mathrm{d}_{6}\right) \delta 155.7,147.6,135.4,129.3$, 129.0, 127.5, 123.1, 112.4, 111.3, 110.6, 84.5 (C-1'), 75.2 (C-4'), 74.0 (C-2'), 71.2 (C-3'), 61.9 (C-5'); HRMS (ESI-TOF) m/z: calcd for $\mathrm{C}_{15} \mathrm{H}_{16} \mathrm{~N}_{4} \mathrm{O}_{4} \mathrm{~S}_{1}\left([\mathrm{M}+\mathrm{H}]^{+}\right), 349.0971$, found 349.0970.

7-(2-Chlorophenyl)-4-aza-7,9-dideazaadenosine (12k). Following a similar procedure as that used for the synthesis of 12a, compound 12k was obtained as a white solid (5 mg, 7\%) starting from 13 (50.0 mg, $0.127 \mathrm{mmol}$ ), (2-chlorophenyl)boronic acid (29.0 mg, $0.191 \mathrm{mmol}), \mathrm{Pd}(\mathrm{OAc})_{2}$ (2.00 mg, $0.00765 \mathrm{mmol}), \mathrm{Na}_{2} \mathrm{CO}_{3}(121.0 \mathrm{mg}, 1.15 \mathrm{mmol})$, and TPPTS (10.0 mg, $\left.0.018 \mathrm{mmol}\right)$ in water/MeCN $(2: 1,3.0 \mathrm{~mL})$ after purification by silica gel column chromatography $\left(\mathrm{CH}_{2} \mathrm{Cl}_{2} / \mathrm{MeOH}\right.$ $=10: 1, \mathrm{v} / \mathrm{v})$, preparative TLC $\left(\mathrm{CH}_{2} \mathrm{Cl}_{2} / \mathrm{MeOH}=20: 1, \mathrm{v} / \mathrm{v}\right)$, and reversed-phase HPLC $(5-80 \%$ $\mathrm{MeOH}$ in water). ${ }^{1} \mathrm{H}$ NMR (300 MHz, DMSO-d 6$) \delta 7.92\left(\mathrm{~s}, 1 \mathrm{H}, \mathrm{H}_{2}\right), 7.62-7.60(\mathrm{~m}, 1 \mathrm{H}, \mathrm{Ar}-H)$, 7.47-7.42 (m, 3H, Ar- $H), 6.78\left(\mathrm{~s}, 1 \mathrm{H}, \mathrm{H}_{8}\right), 5.17\left(\mathrm{~d}, J_{1^{\prime}, 2^{\prime}}=6.2 \mathrm{~Hz}, 1 \mathrm{H}, \mathrm{H}_{1^{\prime}}\right), 5.06\left(\mathrm{~d}, J_{\mathrm{OH}, 2^{\prime}}=5.9\right.$ Hz, 1H, OH), 4.95 (br, 1H, OH-3'), 4.78 (br, 1H, OH-5'), 4.26 (m, 1H, H ${ }^{\prime}$ ), 3.96 (m, 1H, H3'), $3.80\left(\mathrm{dd}, J_{4}{ }^{\prime}, 5^{\prime}=4.7 \mathrm{~Hz}, J_{4}{ }^{\prime},{ }^{\prime},=4.2 \mathrm{~Hz}, 1 \mathrm{H}, \mathrm{H}_{4}{ }^{\prime}\right), 3.54-3.43\left(\mathrm{~m}, 2 \mathrm{H}, \mathrm{H}_{5}{ }^{\prime}, \mathrm{H}_{5}{ }^{\prime}\right) ;{ }^{13} \mathrm{C} \mathrm{NMR}(75 \mathrm{MHz}$, DMSO-d6) $\delta 155.6,147.7,133.5,133.4,132.7,130.0,129.8,129.1,127.5,113.9,111.9,111.6$, 84.6 (C-1'), 75.5 (C-4'), 73.9 (C-2'), 71.3 (C-3'), 62.1 (C-5'); HRMS (ESI-TOF) m/z: calcd for $\mathrm{C}_{17} \mathrm{H}_{17} \mathrm{Cl}_{1} \mathrm{~N}_{4} \mathrm{O}_{4}\left([\mathrm{M}+\mathrm{H}]^{+}\right), 377.1017$, found 377.1010 .

\subsection{Biological materials and methods}

\subsubsection{Cell culture and reference compounds}

All tumor cell lines (HL-60, K-562, Z-138, LN-229, Capan-1, HCT-116, and NCI-H460) were acquired from the American Type Culture Collection (ATCC, Manassas, VA, USA), except for the DND-41 cell line, which was purchased from the Deutsche Sammlung von Mikroorganismen und Zellkulturen (DSMZ Leibniz-Institut, Germany). All cell lines were cultured as recommended 
by the suppliers. Culture media were purchased from Gibco Life Technologies, USA, and supplemented with 10\% fetal bovine serum (HyClone, GE Healthcare Life Sciences, USA).

Buffy coat preparations from healthy donors were obtained from the Blood Transfusion Center in Leuven, Belgium. Peripheral blood mononuclear cells (PBMCs) were isolated by density gradient centrifugation over Lymphoprep $(\mathrm{d}=1.077 \mathrm{~g} / \mathrm{ml})$ (Nycomed, Oslo, Norway) and cultured in cell culture medium (DMEM/F12, Gibco Life Technologies, USA) containing 8\% FBS.

Reference inhibitor compounds staurosporine, docetaxel, etoposide, and vincristine were obtained from Selleckchem (Munich, Germany), while propidium iodide was purchased from Gibco Life Technologies, USA, and mitoxantrone was ordered from Cayman Chemical (Michigan, USA). All stock solutions were prepared in DMSO.

\subsubsection{Cell proliferation assays}

Adherent cancer cell lines LN-229, Capan-1, HCT-116, and NCI-H460 cells were seeded at a density between 500 and 1500 cells per well, in 384-well, black walled, clear-bottomed tissue culture plates (Greiner). After overnight incubation, cells were treated with the test compounds at seven different concentrations ranging from 100 to $6.4 \times 10^{-3} \mu \mathrm{M}$. Suspension cell lines DND-41, HL-60, K-562, and Z-138 were seeded at densities ranging from 2500 to 5500 cells per well in 384-well, black walled, clear-bottomed tissue culture plates containing the test compounds at the same seven concentration points.

The plates were incubated at $37{ }^{\circ} \mathrm{C}$ and monitored for $72 \mathrm{~h}$ in an IncuCyte ${ }^{\circledR}$ device (Essen BioScience Inc., Ann Arbor, MI, USA) for real-time imaging. Images were taken every $3 \mathrm{~h}$, with one field imaged per well under 10x magnification. Cell growth was then quantified based on the percent cellular confluence as analyzed by the IncuCyte ${ }^{\circledR}$ image analysis software. Area under the curve (AUC) values were calculated and used to determine the $\mathrm{IC}_{50}$ values.

\subsubsection{Tubulin immunofluorescence staining}

Human cervix carcinoma HEp-2 cells were seeded at 15000c/well in 8-well chamberslides (Ibidi). After overnight incubation they were treated with compound or carrier (DMSO) for $3 \mathrm{~h}$ and then fixed with 4\% PFA, washed and permeabilised. Further treatment was performed according to standard immunofluorescence procedures and cell nuclei were counterstained with DAPI. Employed antibodies are mouse anti-alpha tubulin (sc-5286, Santa Cruz Biotechnology) and 
secondary goat anti-mouse IgG conjugated to Alexa Fluor ${ }^{\circledR} 488$ (A11001, Invitrogen). Images were taken with a Leica TCS SP5 confocal microscope employing an HCX PL APO 63x (NA 1.2)/water immersion objective.
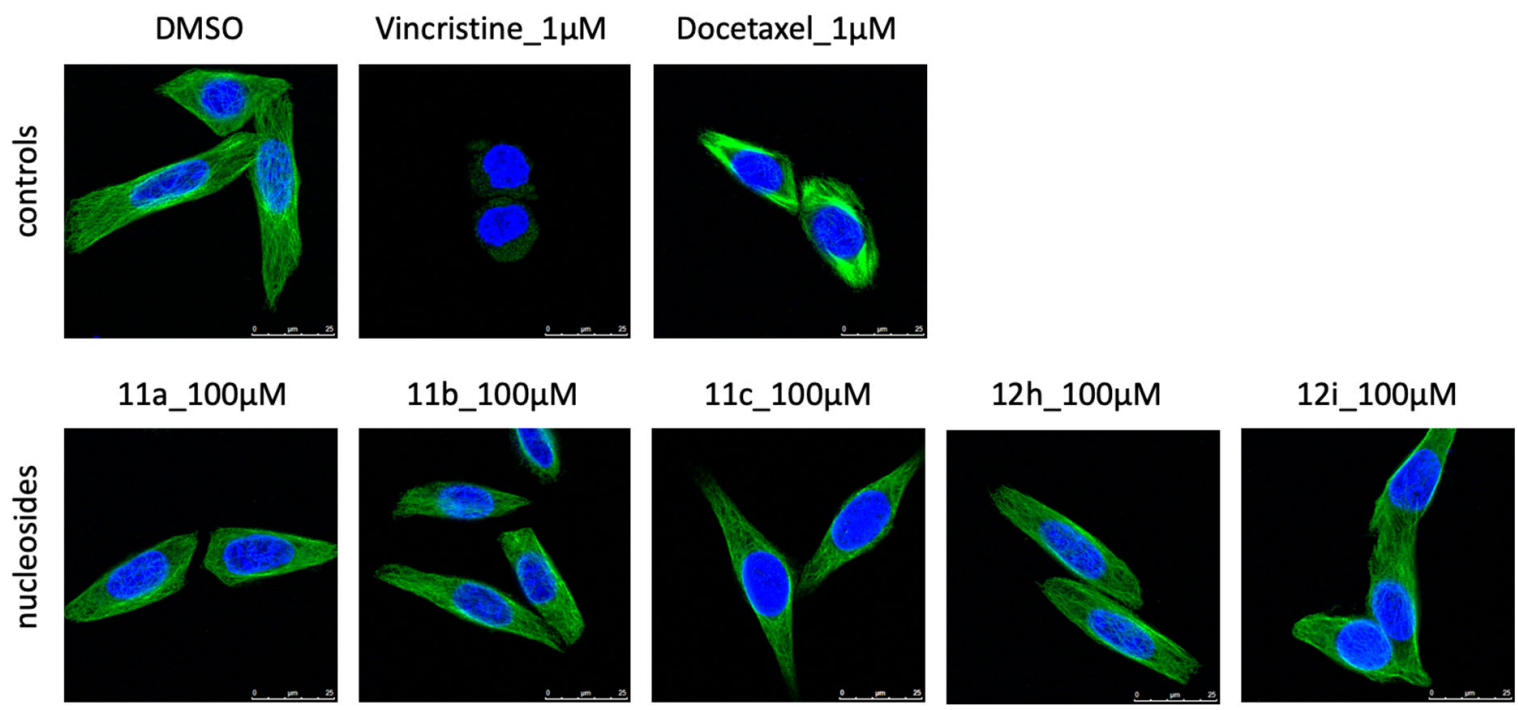

Figure S1. Immunofluorescence staining of alpha-tubulin in HEp-2 cells treated for $3 \mathrm{~h}$ with the indicated concentrations of compounds $11 \mathbf{a}, 11 \mathbf{b}, 11 \mathbf{c}, 12 \mathbf{h}$, and $12 \mathbf{i}$, or reference compounds vincristine and docetaxel. Green: alpha-tubulin, blue: DAPI. Scale bar: $25 \mu \mathrm{M}$.

\subsubsection{DNA intercalation assay}

The DNA intercalation assay was performed as described by Beauchemin et al. ${ }^{2}$ Acridine orange (Honeywell FLUKA) was stored at $4{ }^{\circ} \mathrm{C}$ and protected from light in a $1 \mathrm{mM}$ stock solution in water. Then, $50 \mathrm{nM}$ acridine orange and $20 \mu \mathrm{g} / \mathrm{mL}$ salmon sperm DNA (Invitrogen \#15632-011) were incubated with compounds in HBS-EP buffer (GE Healthcare, Sweden) for $20 \mathrm{~min}$. The assay was formatted for 384 well plates (Greiner \#781076) in a reaction volume of $50 \mu \mathrm{L}$ per well. Propidium iodide and mitoxantrone (MTX) were used as positive controls, and all test compounds were tested in triplo at $20 \mu \mathrm{M}$. Fluorescence polarization was measured using a SaFire II microplate reader (Tecan, Switzerland). 


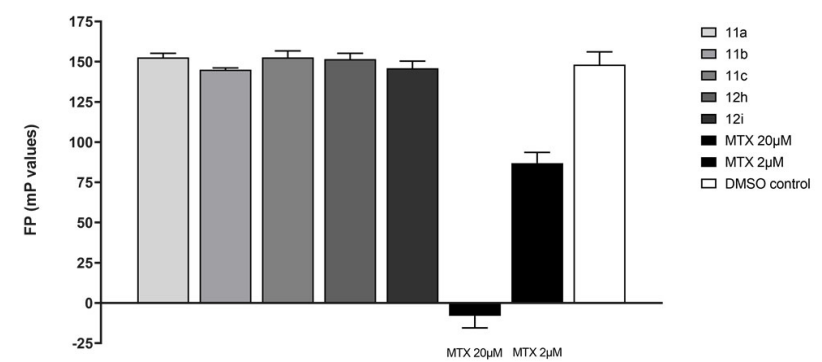

Figure S3. Decrease in fluorescence polarization (FP) due to intercalation into DNA induced by compounds 11a, 11b, 11c, 12h, and $12 \mathrm{i}$ in comparison to reference compound mitoxantrone.

\subsubsection{Gamma H2A.X immunofluorescence staining}

Human cervix carcinoma HEp-2 cells were seeded at 4500c/well in 96-well, black-walled, clearbottomed tissue culture plates (Falcon). After overnight incubation they were treated with compound or carrier (DMSO) for $24 \mathrm{~h}$ and then fixed with 4\% PFA, washed and permeabilised. Further treatment was performed according to standard immunofluorescence procedures, using rabbit anti-gamma H2A.X (phospho S139) and secondary goat anti-rabbit IgG conjugated to Alexa Fluor ${ }^{\circledR}$ 647. Nuclei were counterstained with DAPI, and images were taken with a CellInsight CX5 high-content imager (ThermoFisher Scientific, Massachusetts, USA).

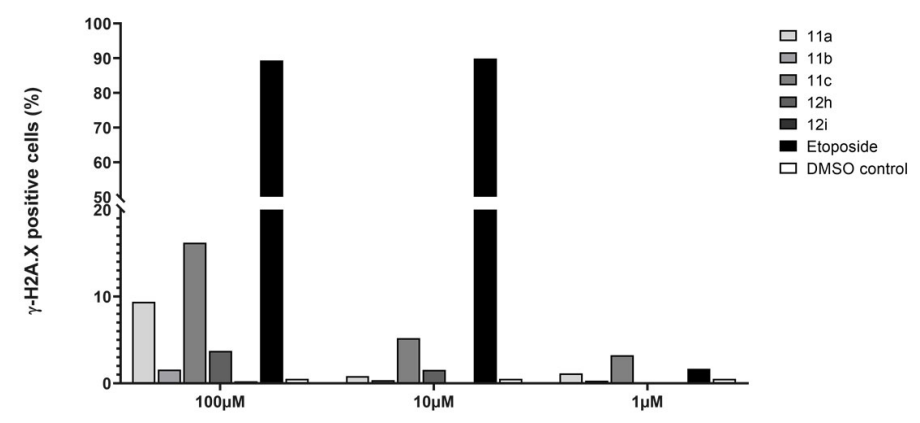

Figure S3. Dose dependency of DNA damage induced by compounds $11 \mathbf{a}, 11 \mathbf{b}, 11 \mathrm{c}, 12 \mathrm{~h}$, and $12 \mathbf{i}$ in comparison to the reference compound etoposide measured as variation (\%) of $\gamma-\mathrm{H} 2 \mathrm{AX}$ levels.

\subsubsection{Apoptosis induction assay on PBMC cells}

PBMCs were seeded at 28000 cells per well in 384-well, black-walled, clear-bottomed tissue culture plates containing the test compounds at seven different concentrations ranging from 100 to $6.4 \times 10^{-3} \mu \mathrm{M}$. IncuCyte ${ }^{\circledR}$ Caspase 3/7 Green Reagent was added as recommended by the supplier, 
and the plates were incubated and monitored at $37{ }^{\circ} \mathrm{C}$ for 3 days in the IncuCyte ${ }^{\circledR}$. Images were taken every $3 \mathrm{~h}$ in the brightfield and green fluorescence channel, with one field imaged per well under 10x magnification, followed by quantification of the percent confluence in both channels using the IncuCyte ${ }^{\circledR}$ image analysis software. Percentage green confluence was normalized to percentage phase confluence and these relative values were used for the calculation of IC50's for apoptosis induction. All compounds were tested in two independent experiments, which implies PBMC originating from two different donors.

Table S1. Apoptosis Induction in PBMC and Capan-1 cells by C-Nucleosides 11a-c and 12h-i.

\begin{tabular}{|c|c|c|c|c|c|}
\hline \multirow{2}{*}{ Compound } & \multicolumn{3}{|c|}{ "PBMC caspase 3/7 activation" } & \multirow{2}{*}{$\begin{array}{c}\text { Capan-1 caspase 3/7 } \\
\text { activation" }\end{array}$} \\
\cline { 2 - 5 } & \multicolumn{2}{|c|}{ Donor 1 } & \multicolumn{2}{c|}{ Donor 2 } & $72 \mathrm{~h}$ \\
\cline { 2 - 5 } & $24 \mathrm{~h}$ & $72 \mathrm{~h}$ & $24 \mathrm{~h}$ & $72 \mathrm{~h}$ & - \\
\hline 11a & 11.0 & 0.2 & 0.1 & 0.05 & 9,6 \\
\hline 11b & $>100$ & 48.0 & $>100$ & 29.0 & 0,02 \\
\hline 11c & 0.4 & 0.4 & 0.1 & 0.1 & $>100$ \\
\hline 12h & $>100$ & $>100$ & $>100$ & 98.0 & - \\
\hline 12i & $>100$ & $>100$ & $>100$ & 98.0 & 0,0002 \\
\hline Staurosporine & 0.4 & 0.4 & 0.2 & 0.1 & \\
\hline
\end{tabular}

\subsubsection{Apoptosis induction assay on Capan-1 cells}

Capan-1 were seeded at 500 cells per well in 384-well, black-walled, clear-bottomed tissue culture plates (Greiner). After overnight incubation, cells were treated with the test compounds at six different concentrations ranging from 10 to $3.2 \times 10^{-3} \mu \mathrm{M}$. IncuCyte ${ }^{\circledR}$ Caspase $3 / 7$ Green Reagent was added as recommended by the supplier, and the plates were incubated and monitored at $37^{\circ} \mathrm{C}$ for 3 days in the IncuCyte ${ }^{\circledR}$. Images were taken every $3 \mathrm{~h}$ in the brightfield and the green fluorescence channel, with one field imaged per well under 10x magnification, followed by quantification of the percent confluence in both channels using the IncuCyte ${ }^{\circledR}$ image analysis software. After $72 \mathrm{~h}$ the percentage of apoptotic cells was calculated by normalizing the percentage green confluence to the percentage phase confluence. All compounds were tested in duplicate in two independent experiments. 


\section{References}

(1) Li, Q. F.; Lescrinier, E.; Groaz, E.; Persoons, L.; Daelemans, D.; Herdewijn, P.; De Jonghe, S. Synthesis and Biological Evaluation of Pyrrolo[2,1-f][1,2,4]triazine C-Nucleosides with a Ribose, 2-Deoxyribose, and 2,3Dideoxyribose Sugar Moiety. Chemmedchem 2018, 13, 97-104.

(2) Rogakou, E. P.; Pilch, D. R.; Orr, A. H.; Ivanova, V. S.; Bonner, W. M. DNA double-stranded breaks induce histone H2AX phosphorylation on serine 139. J. Biol. Chem. 1998, 273, 5858-5868. 


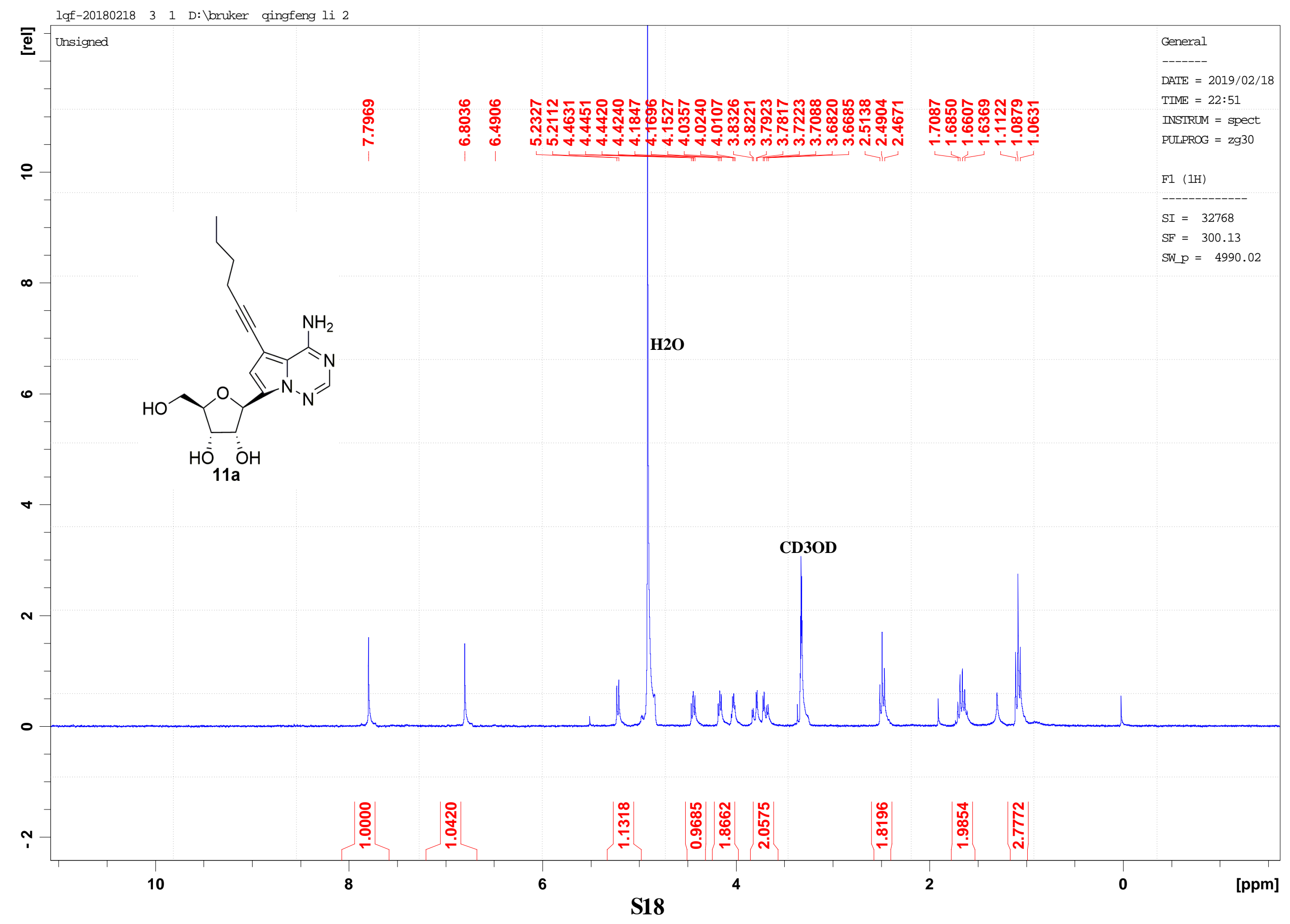




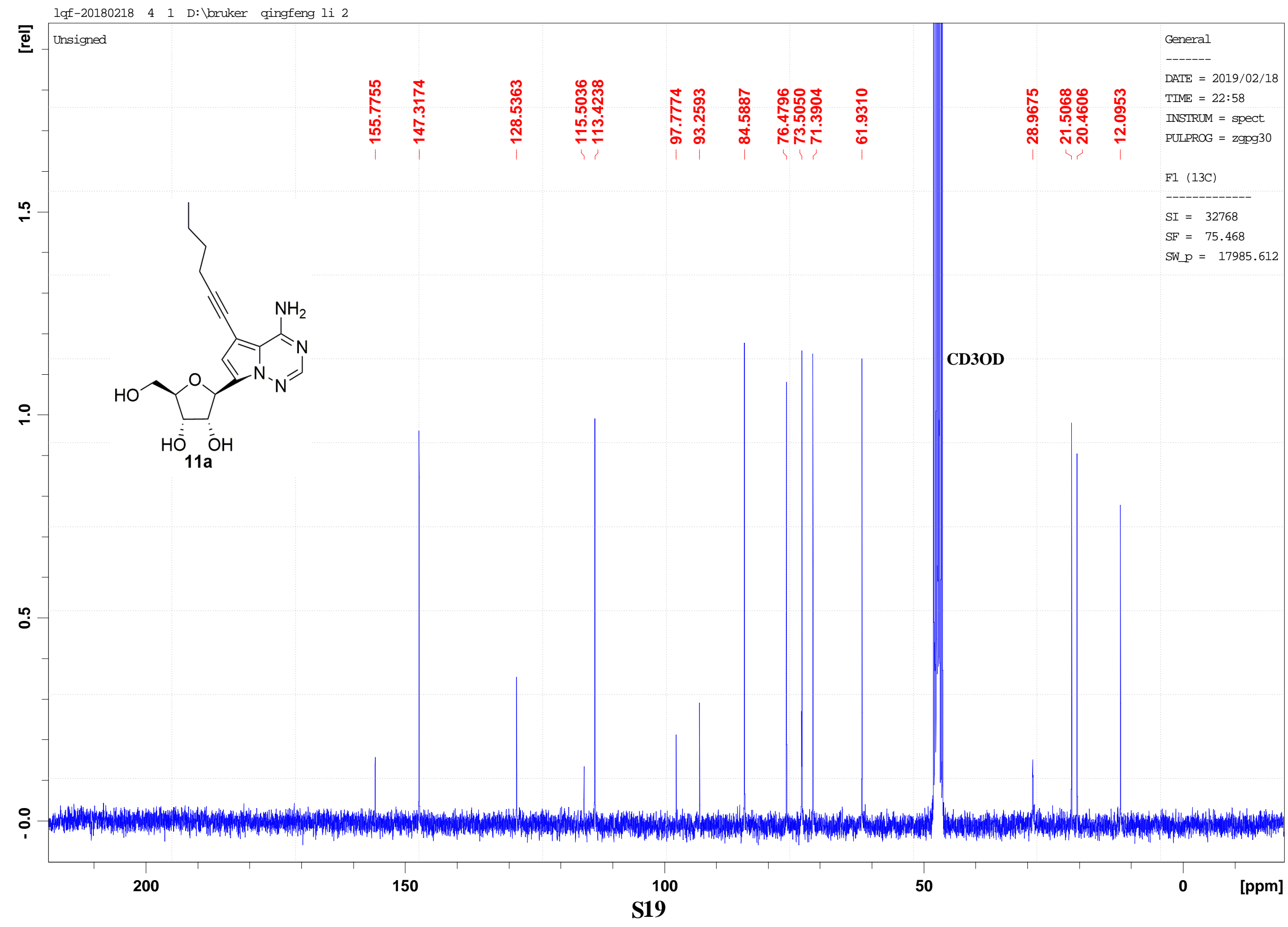




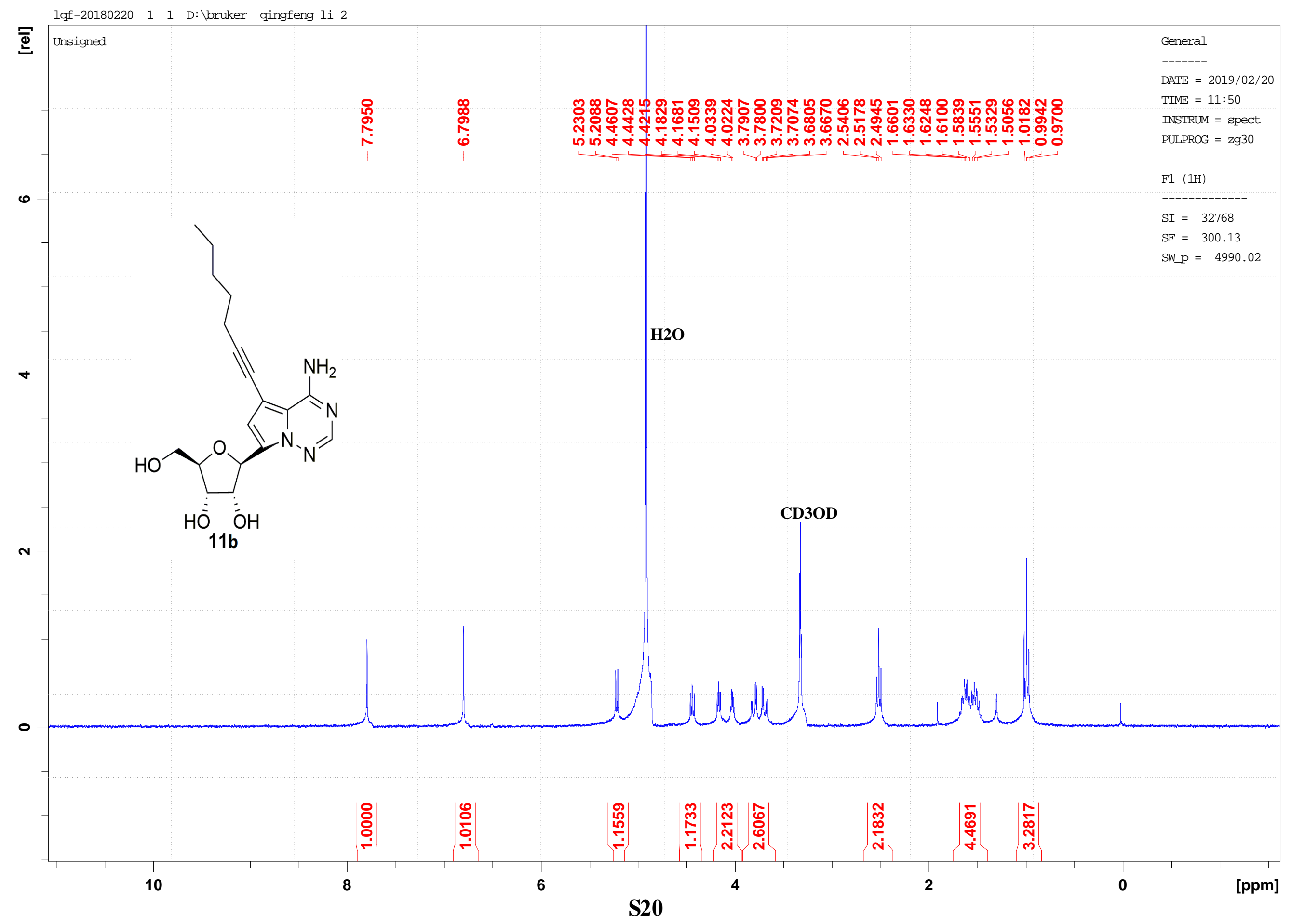




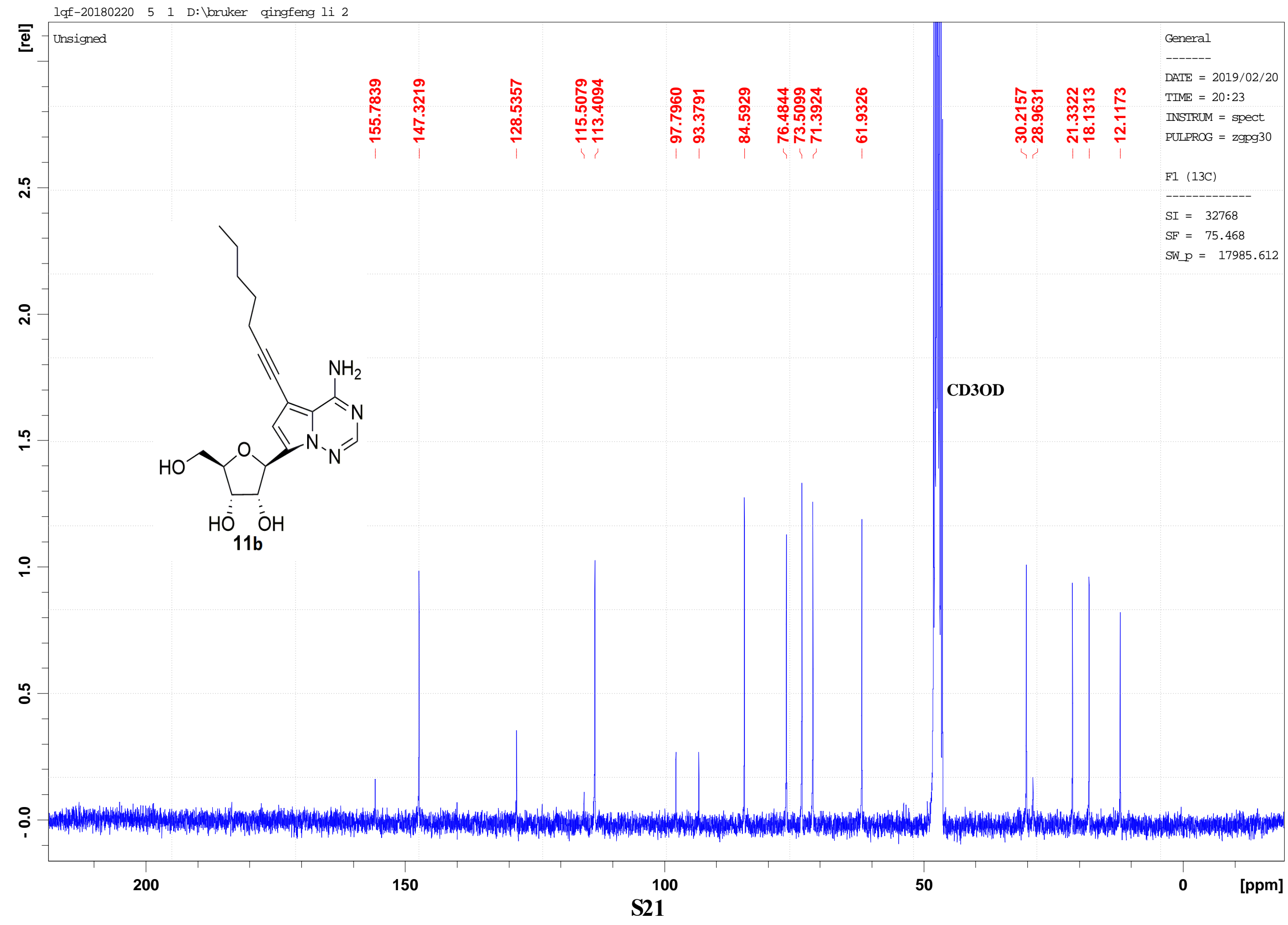




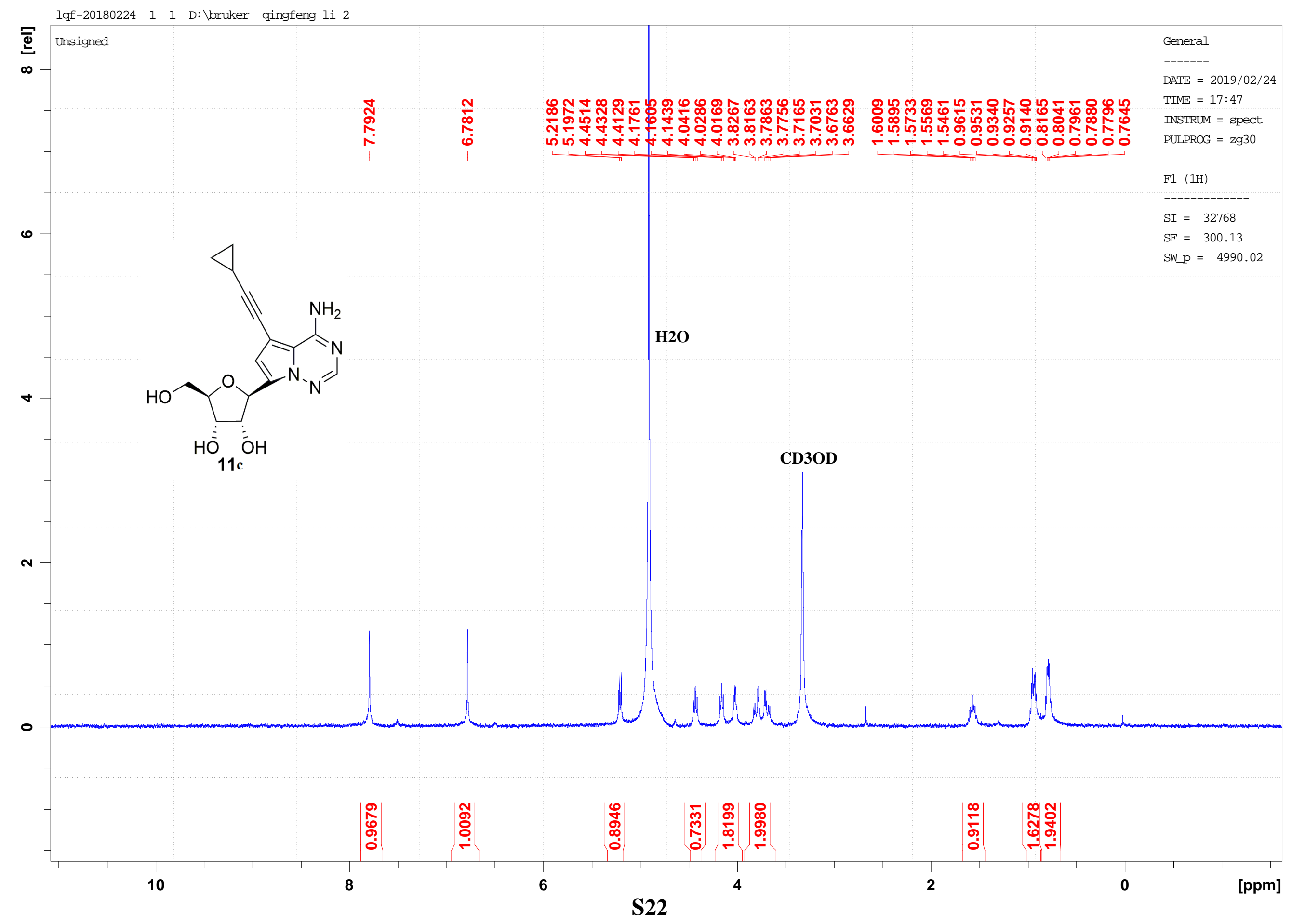




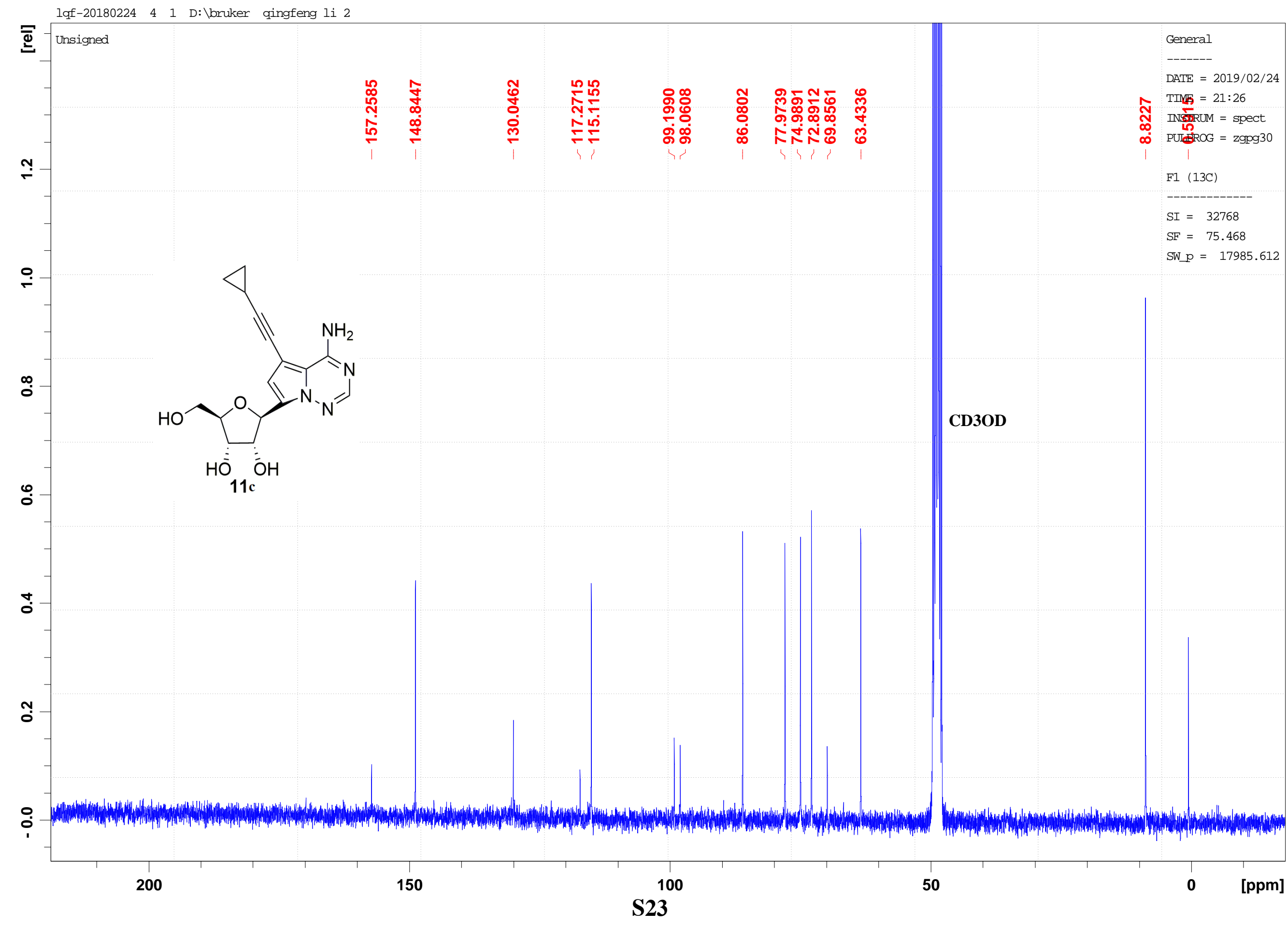




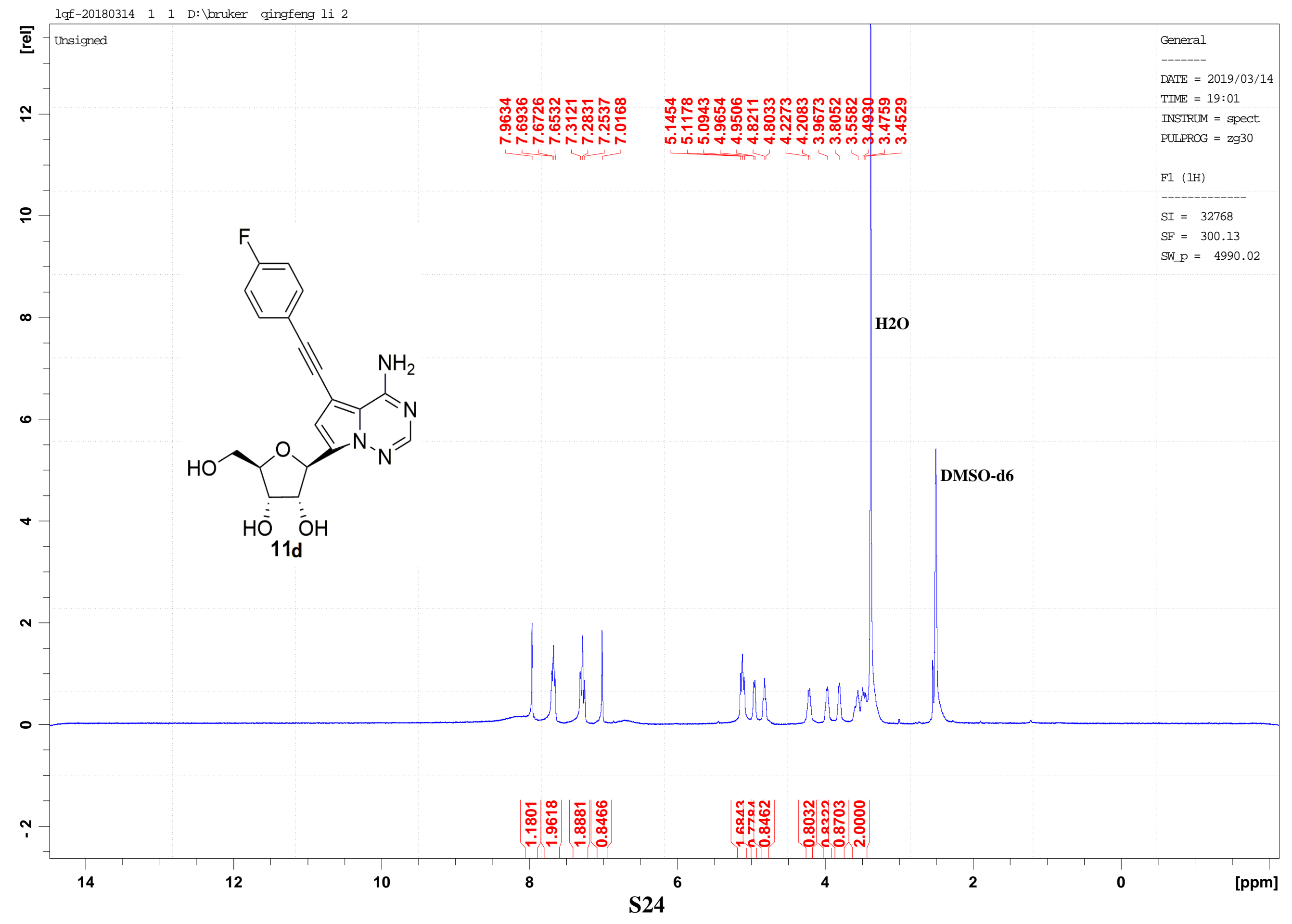




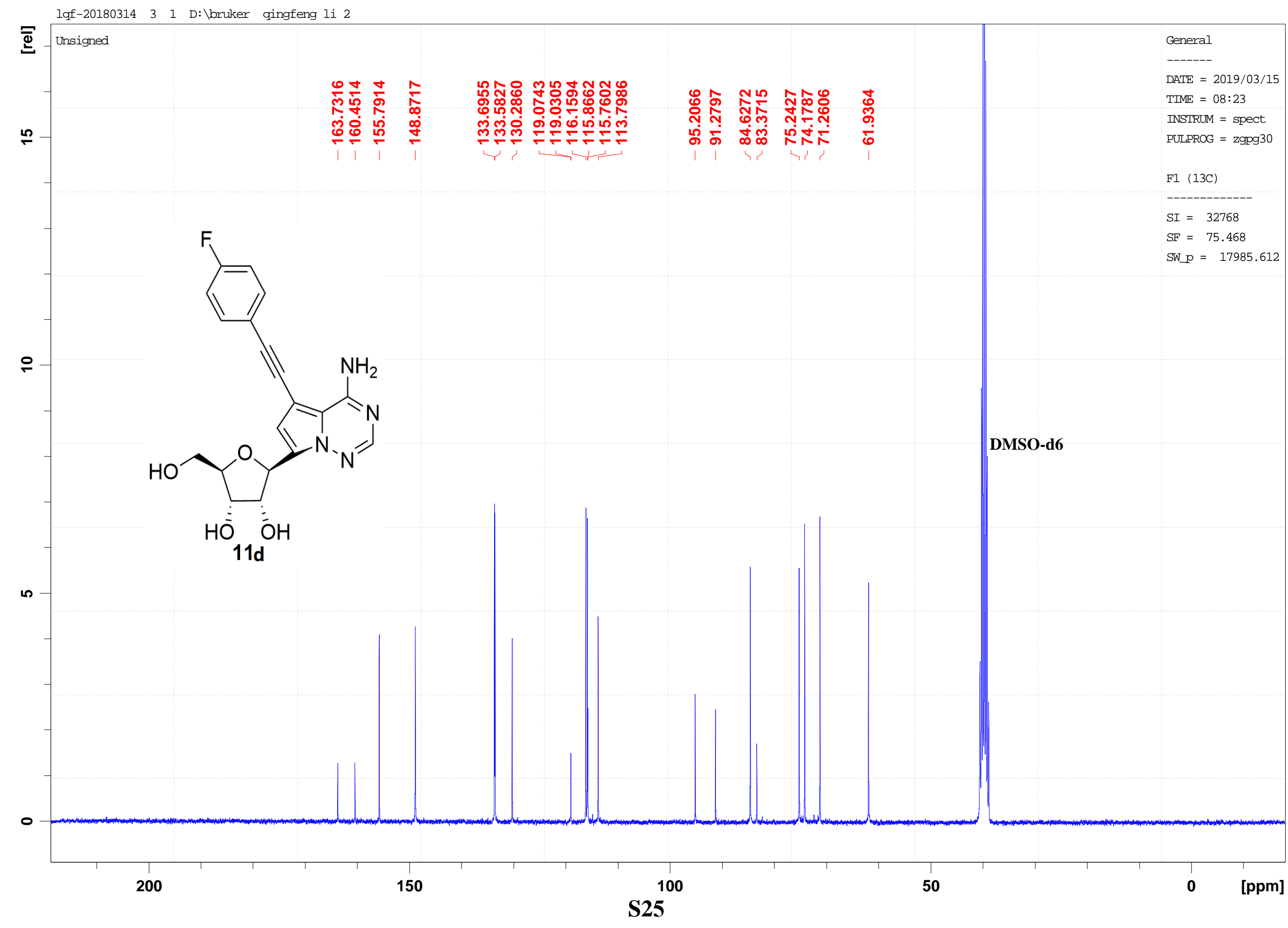




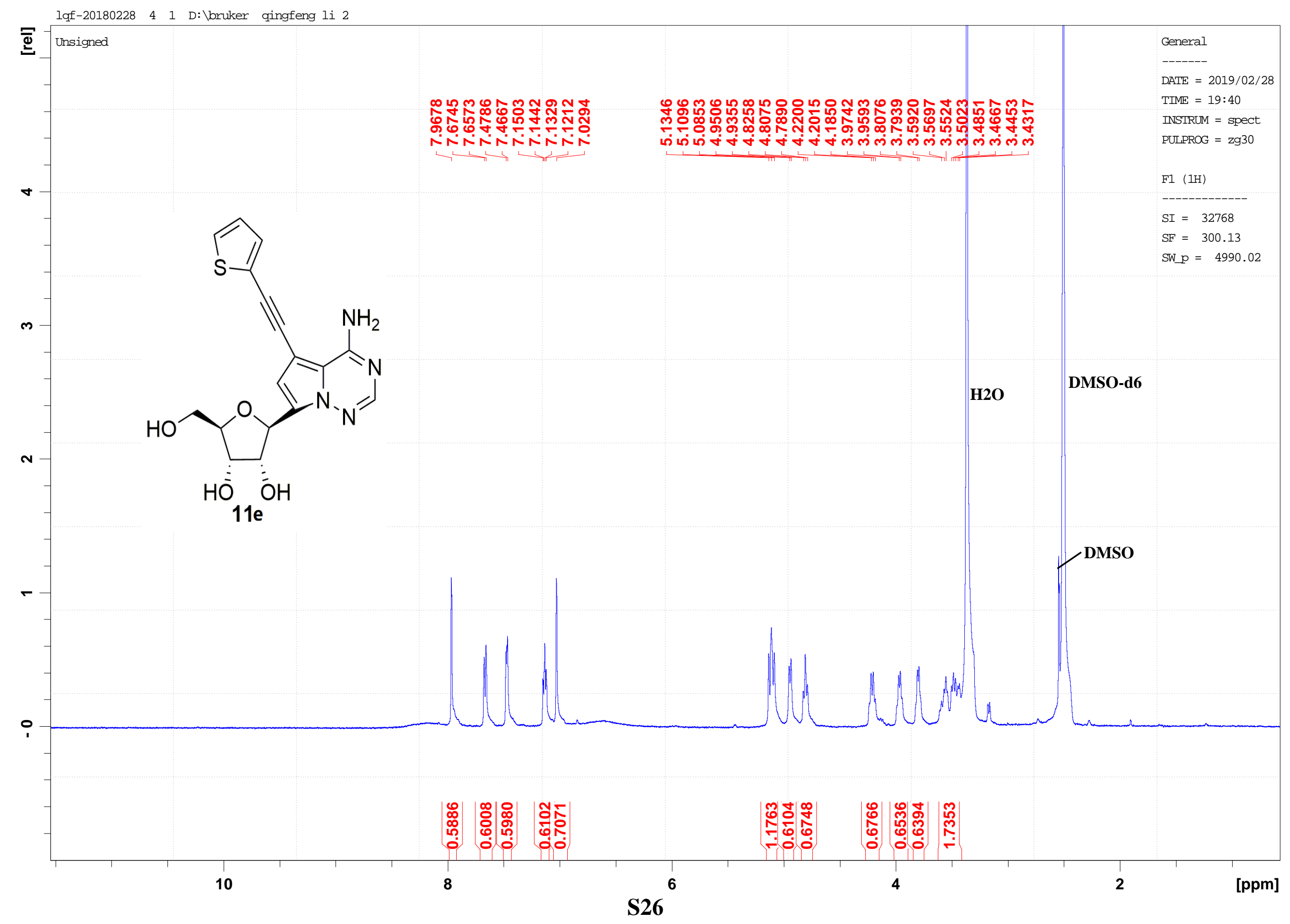




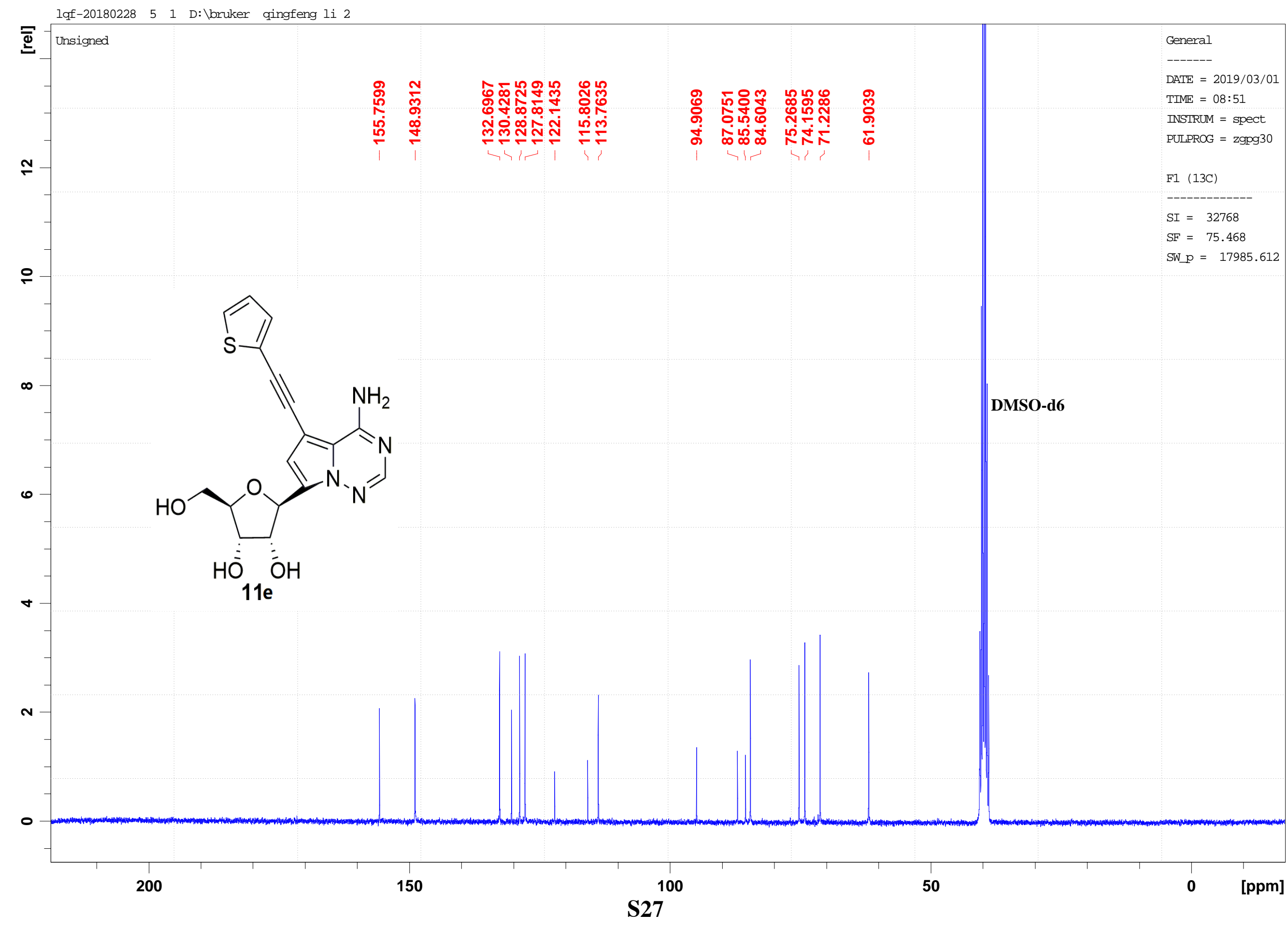




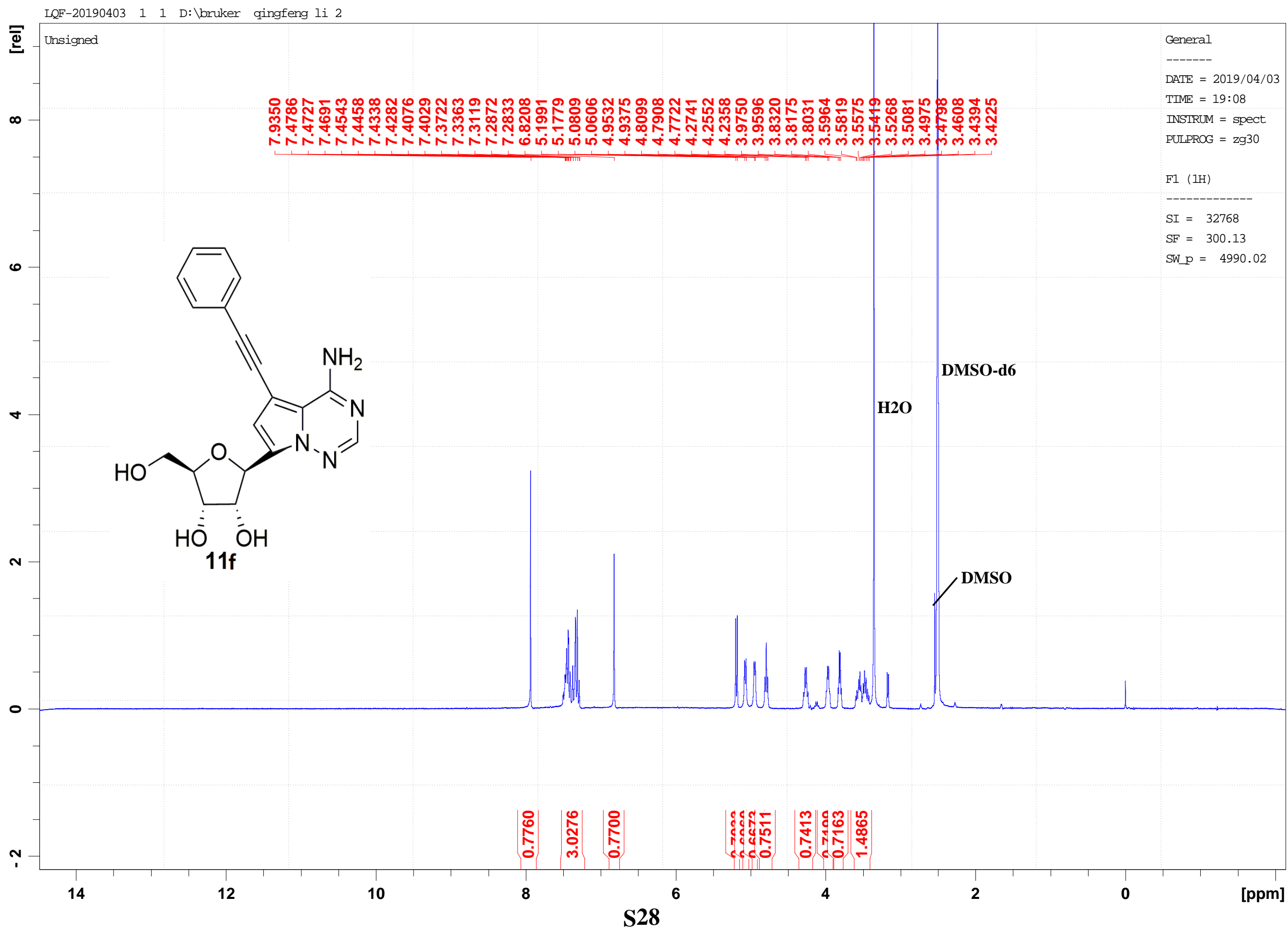




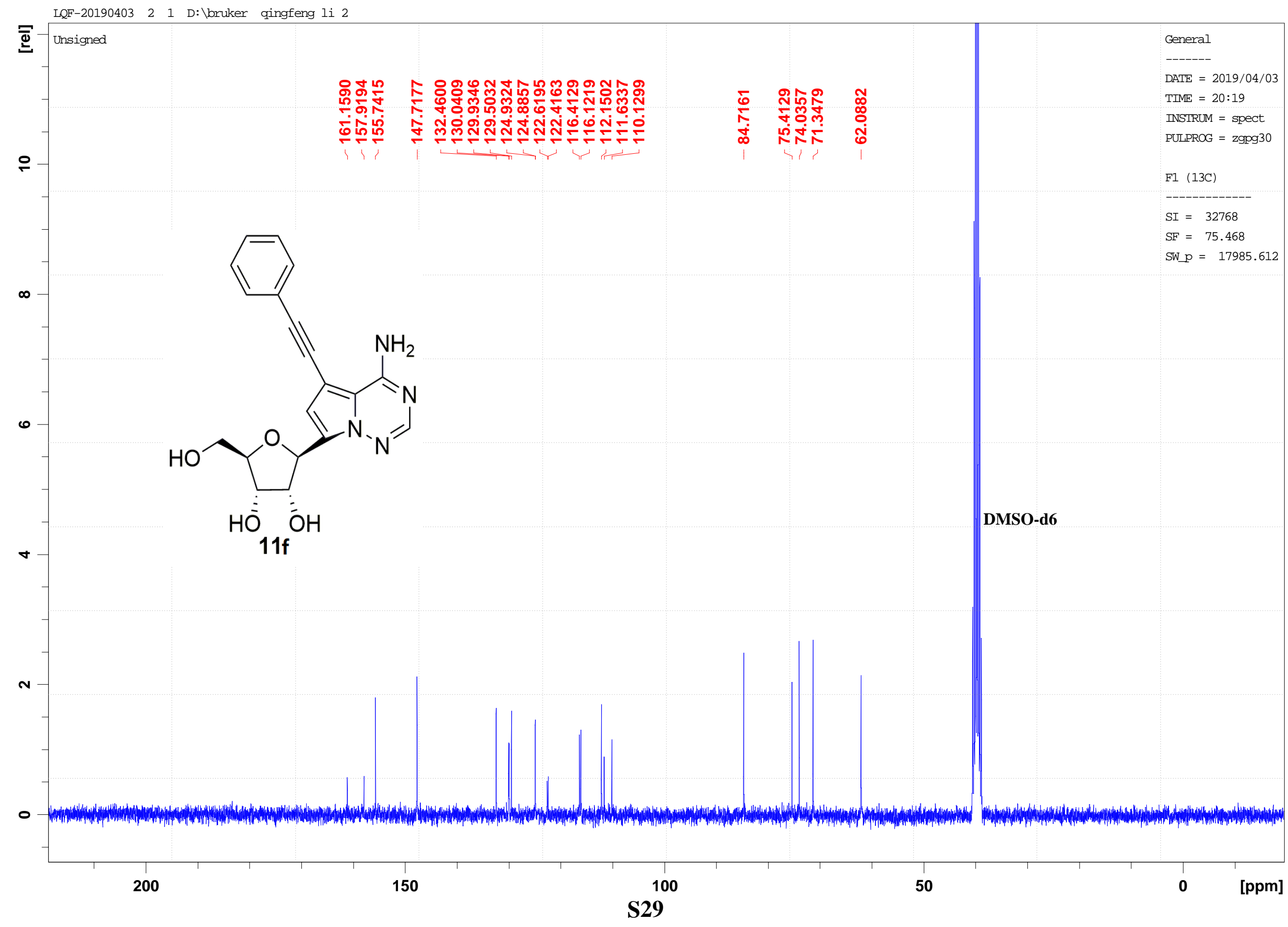




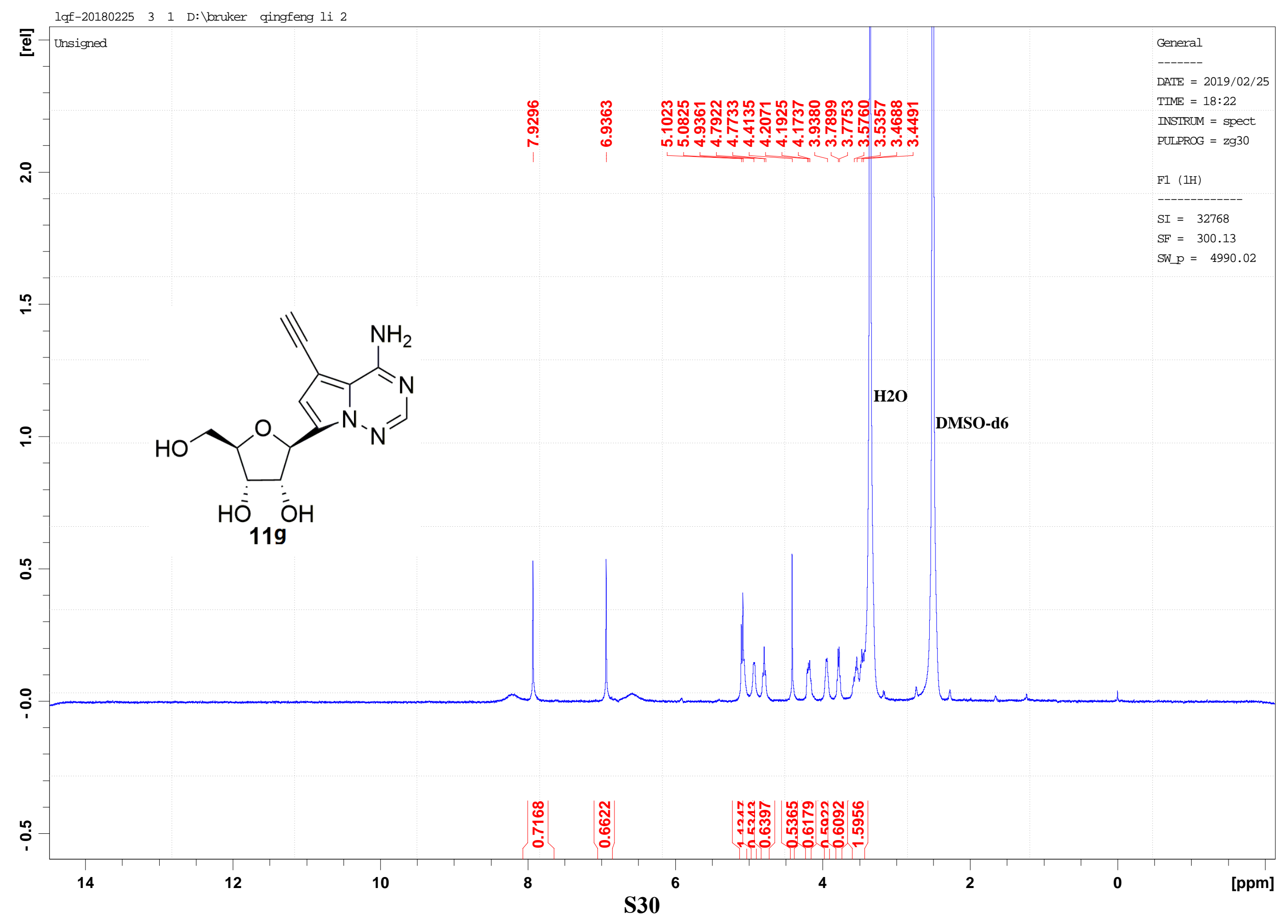




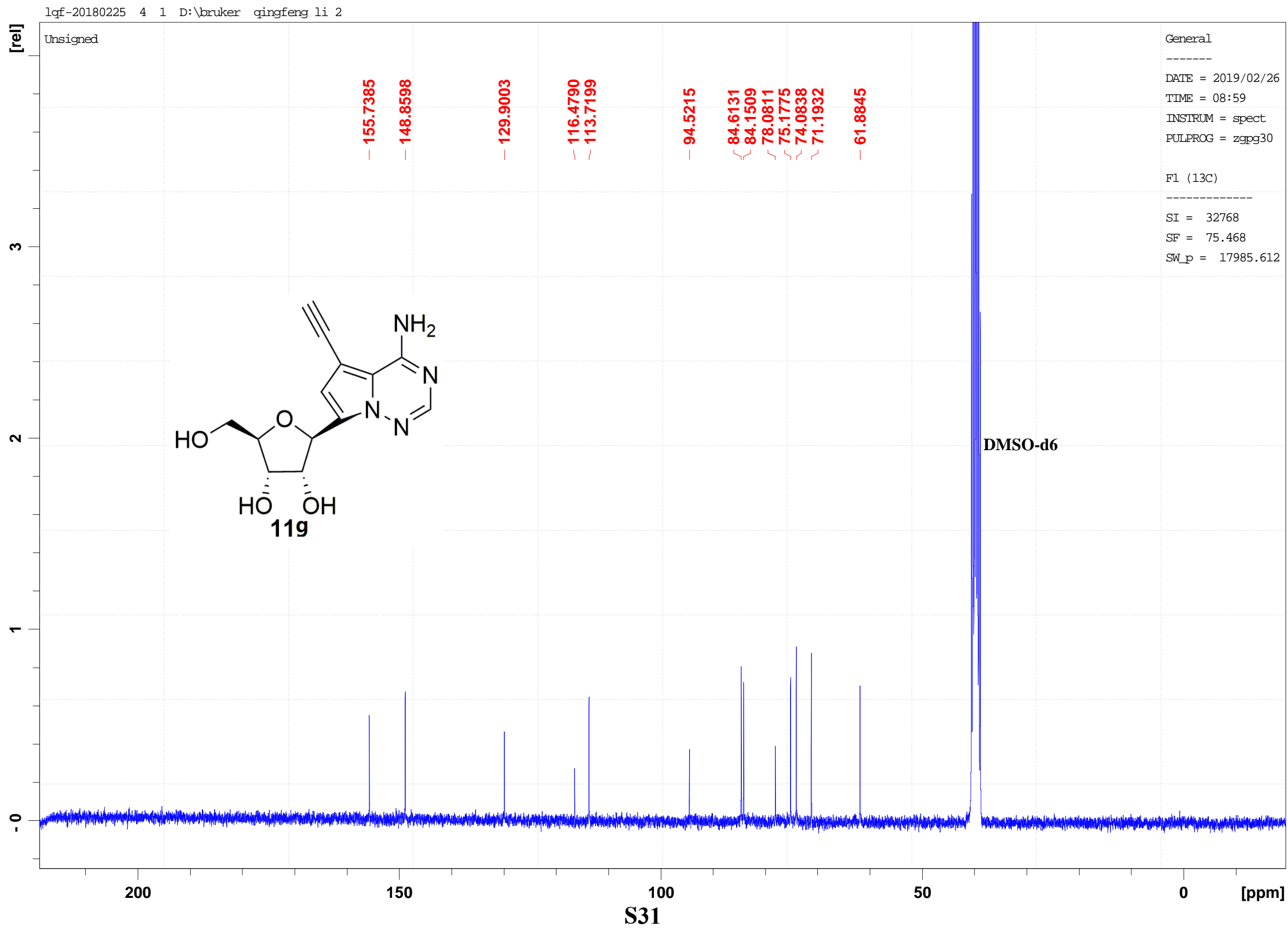




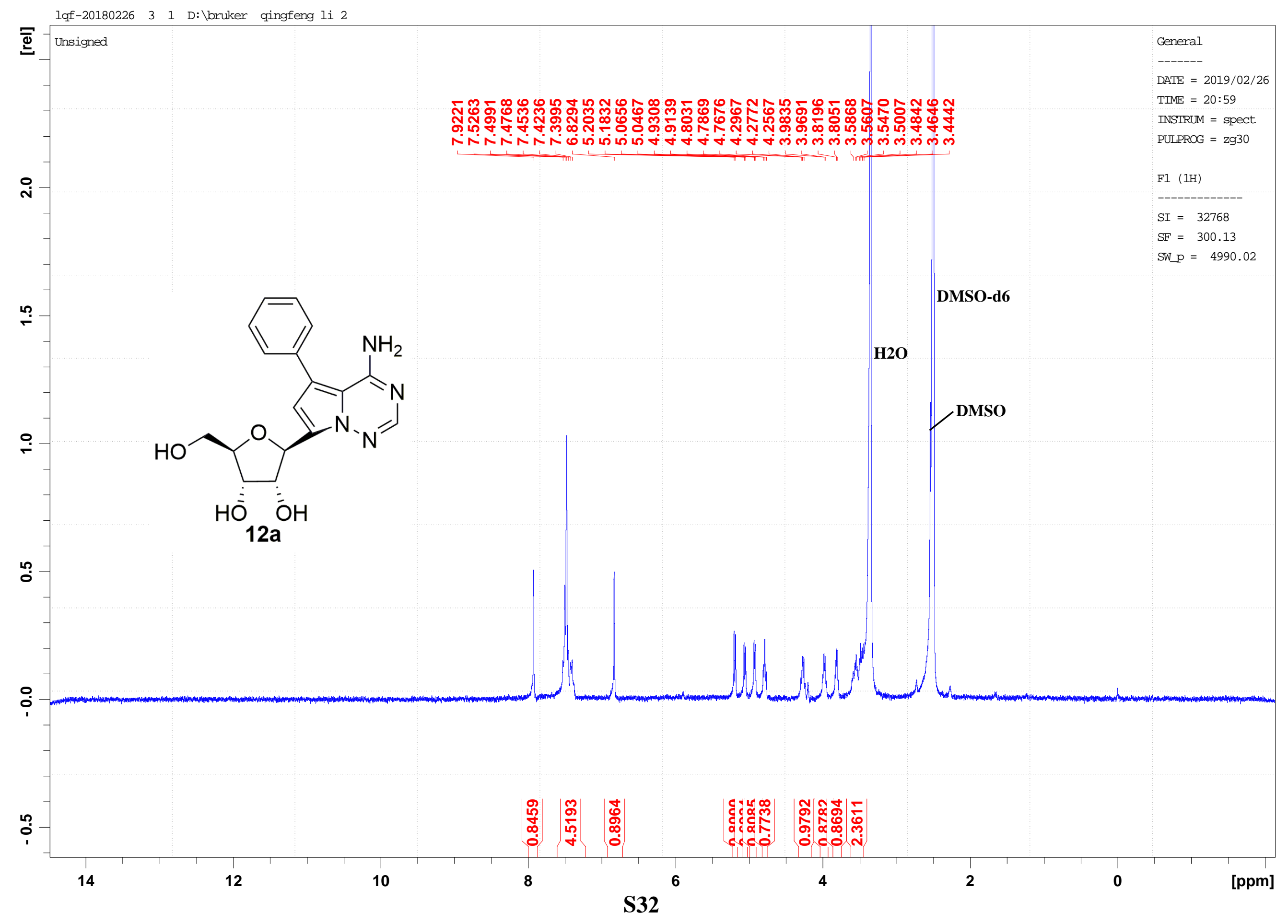




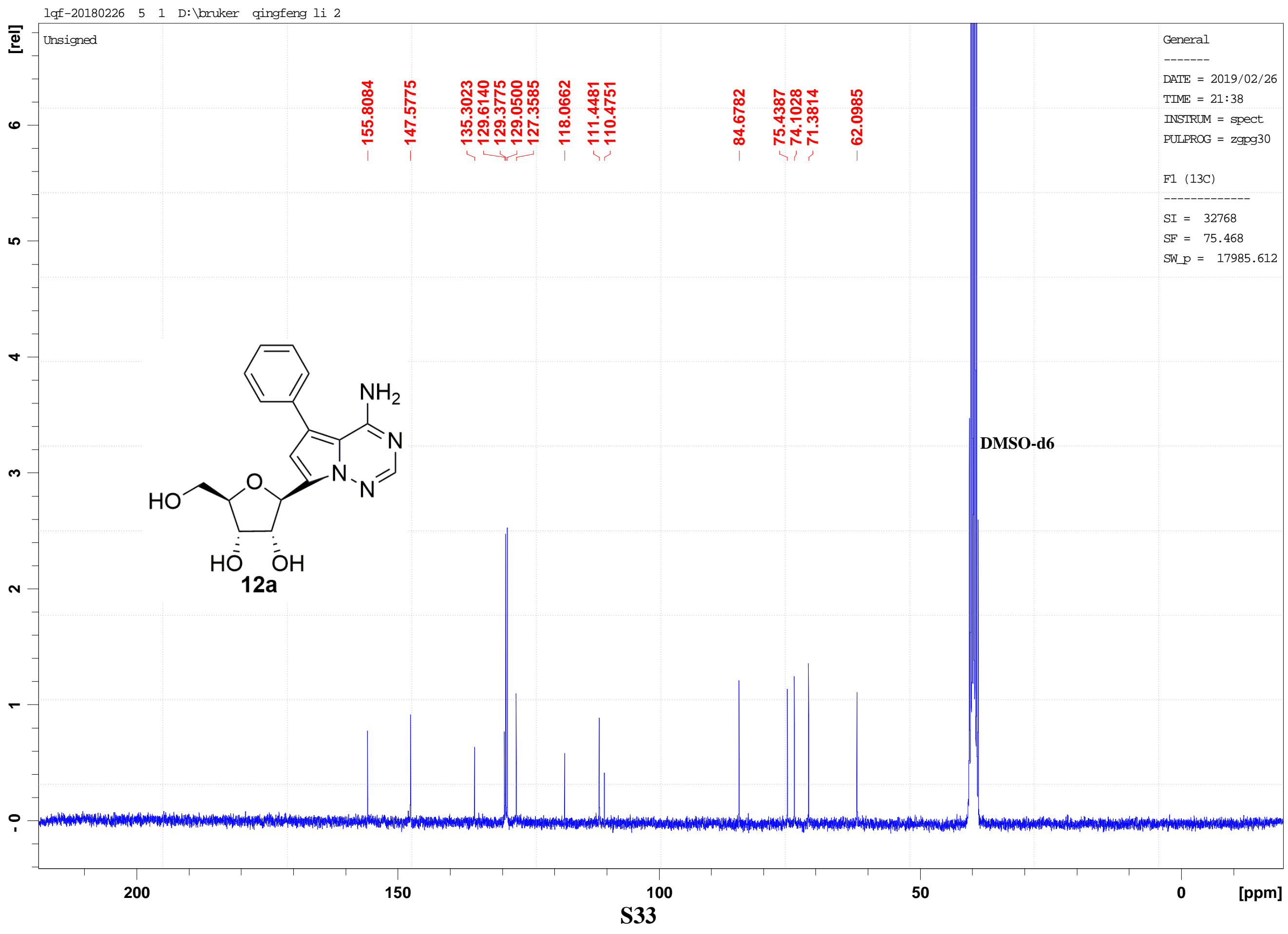




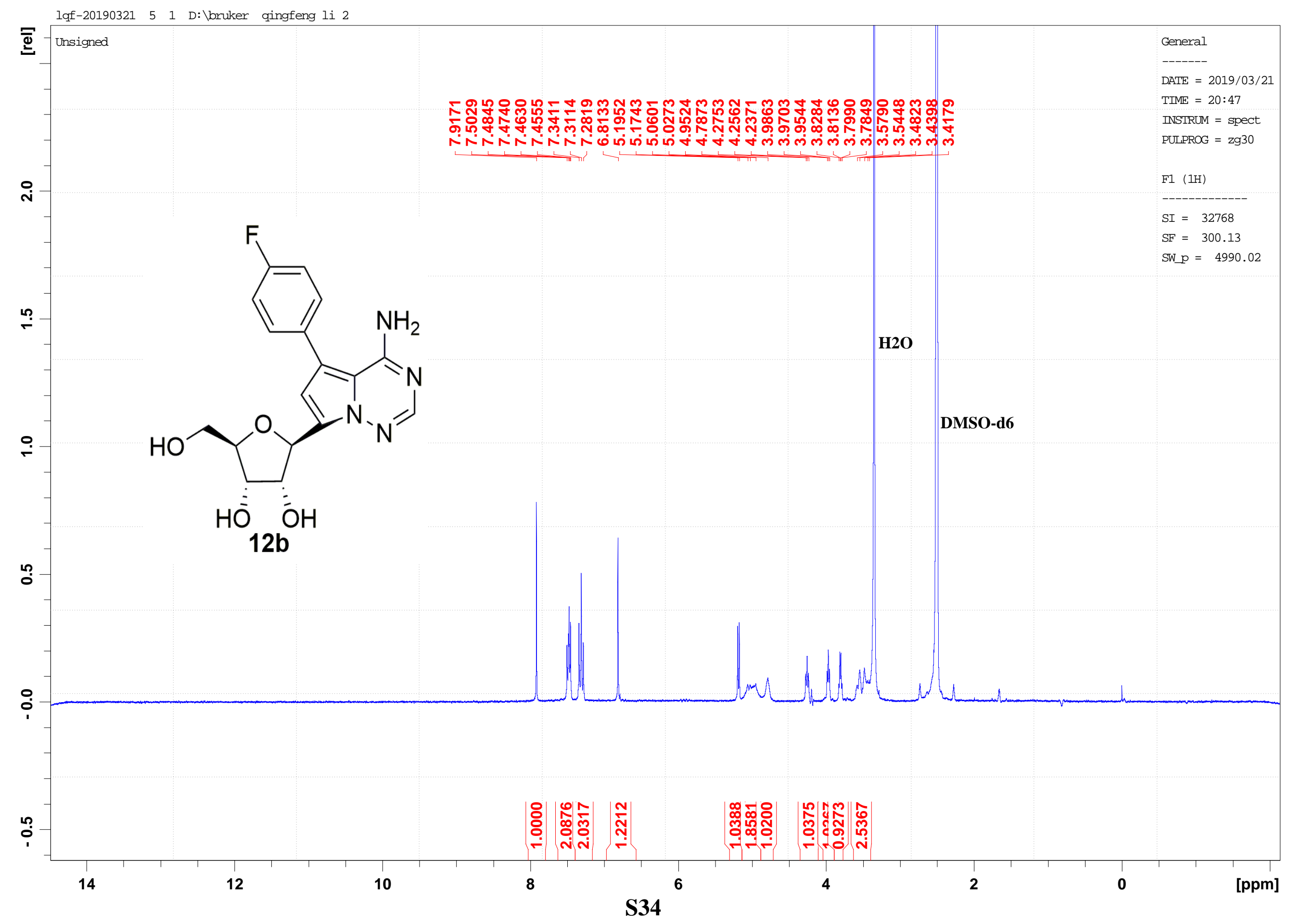




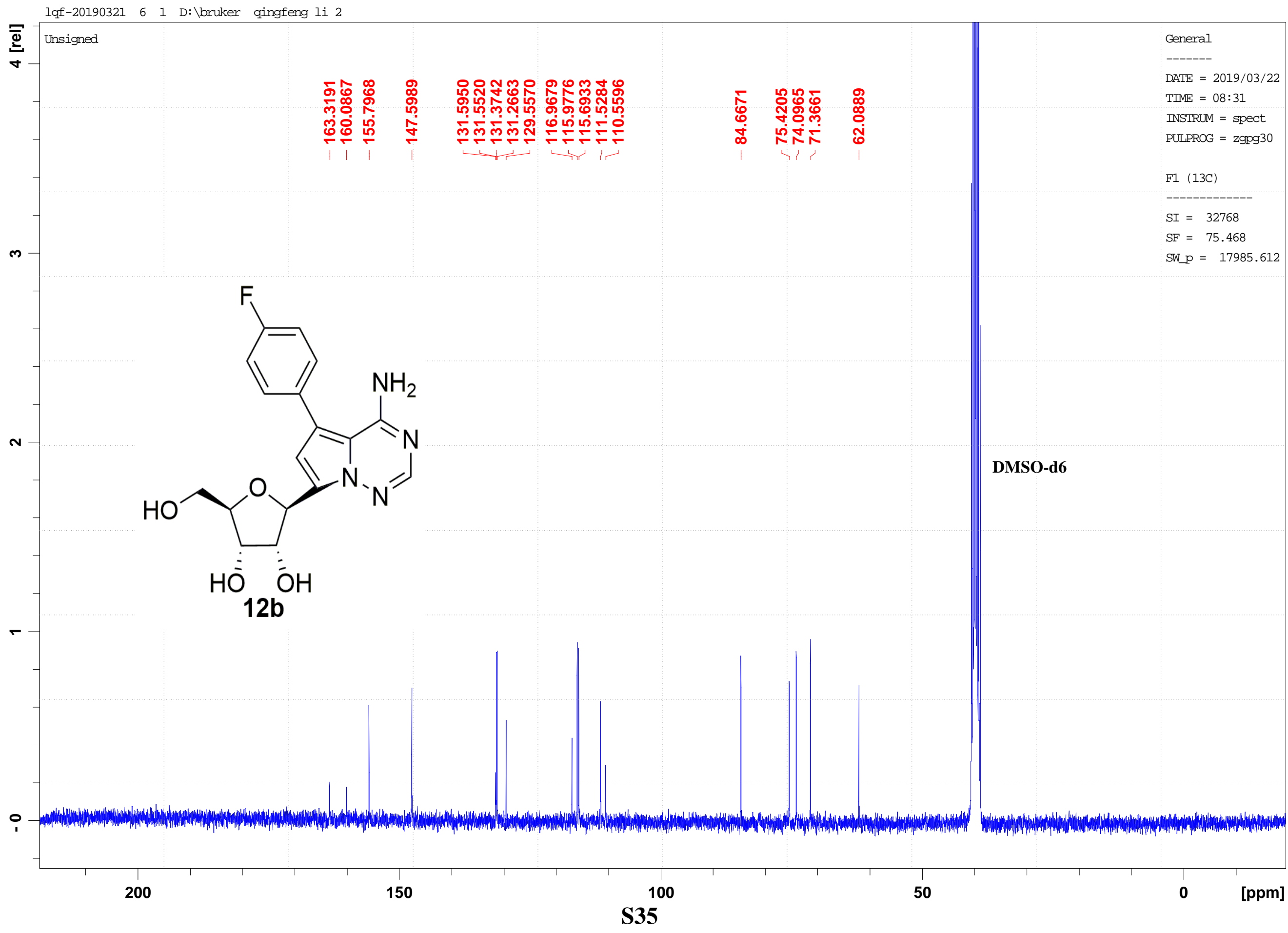









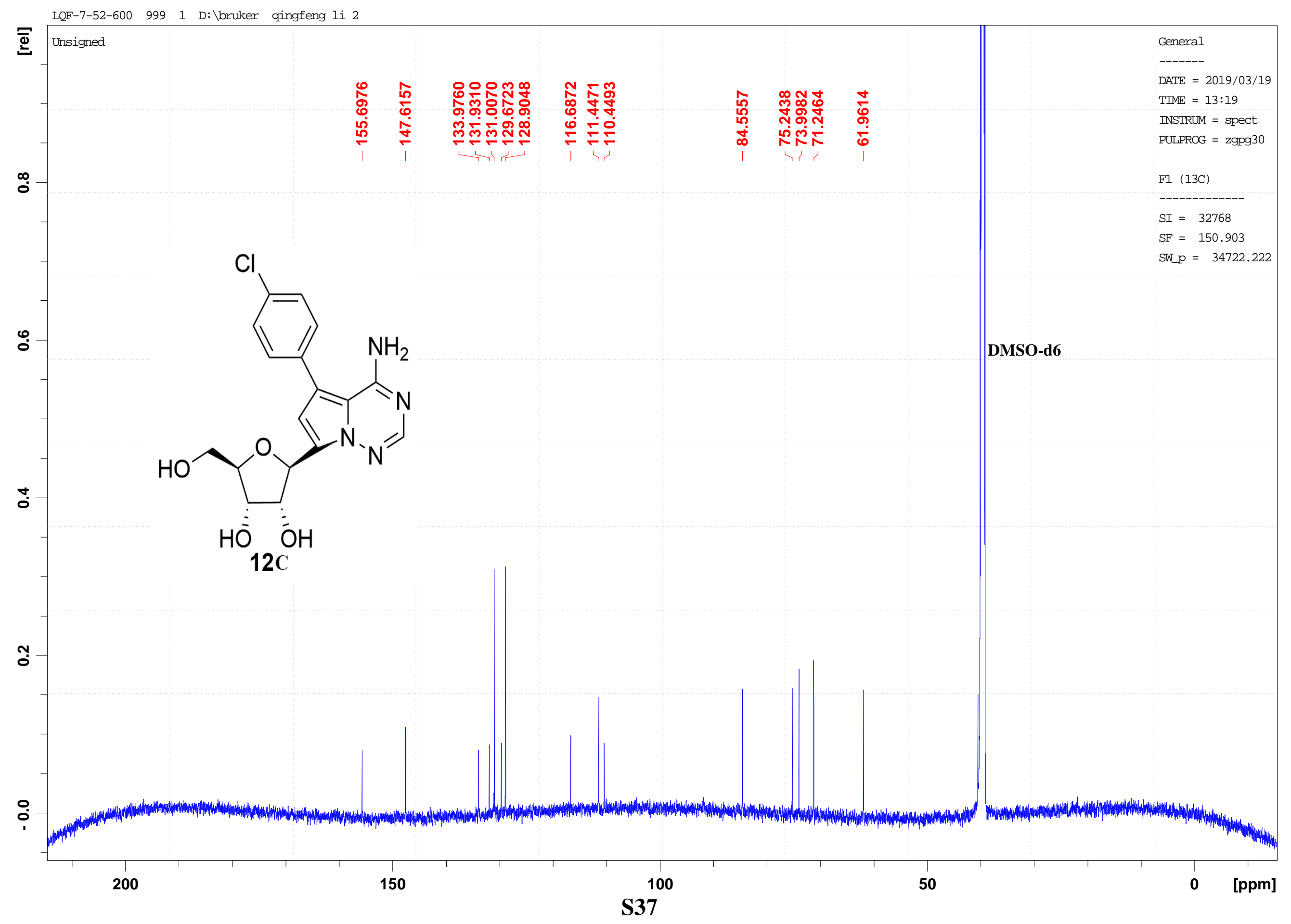




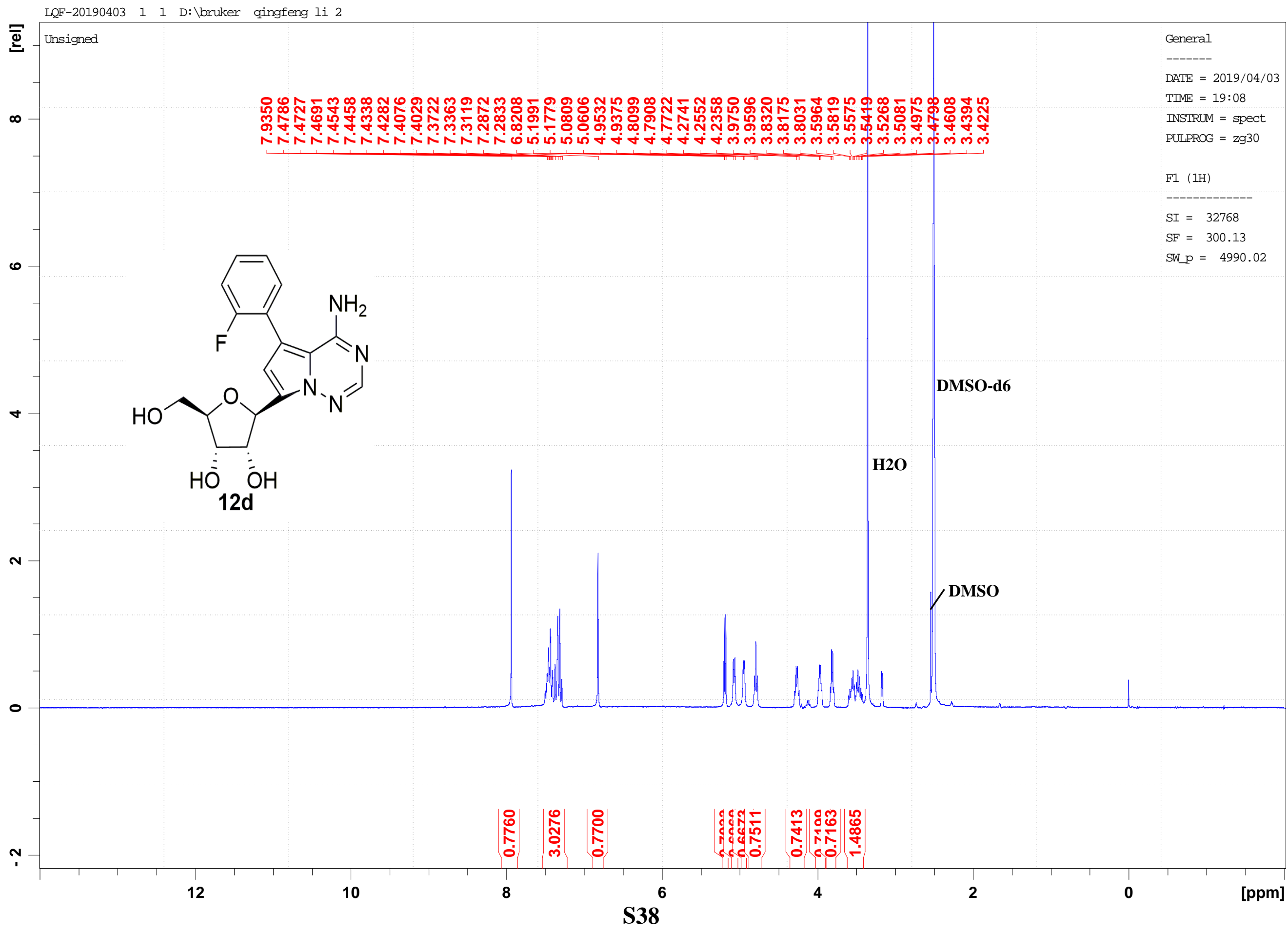




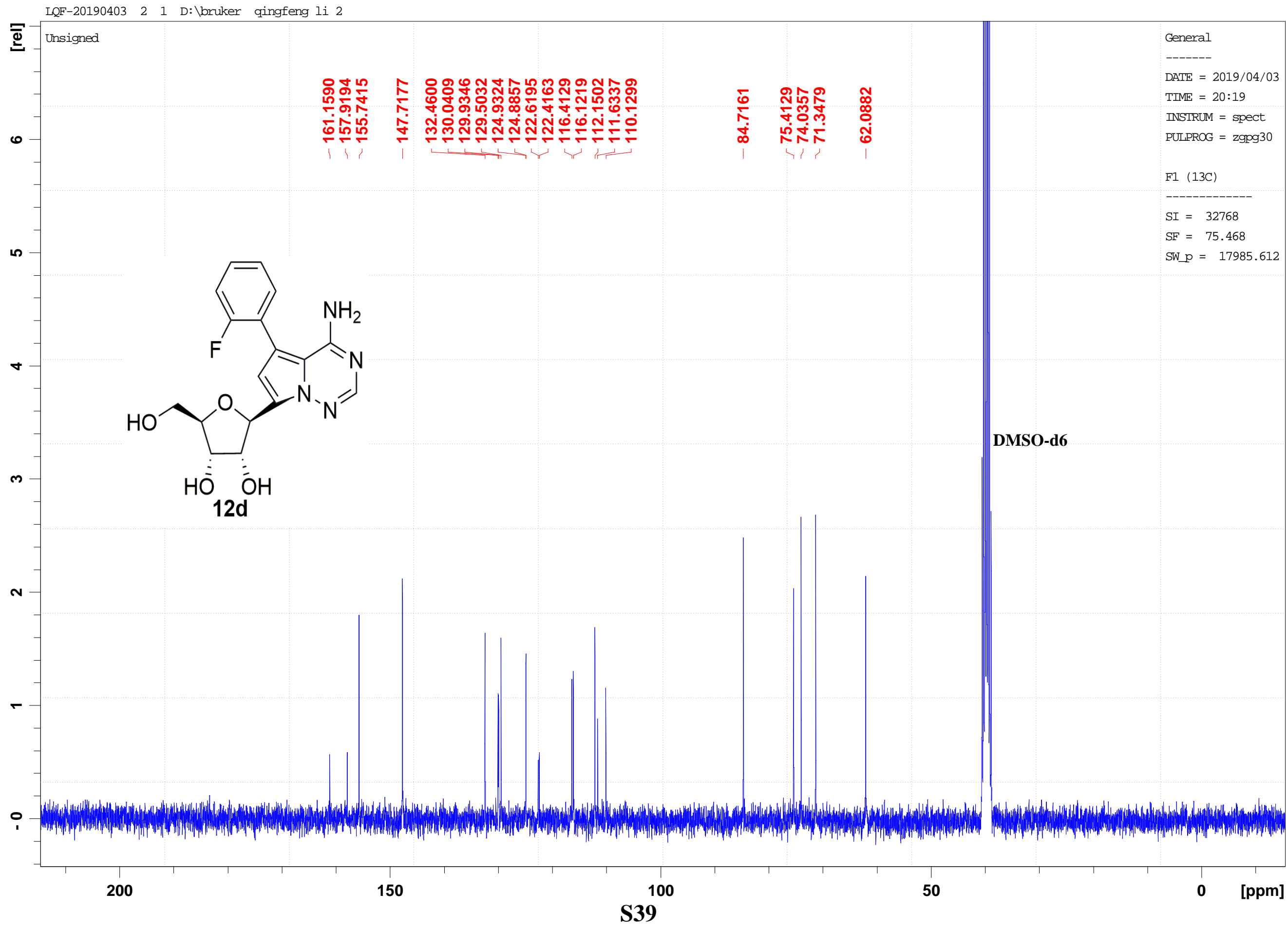




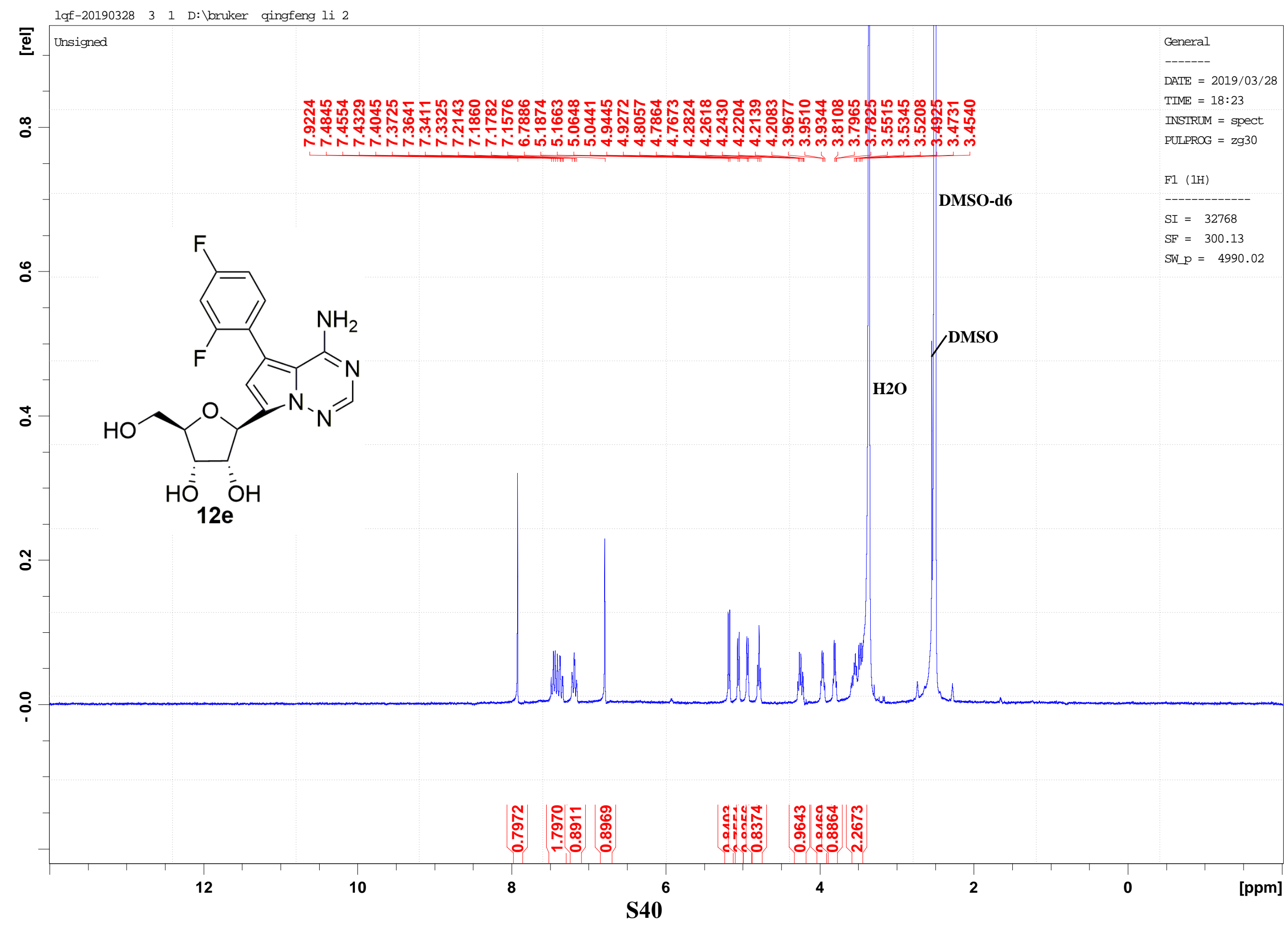




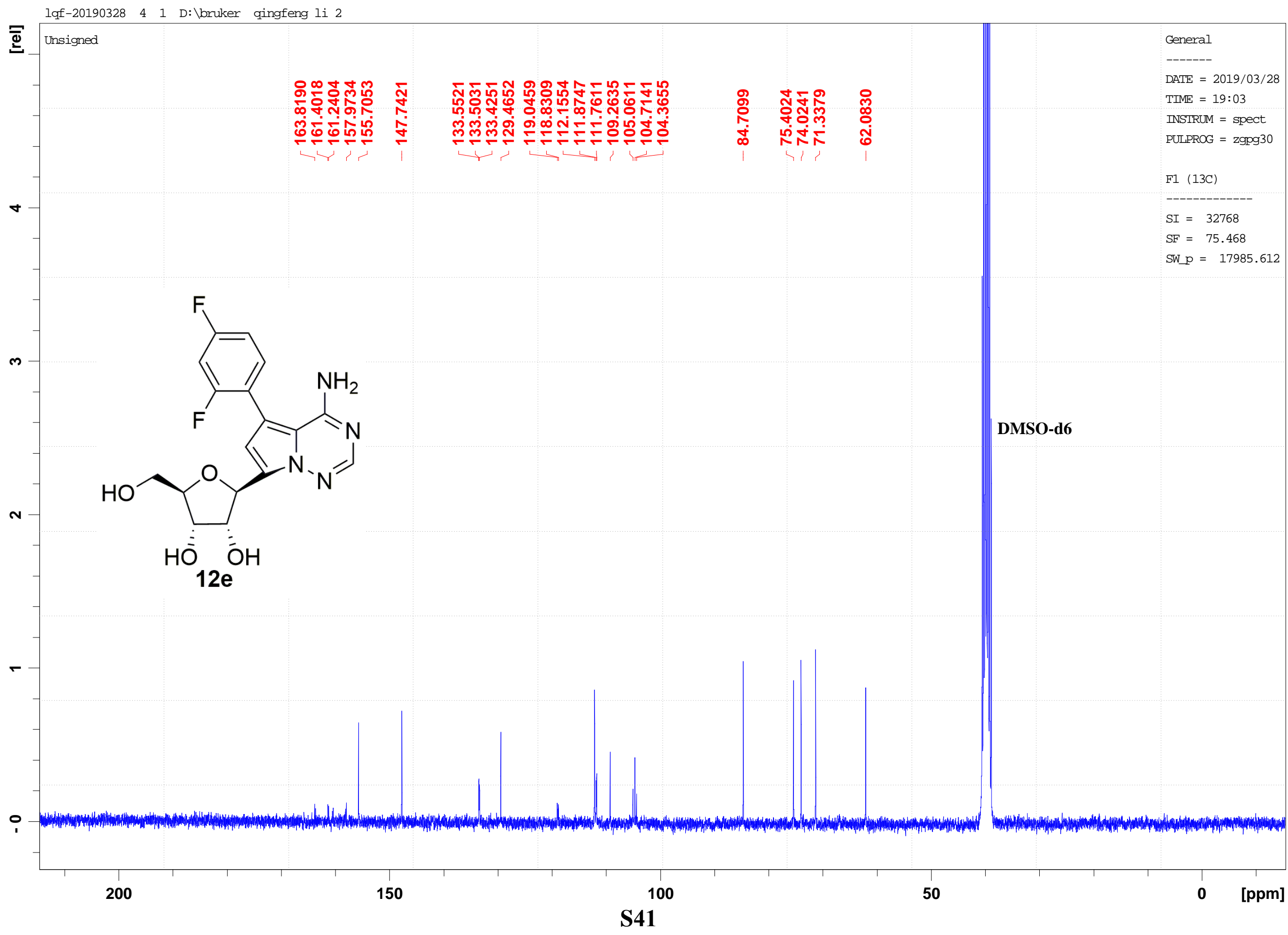




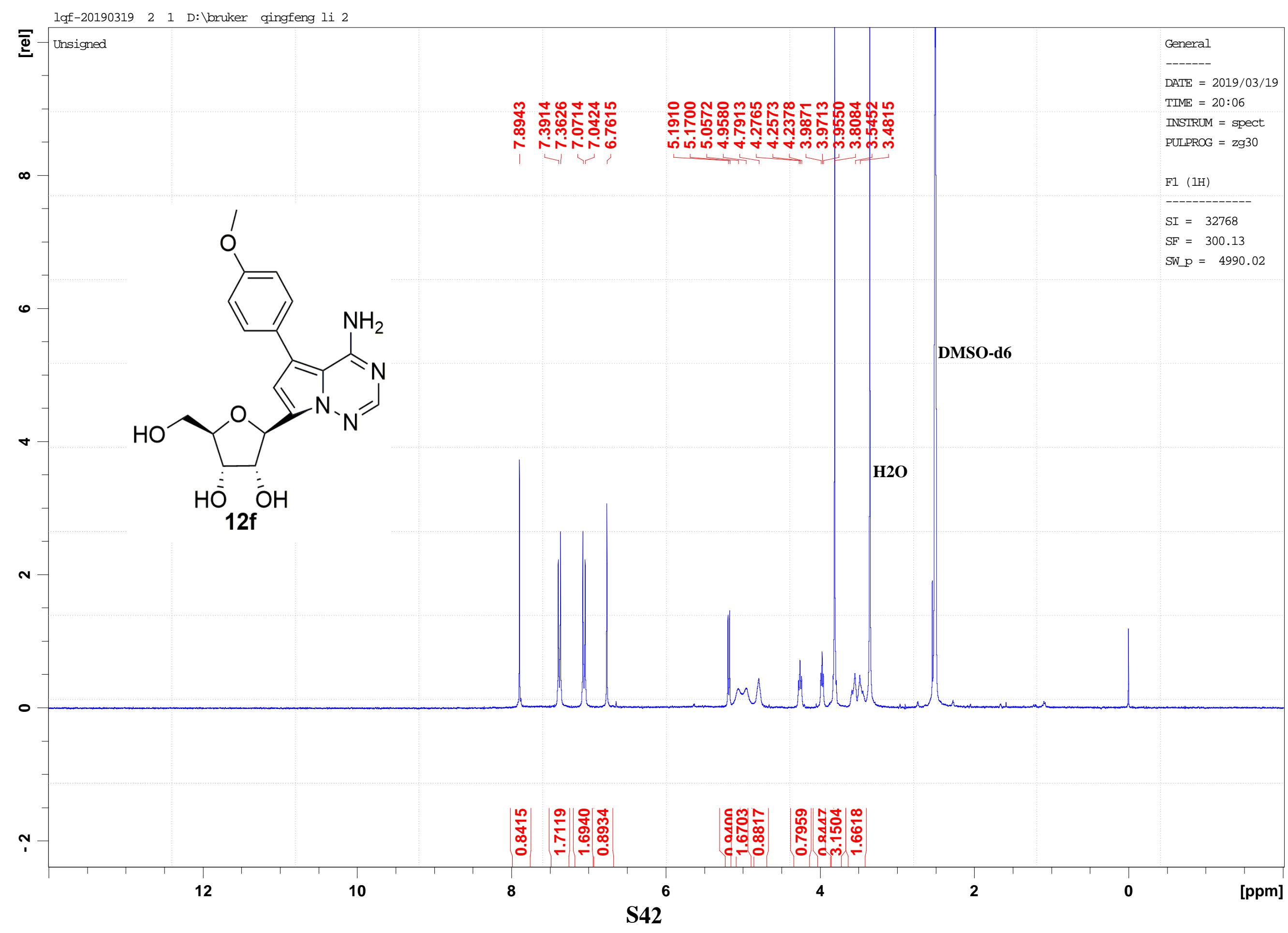




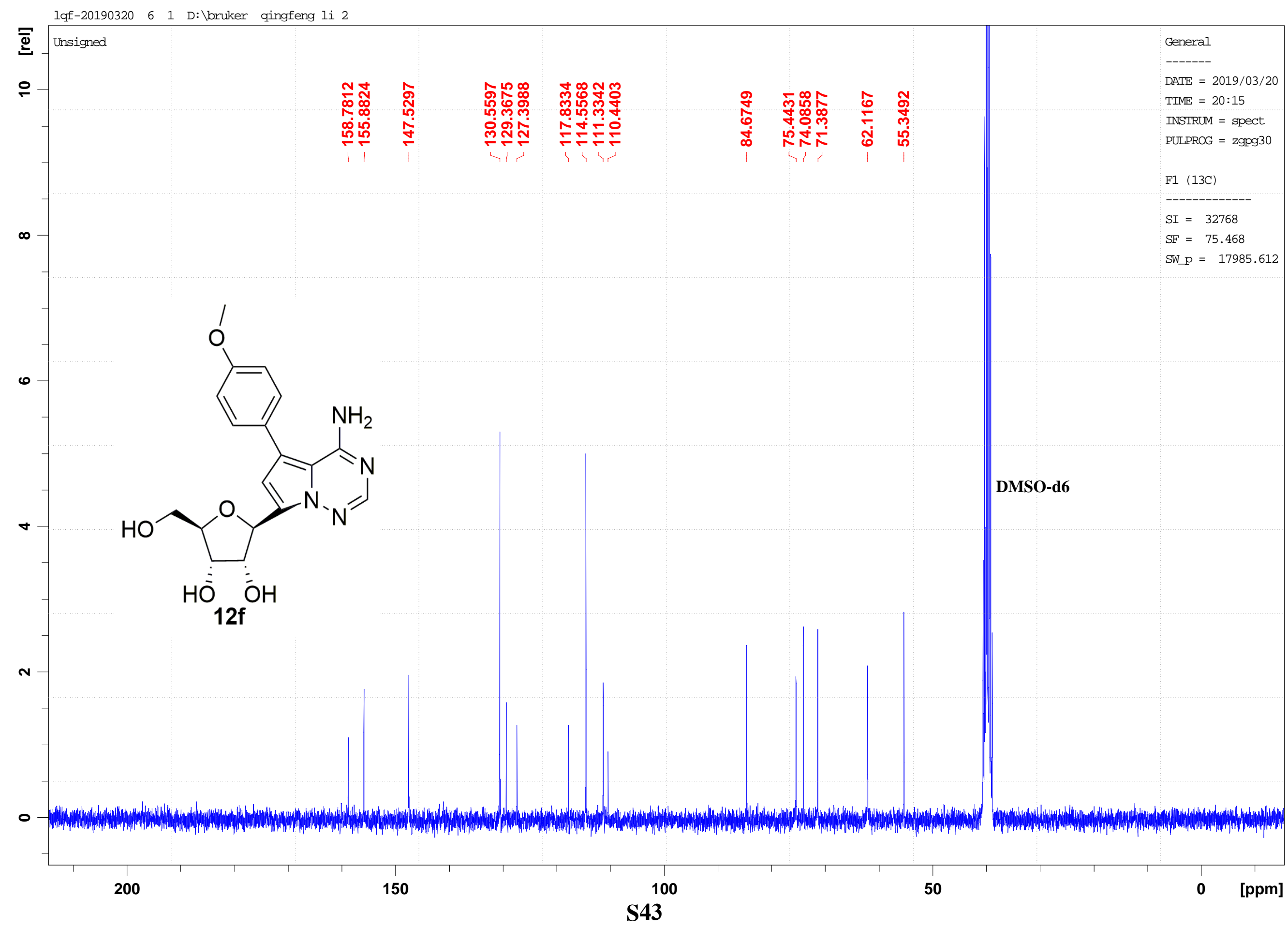




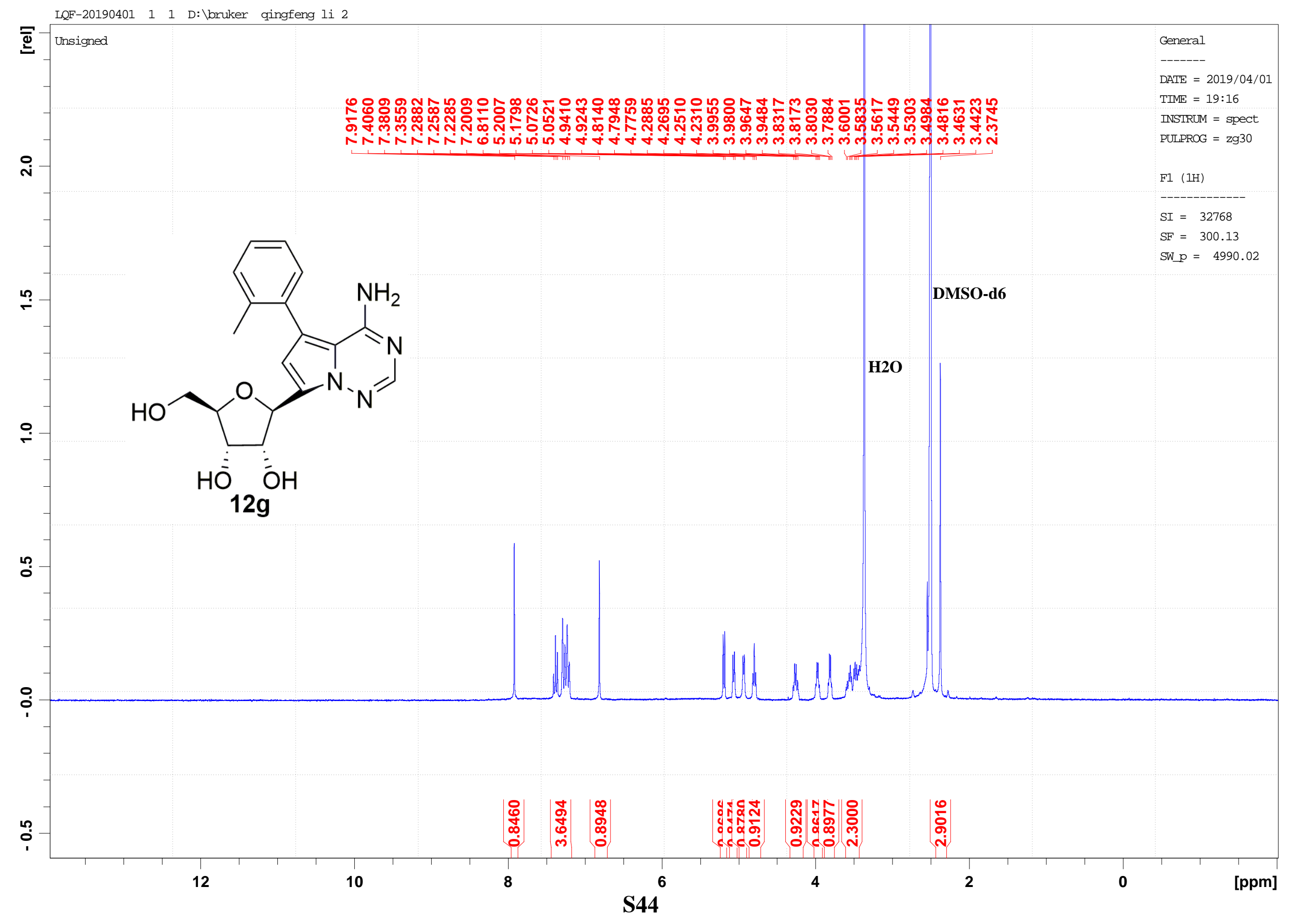




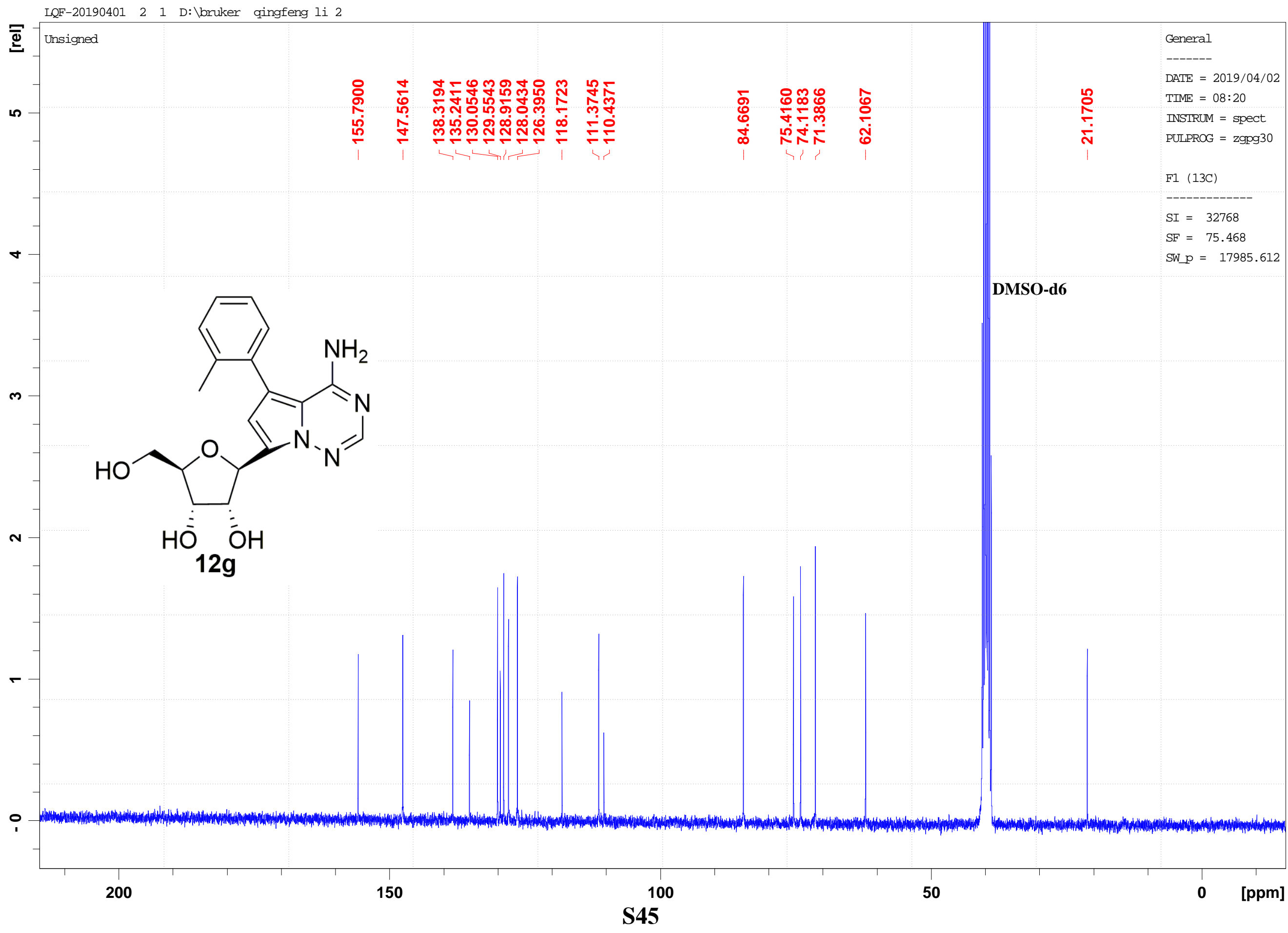




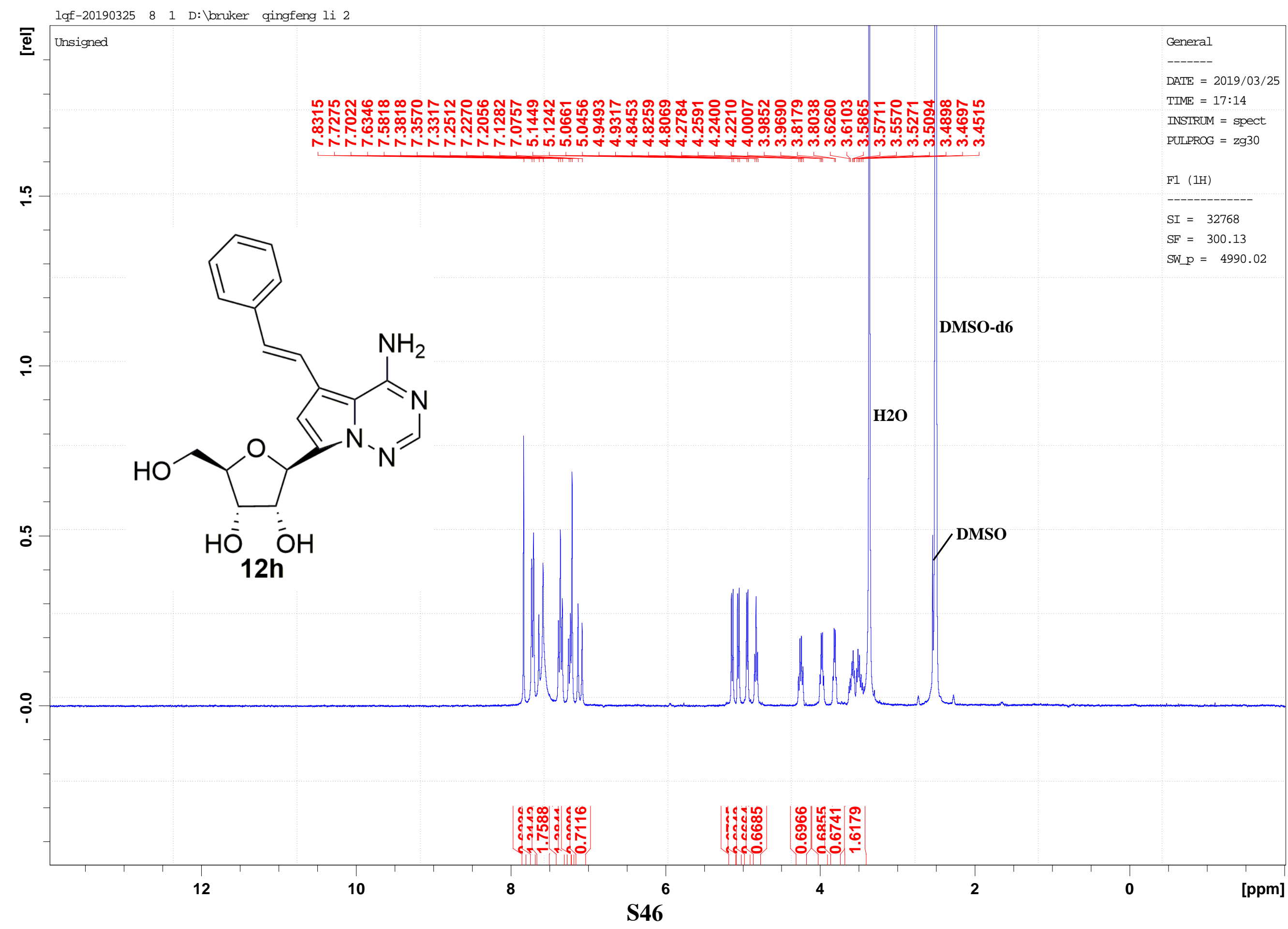




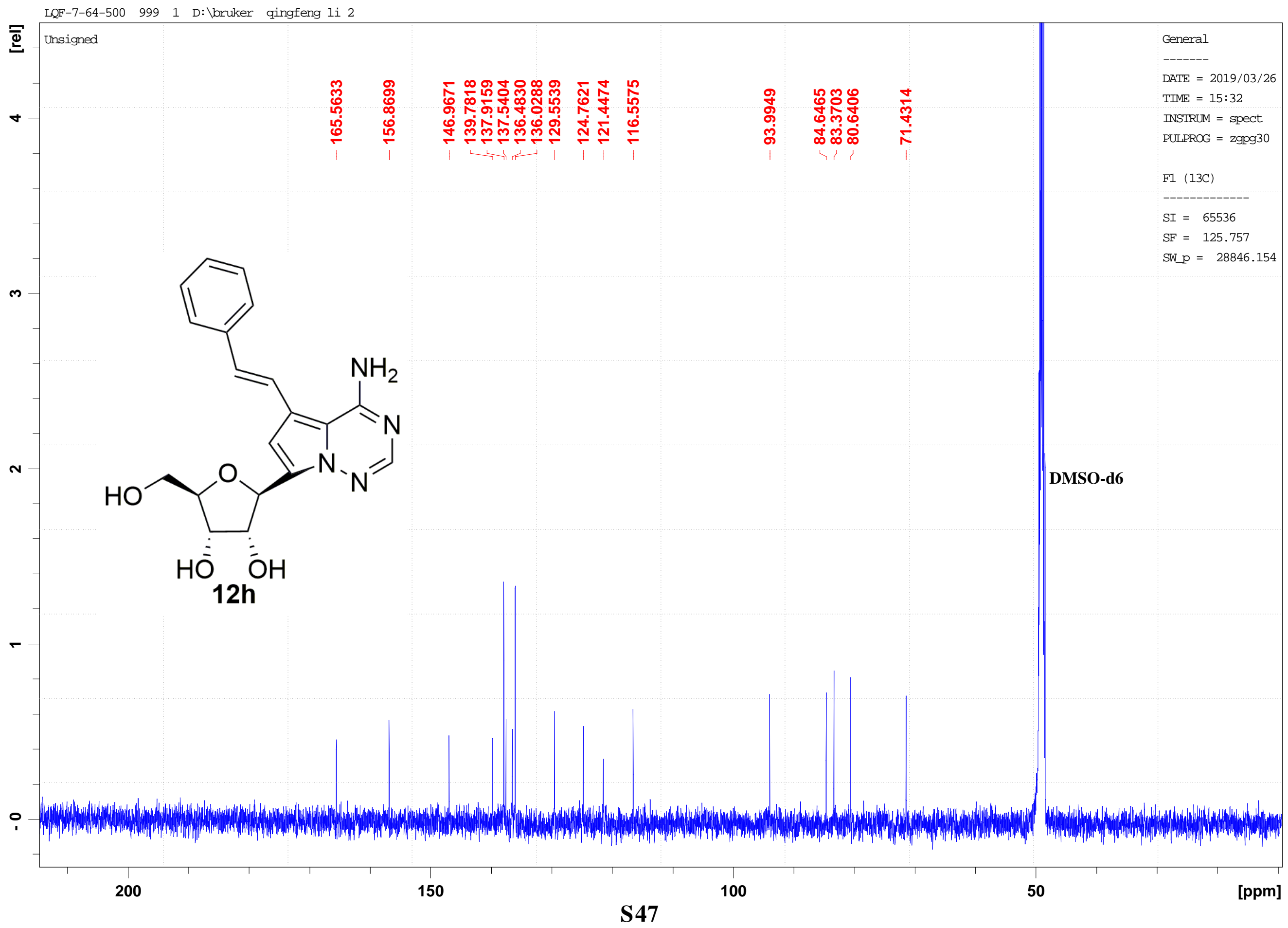




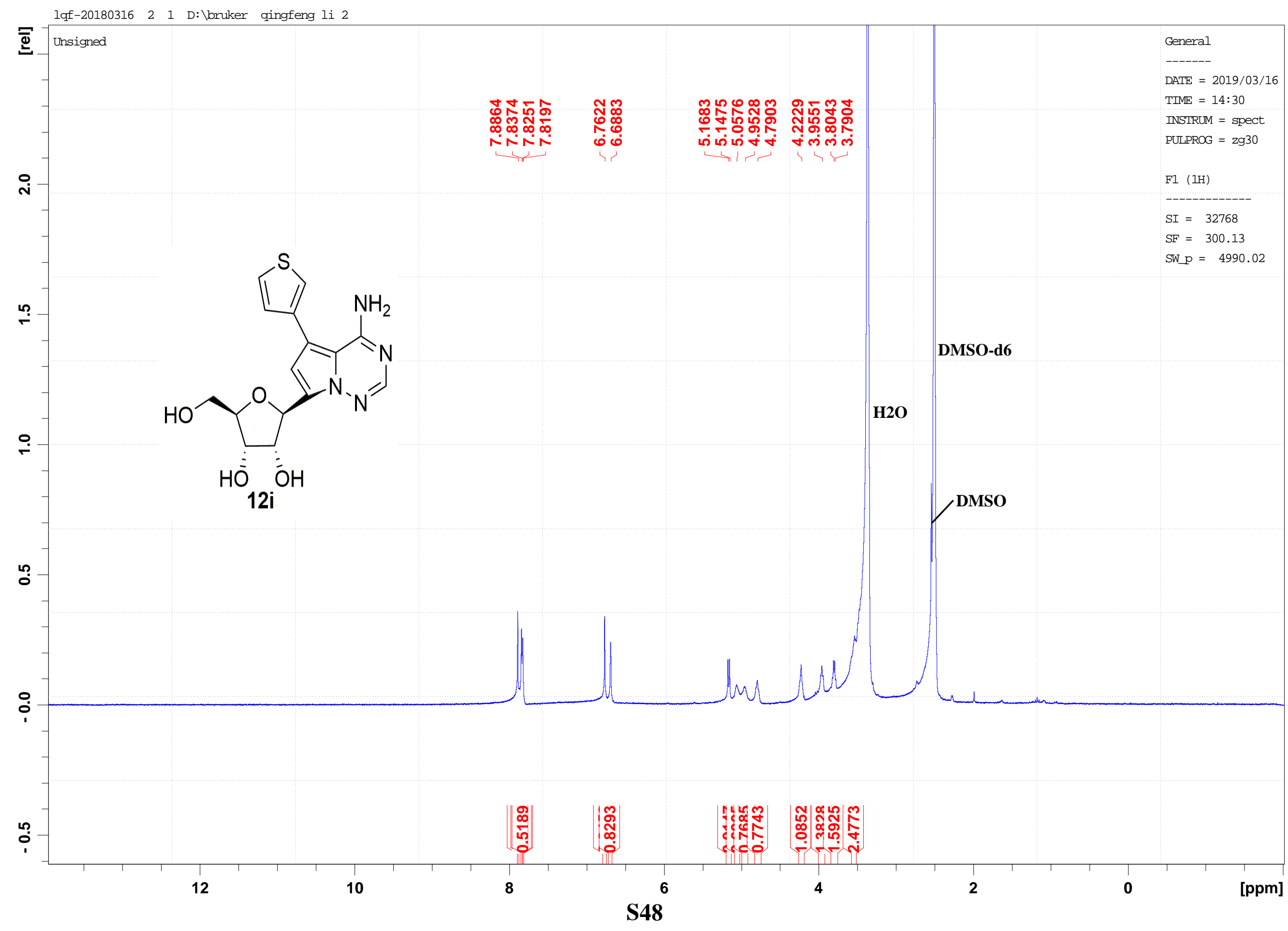




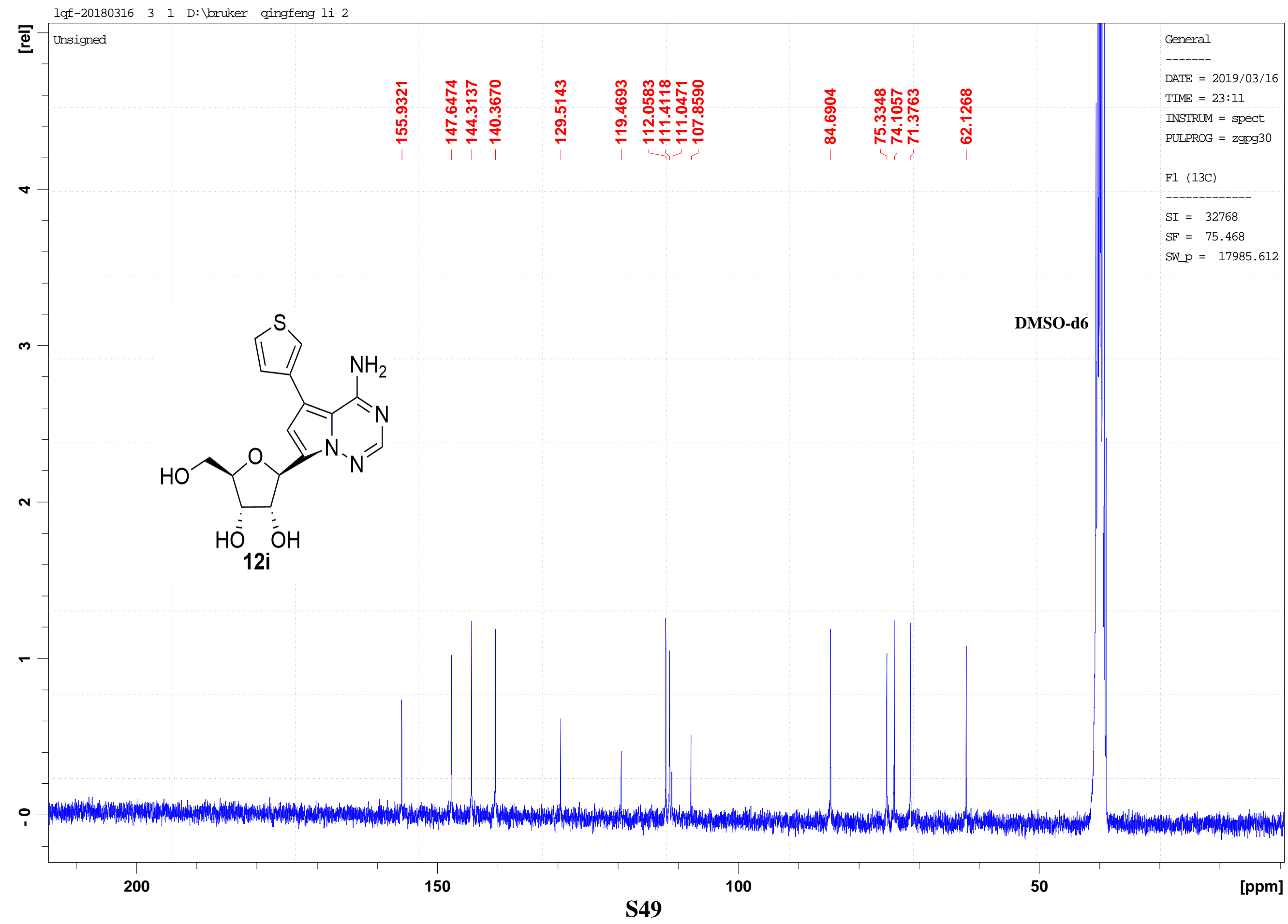




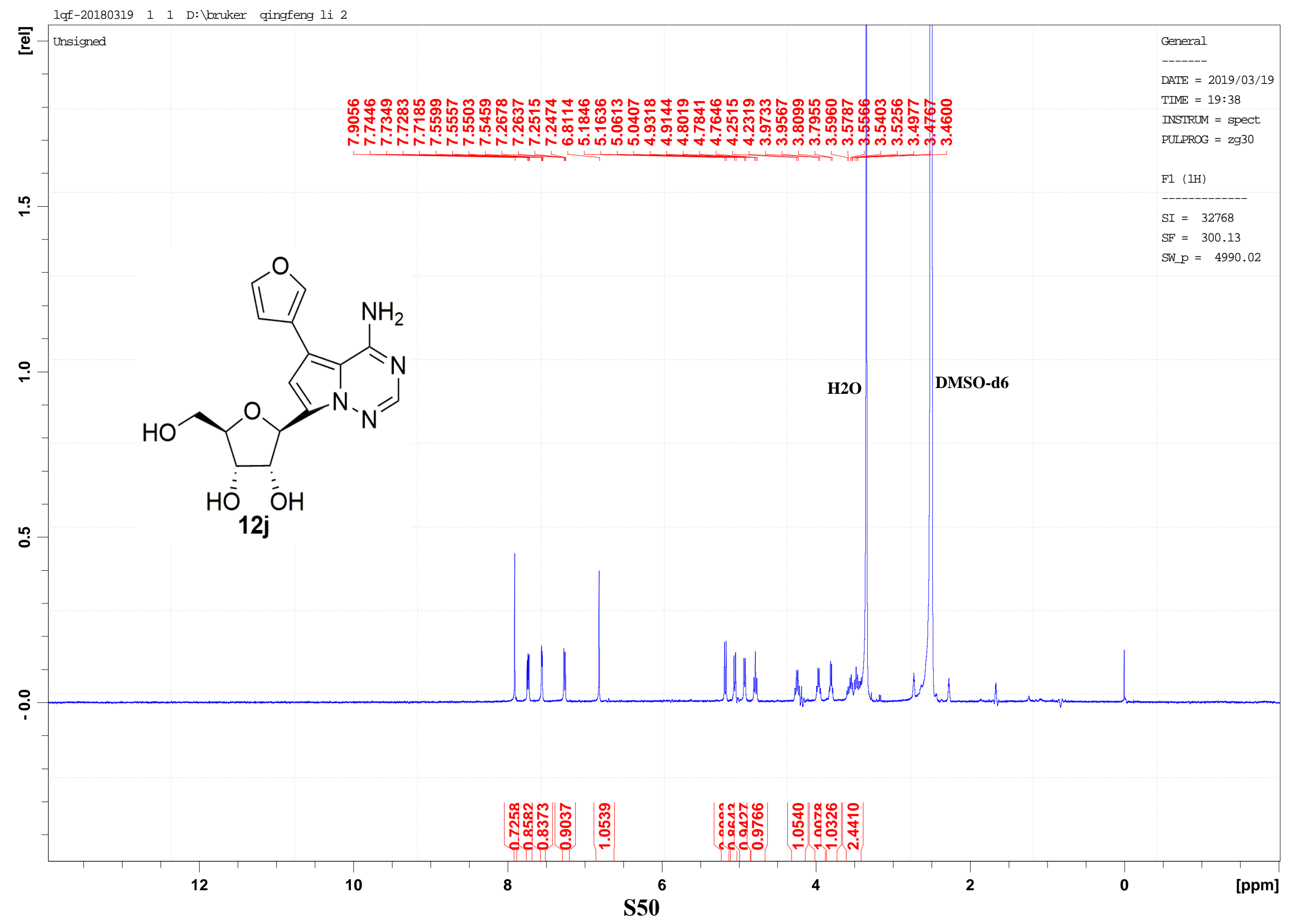




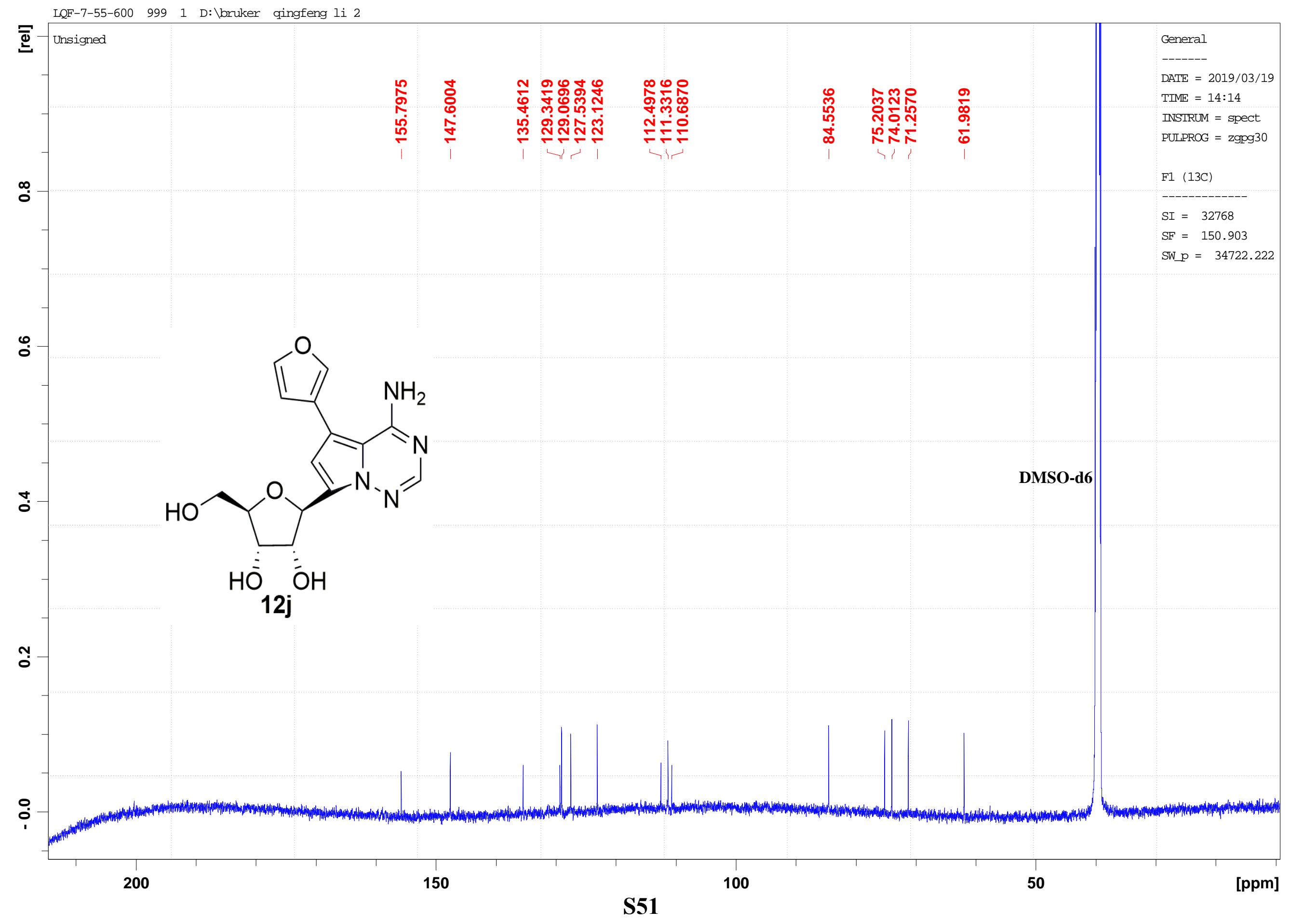




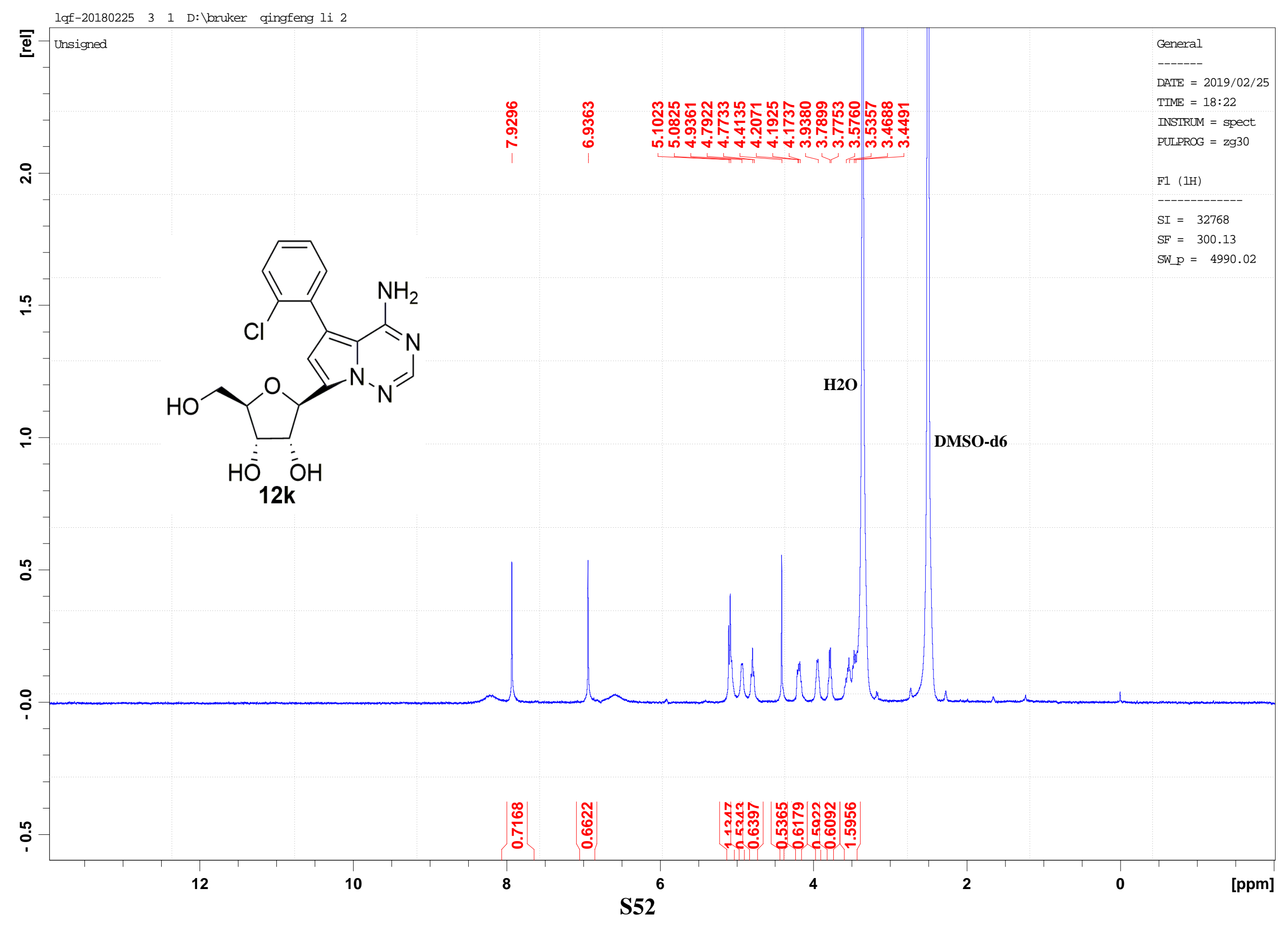




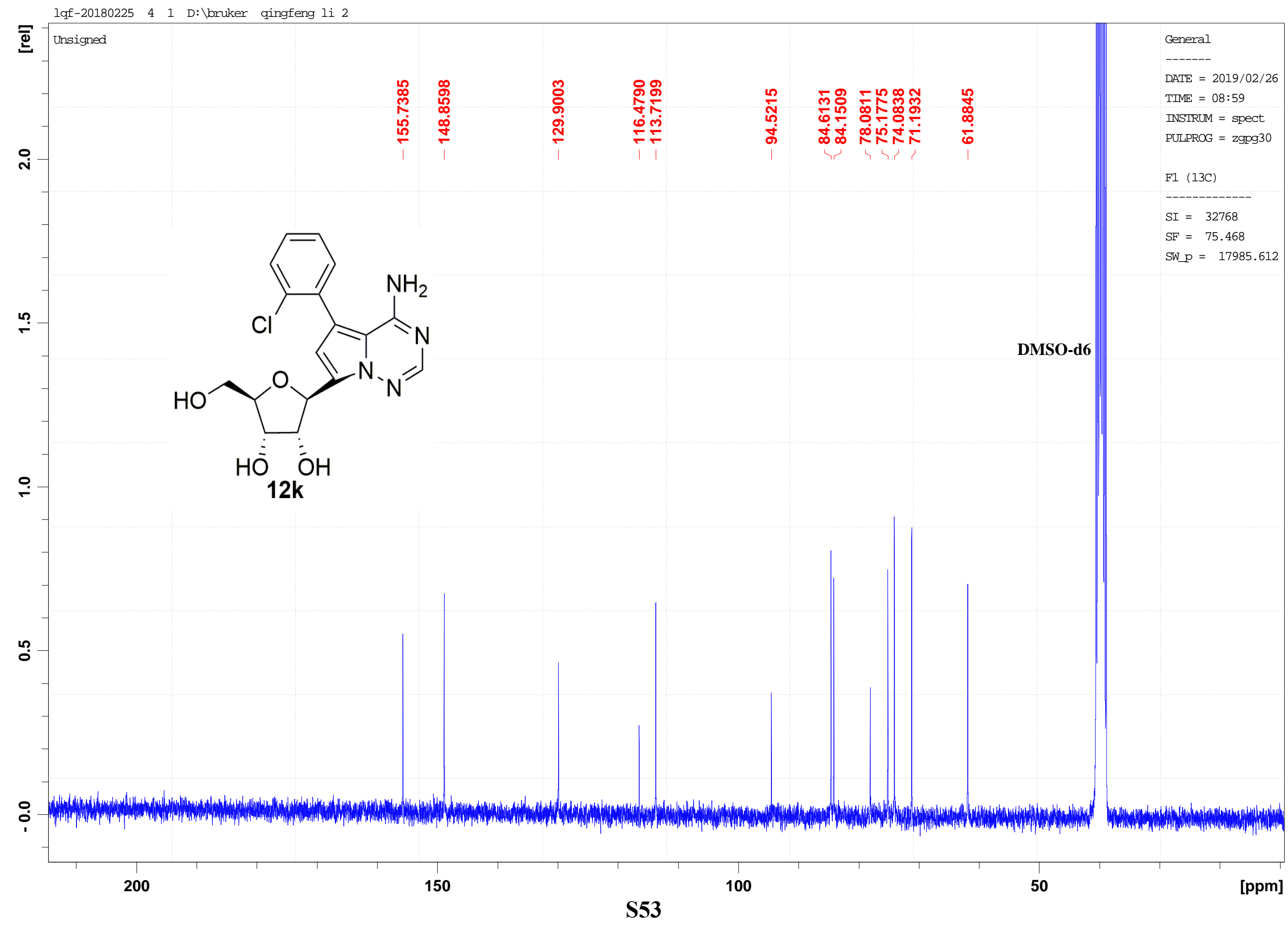




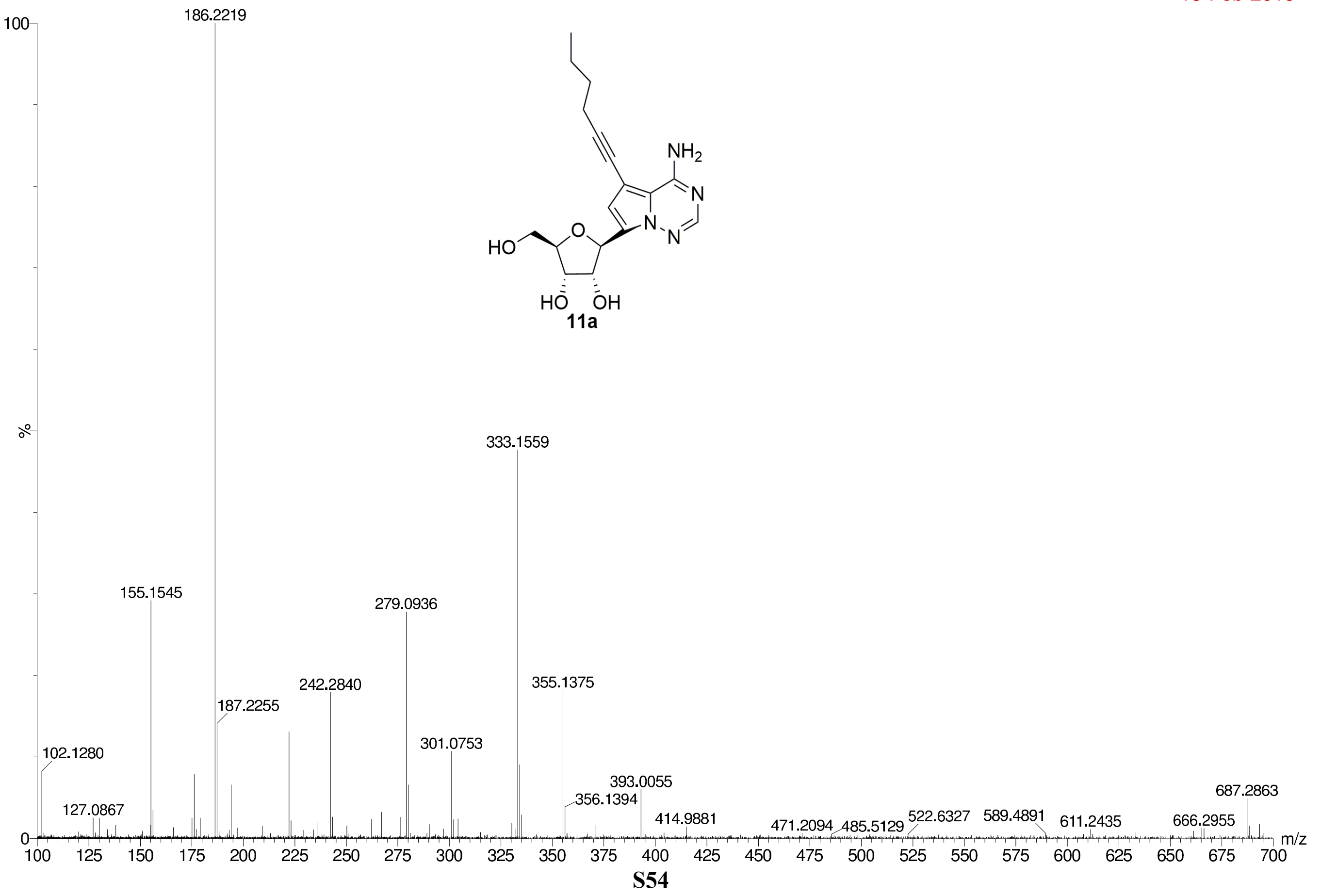




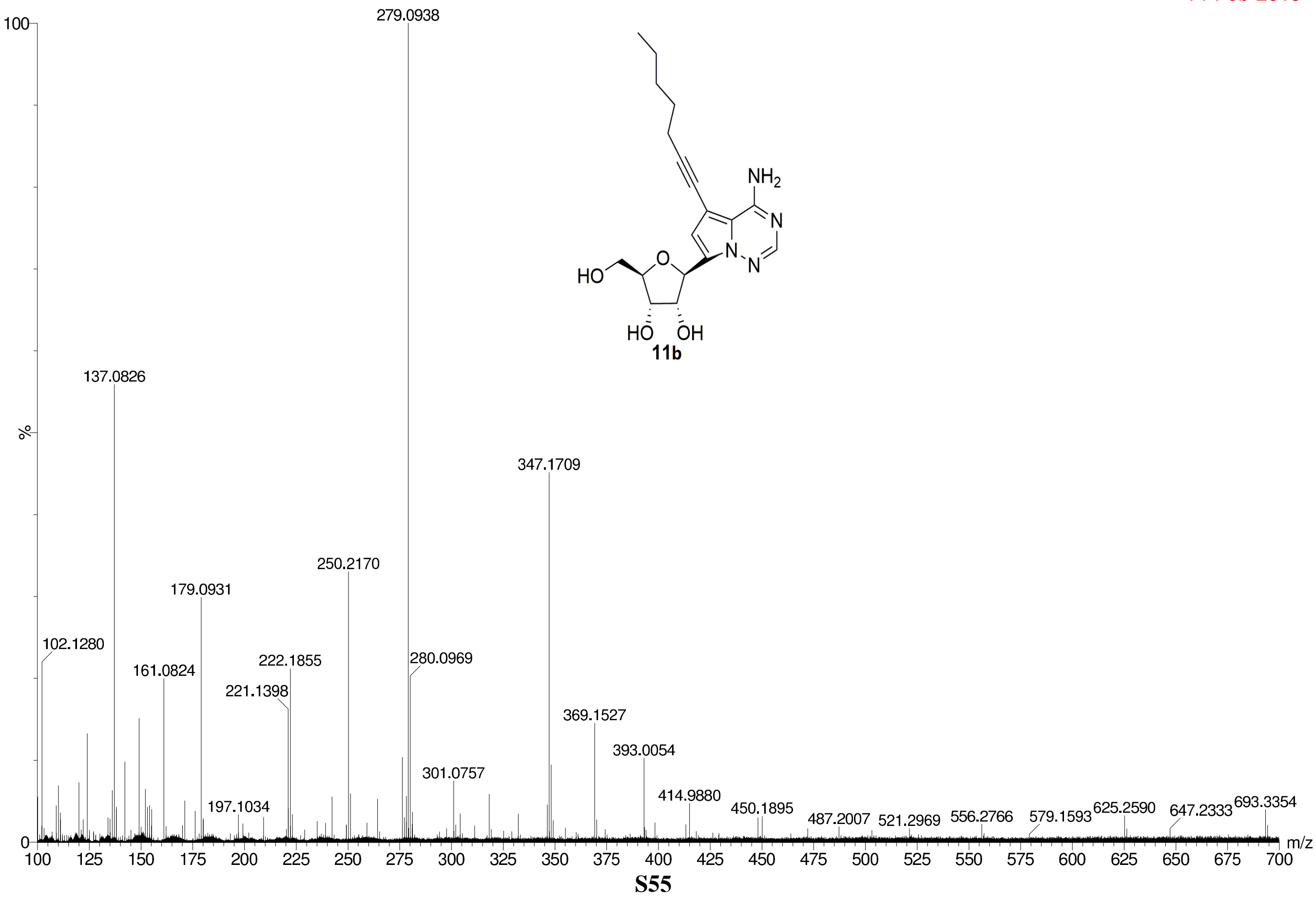




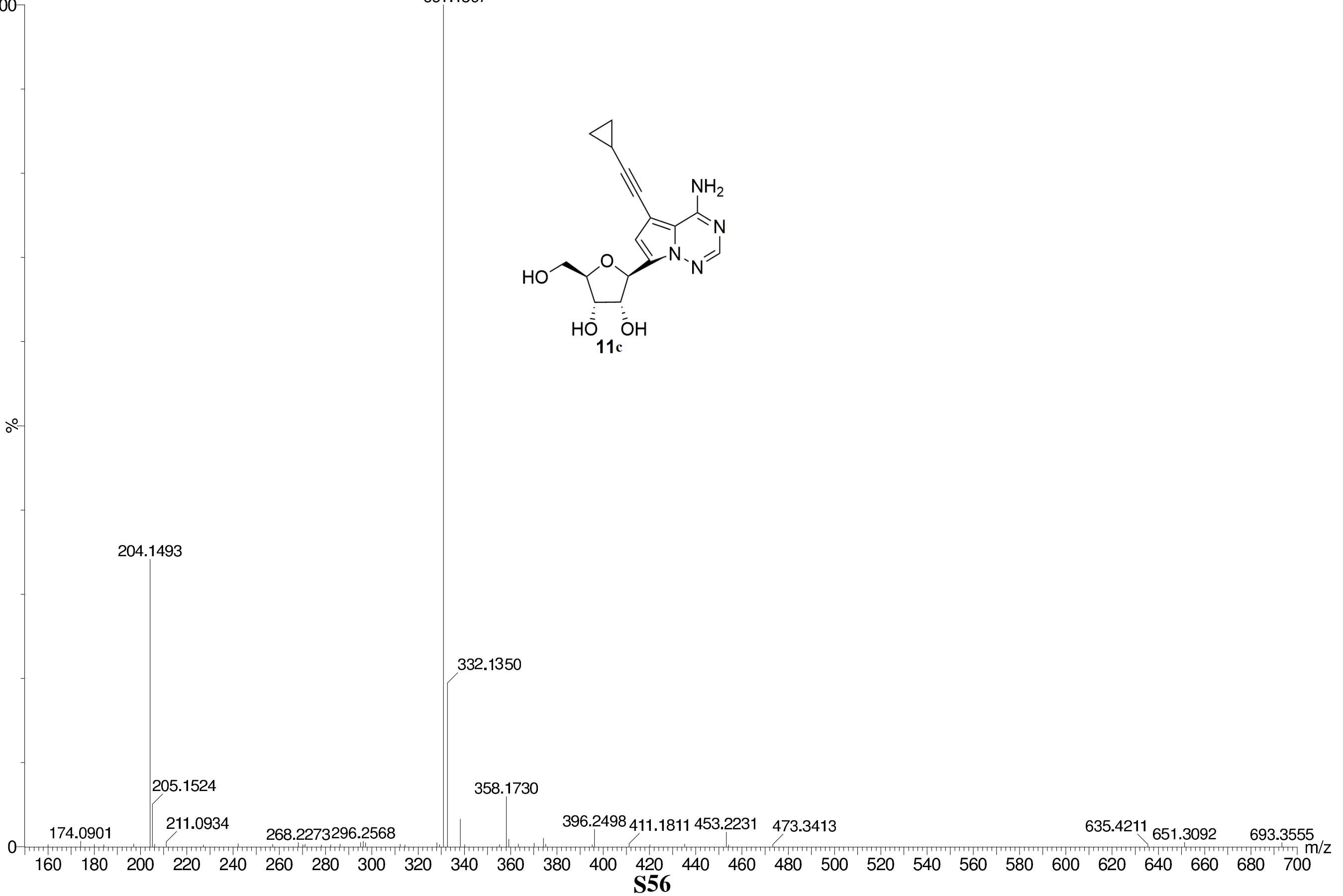




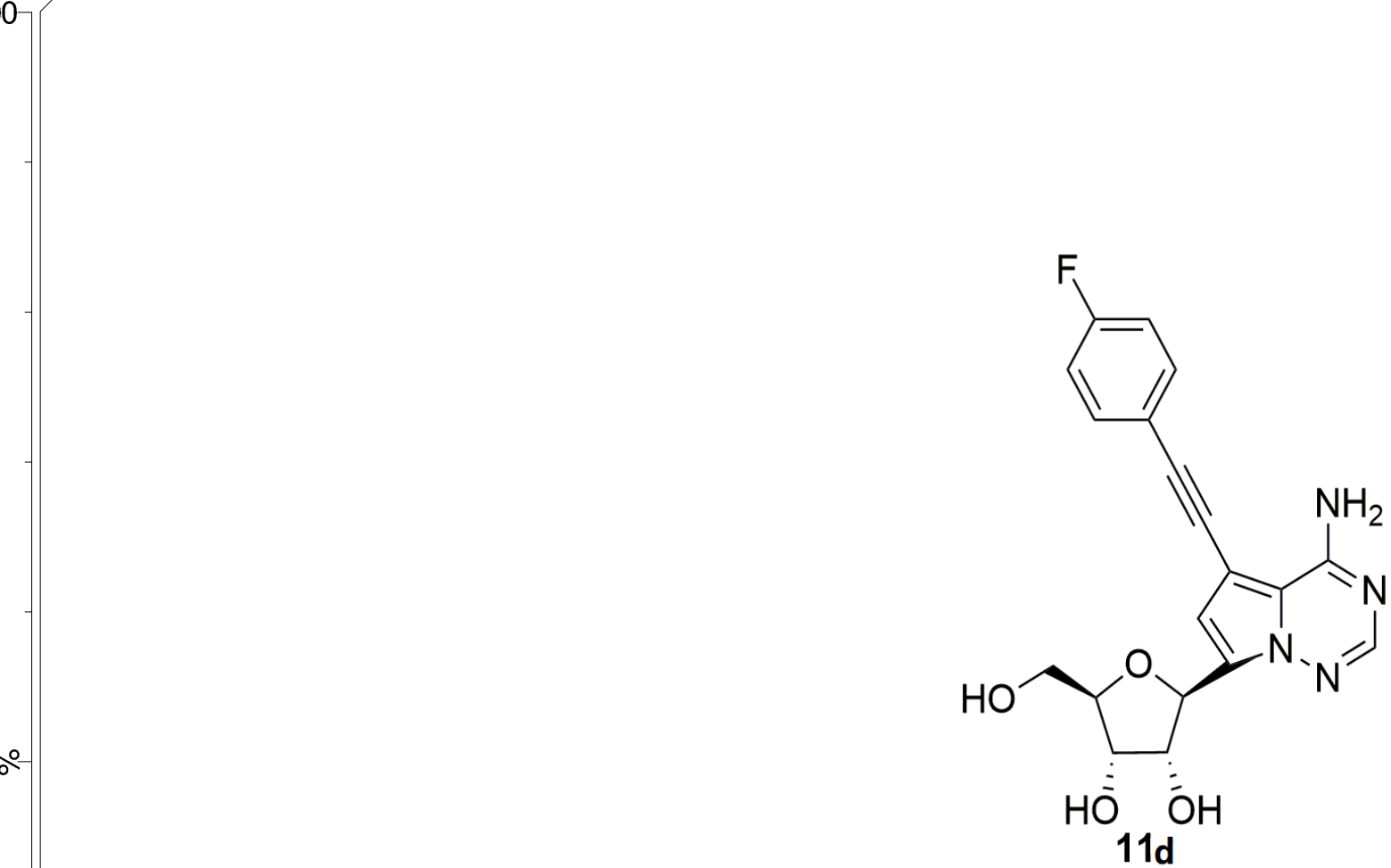

$103.1316 \quad 155.1549$

385.1304

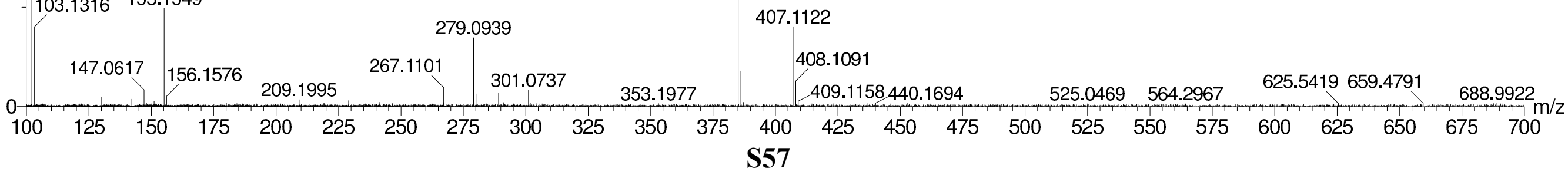




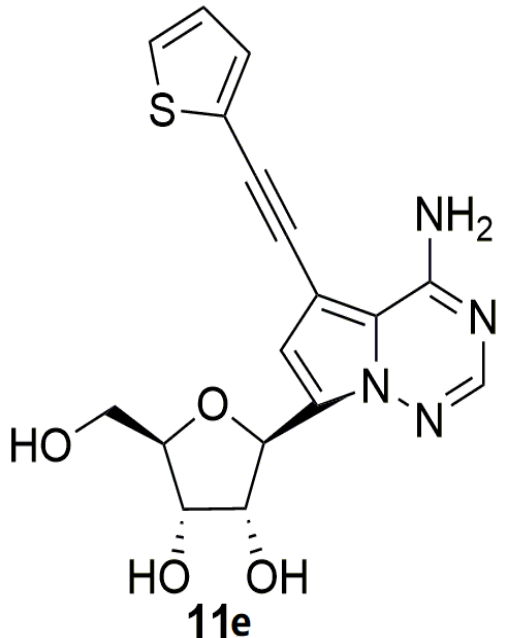

155.1551

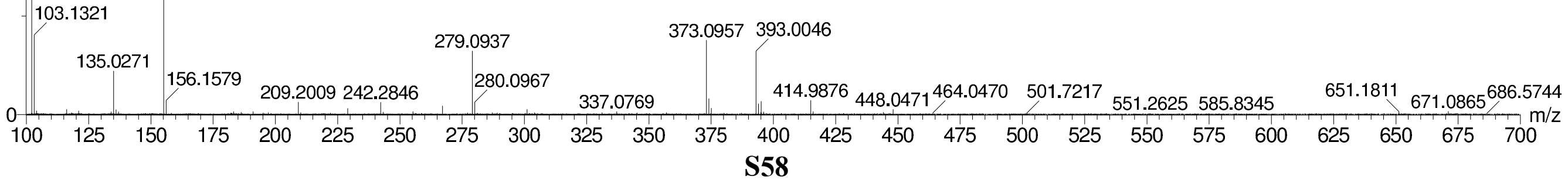




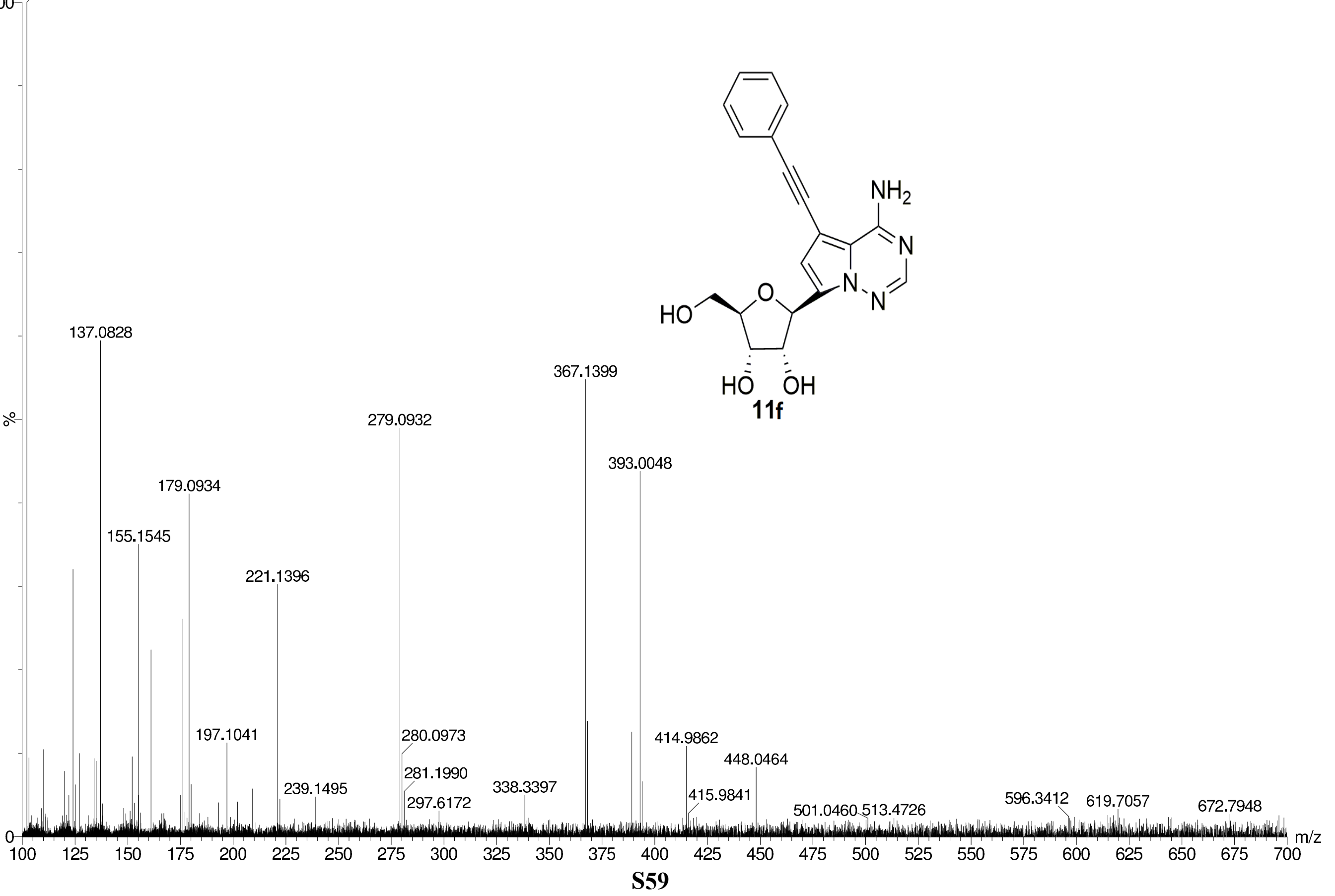




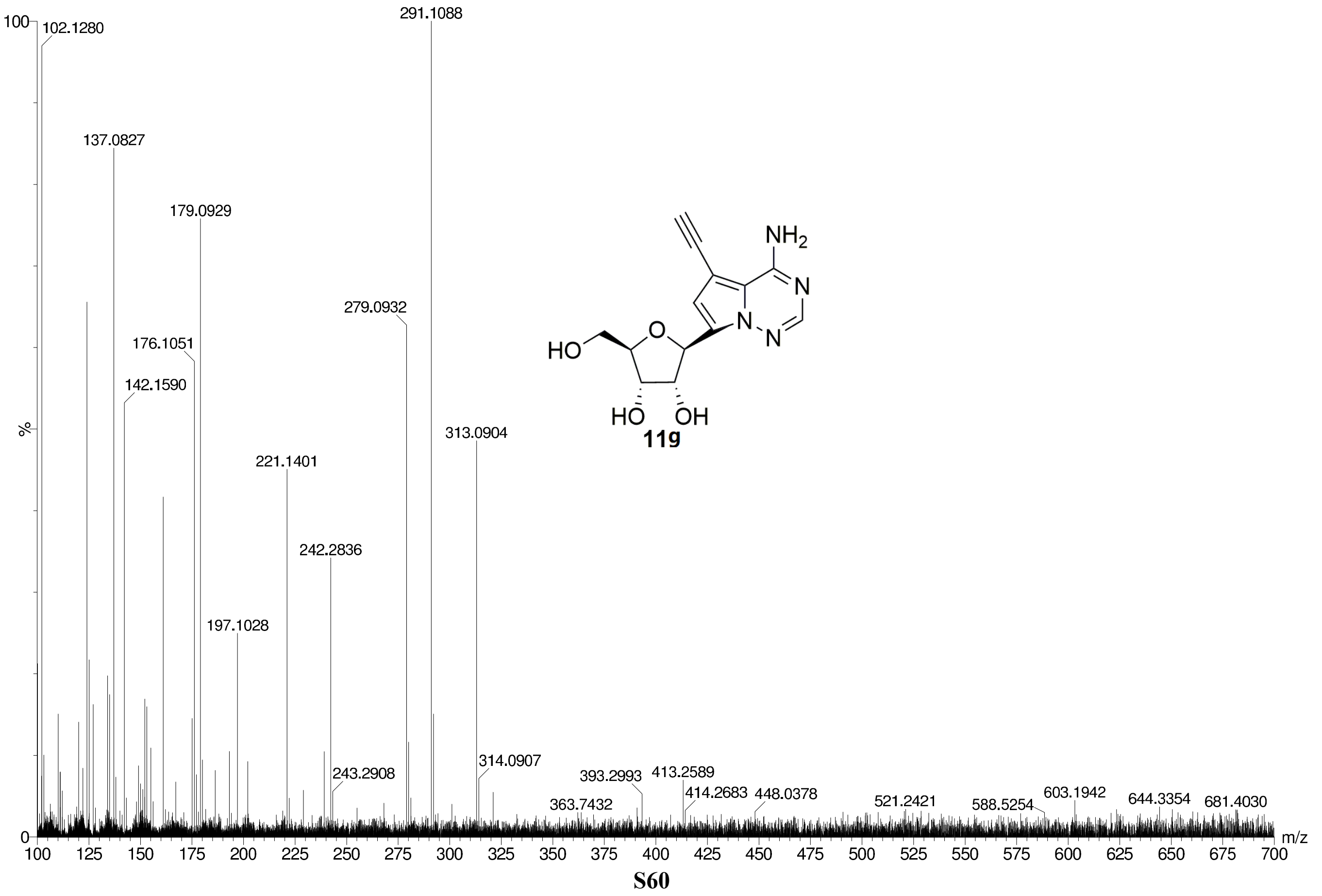


accurate mass

343.1394

100

100
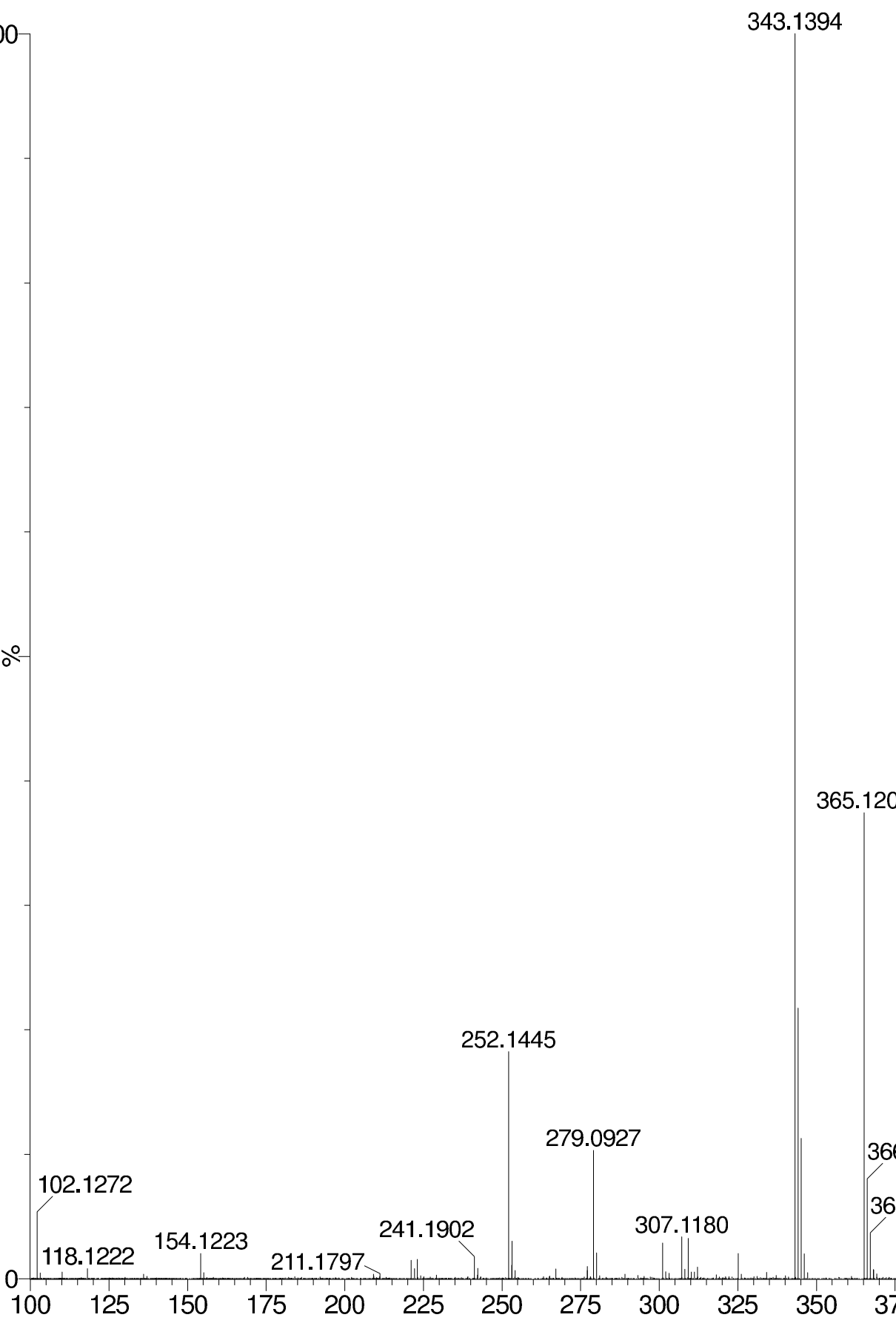

65.1207

366.1238

367.1342

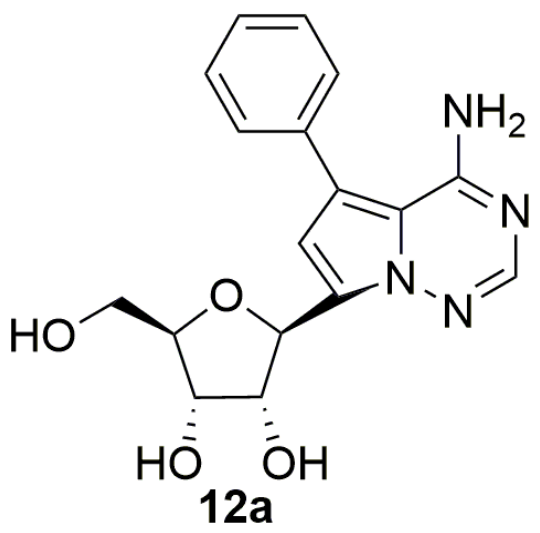

425.1784

685.2728

425.1811 468.2104 \begin{tabular}{llll|l}
530.2310 & 579.1601 & 621.2255 & 643.2080 & 687.2793
\end{tabular} 


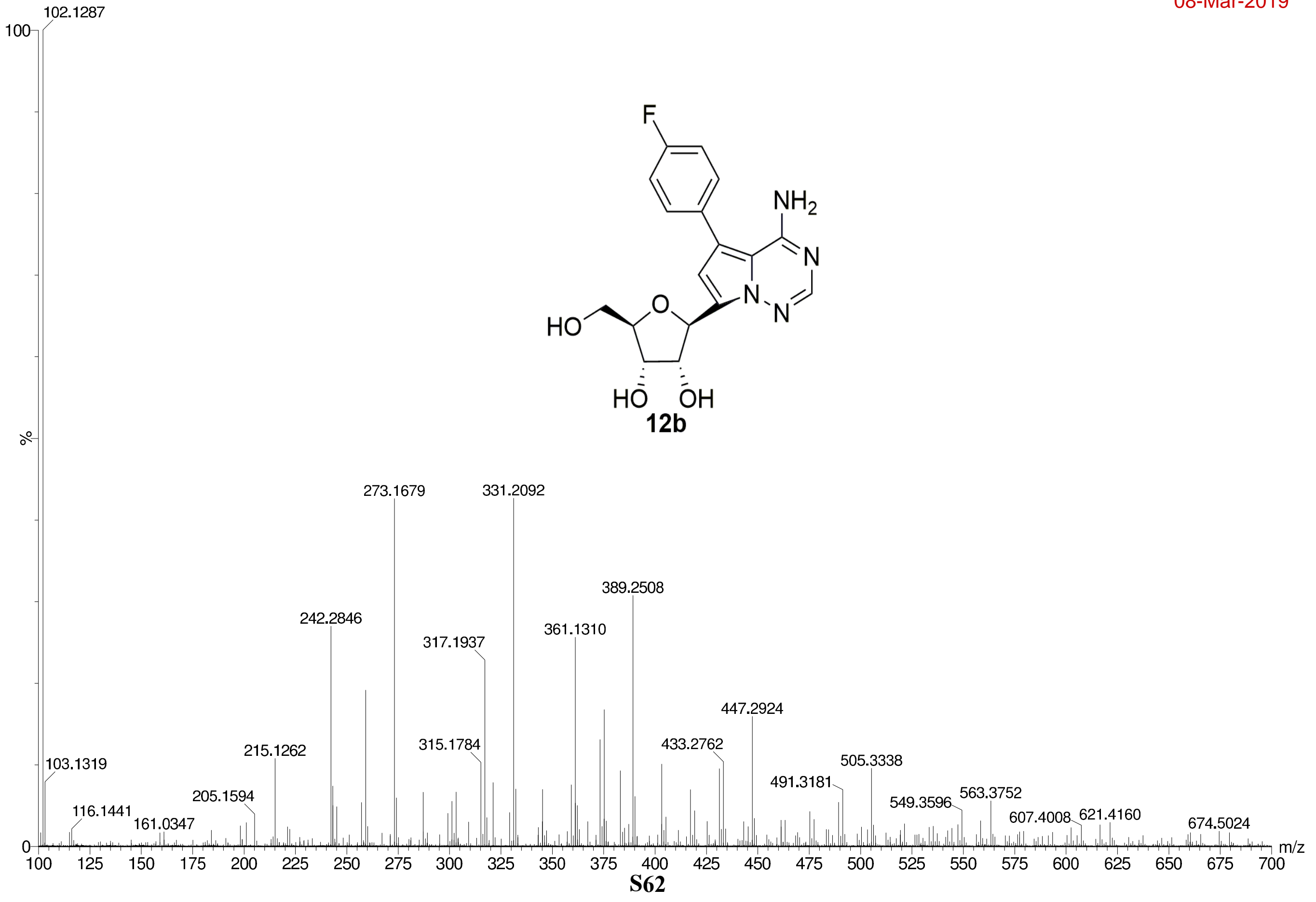




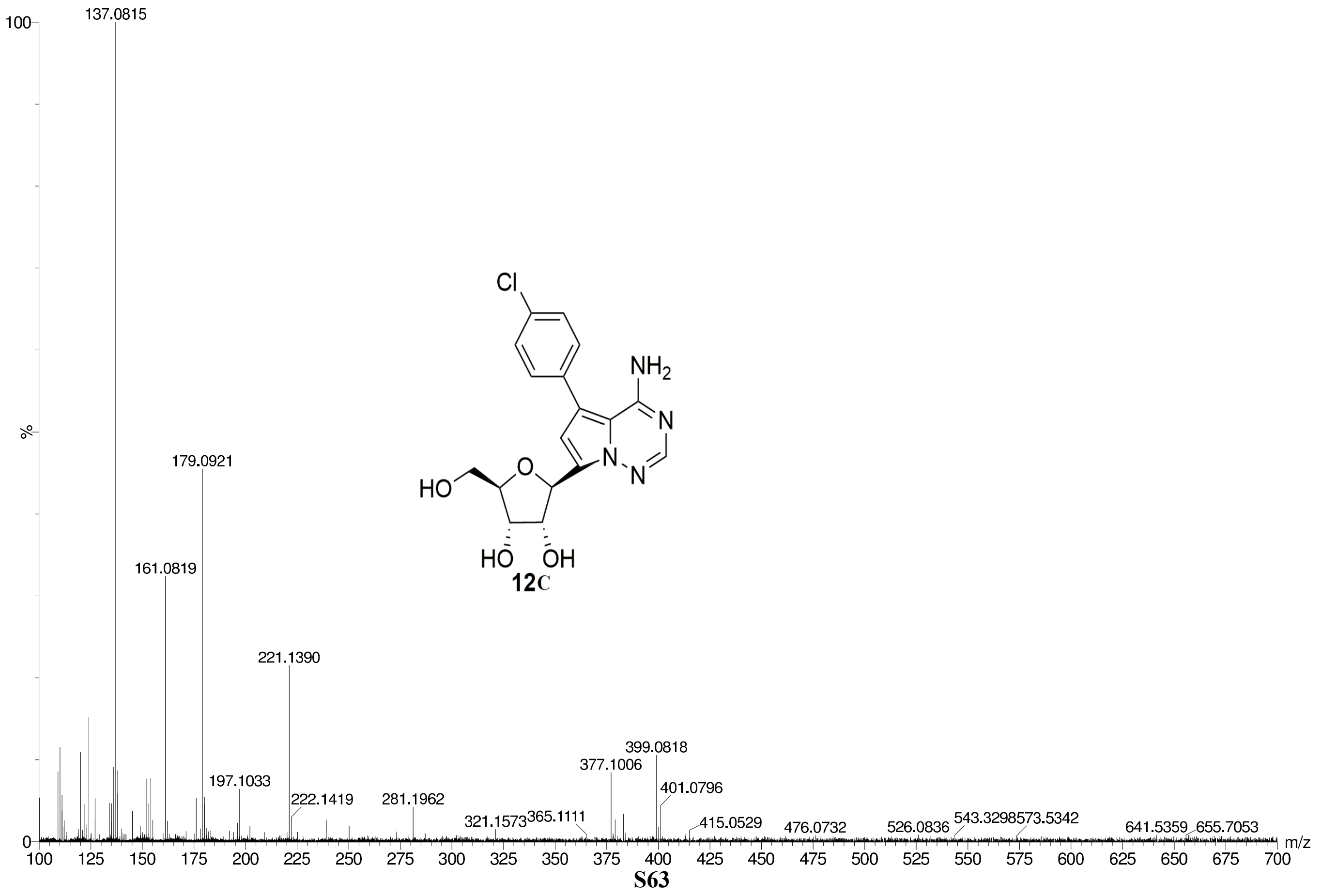


accurate mass

361.1310

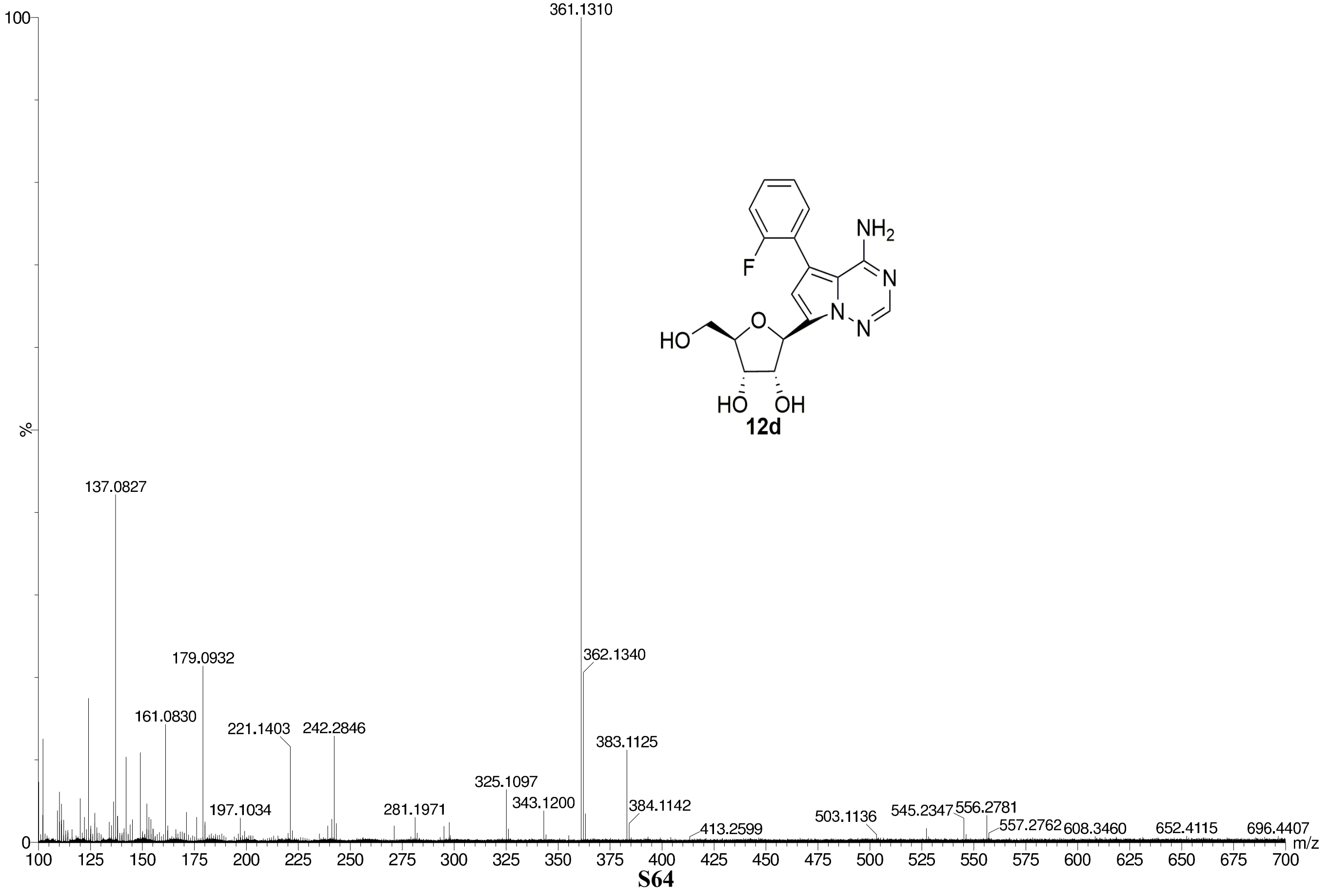




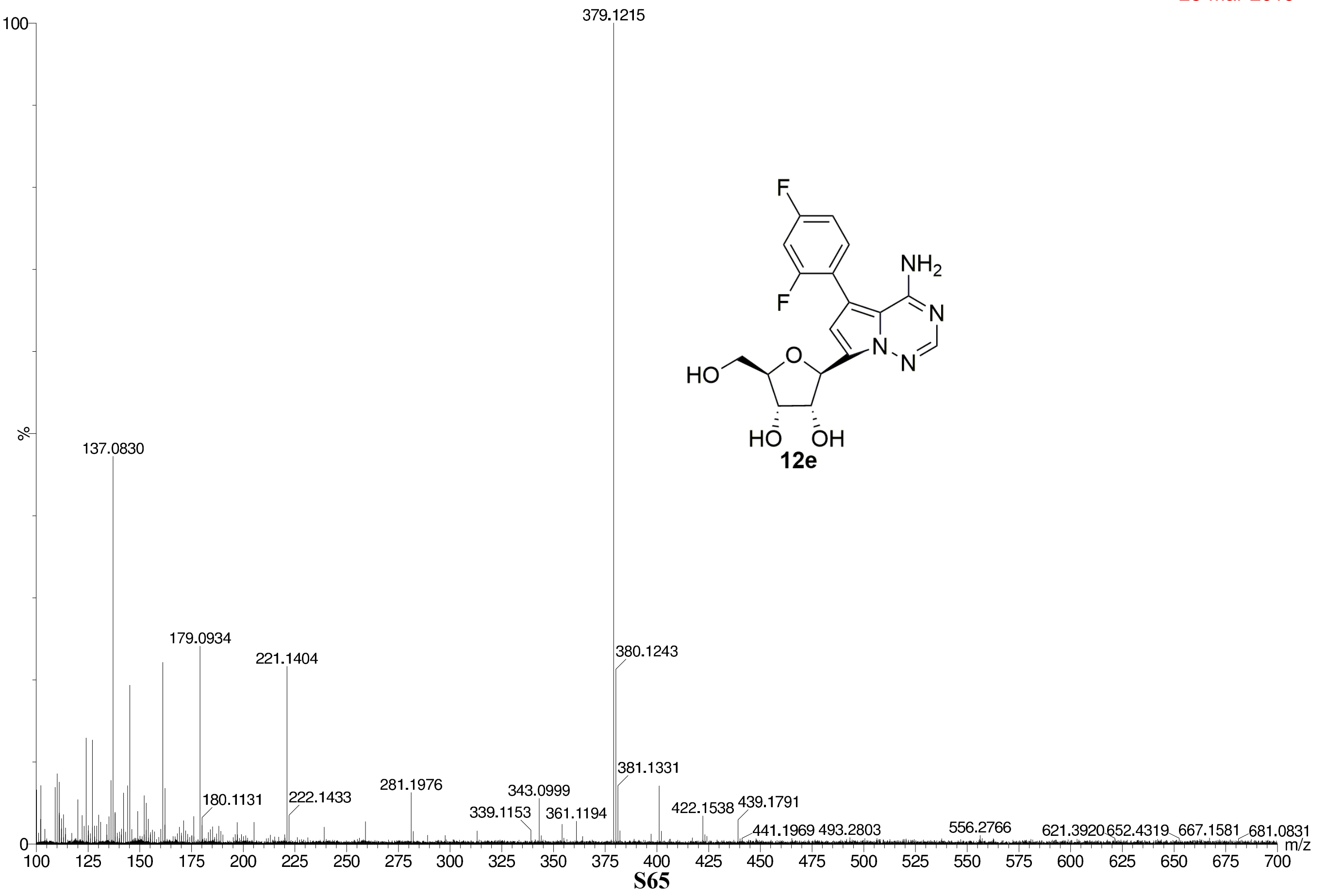




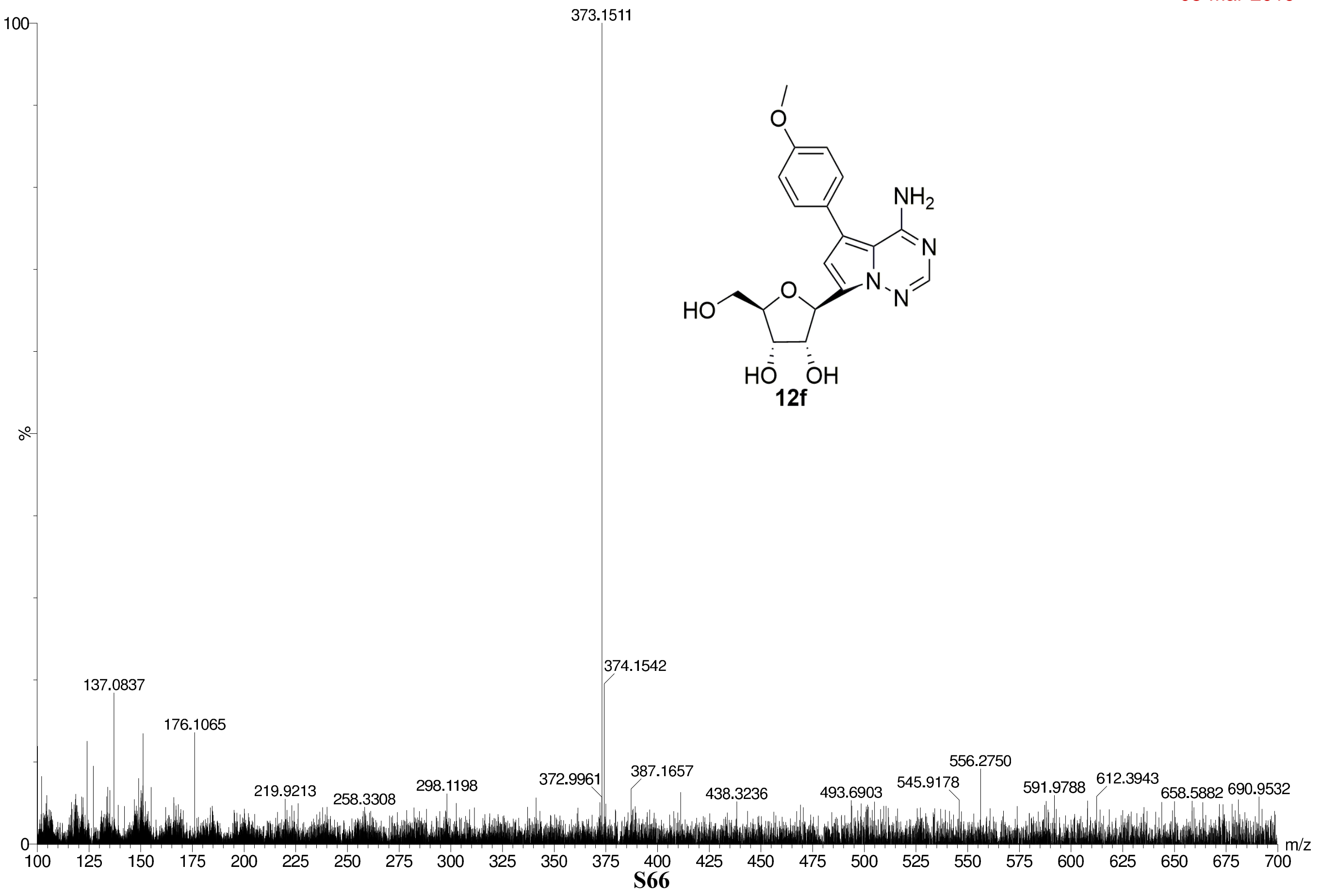




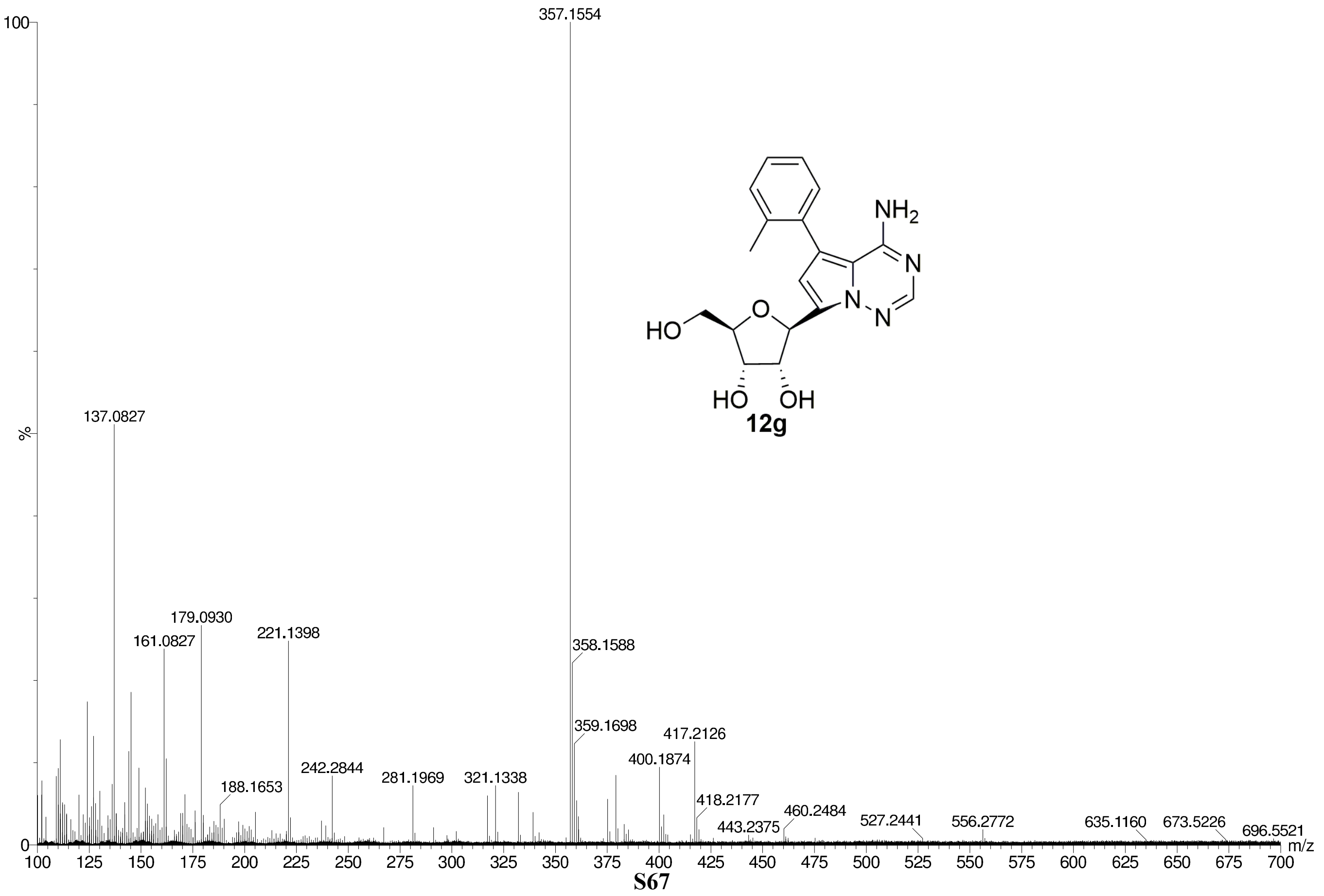




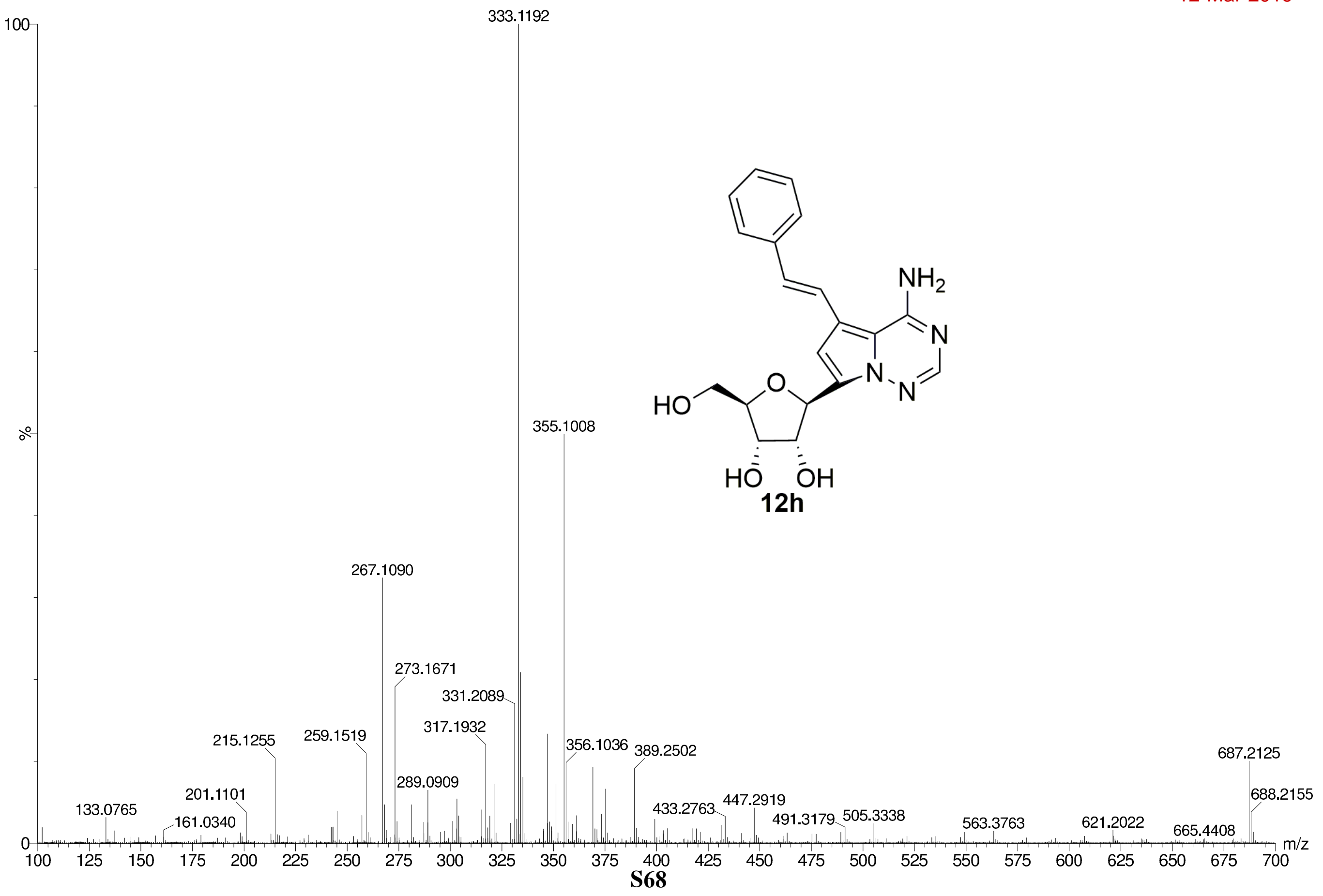




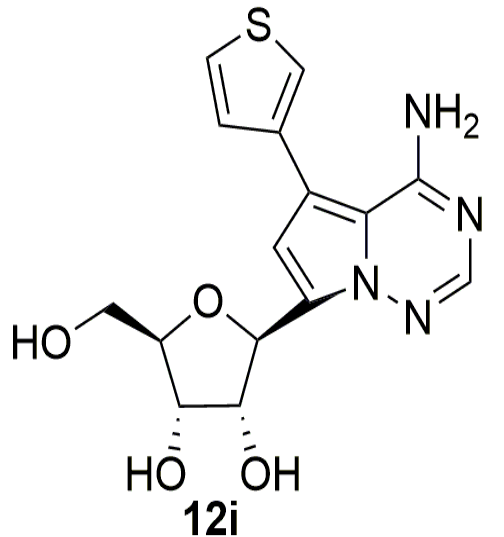

204.1282

391.1351

$413.2654 \quad 489.0102$ 650.7240 \begin{tabular}{l|l|l}
453.2570 & 468.5674 & 513.8329
\end{tabular} $559.6856 \quad 596.8278$

633.0443

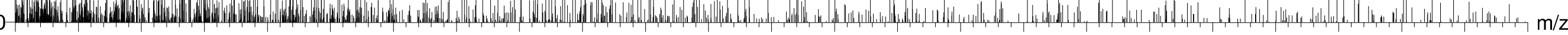

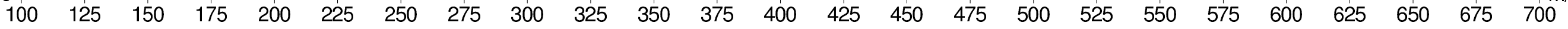




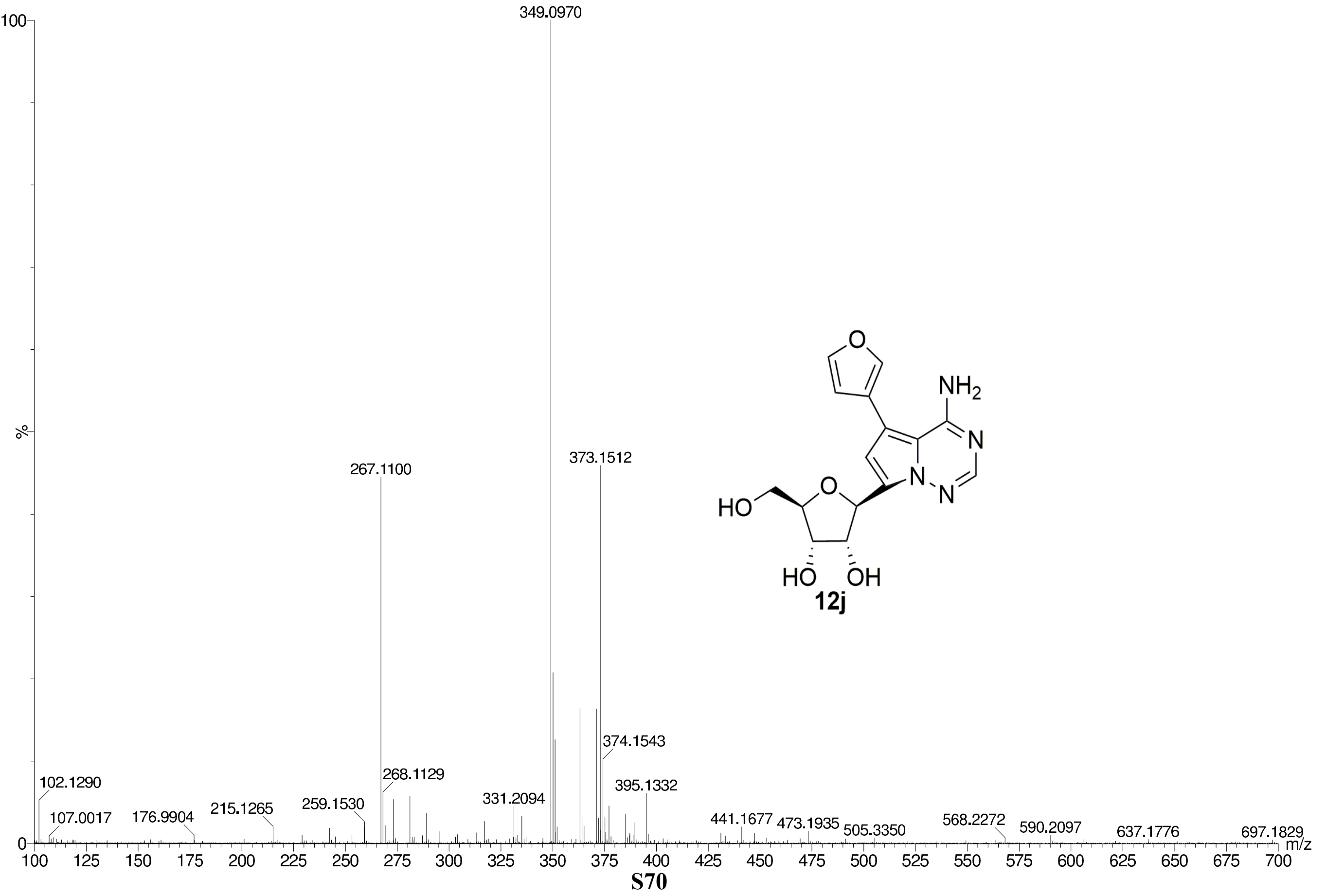


accurate mass

377.1010

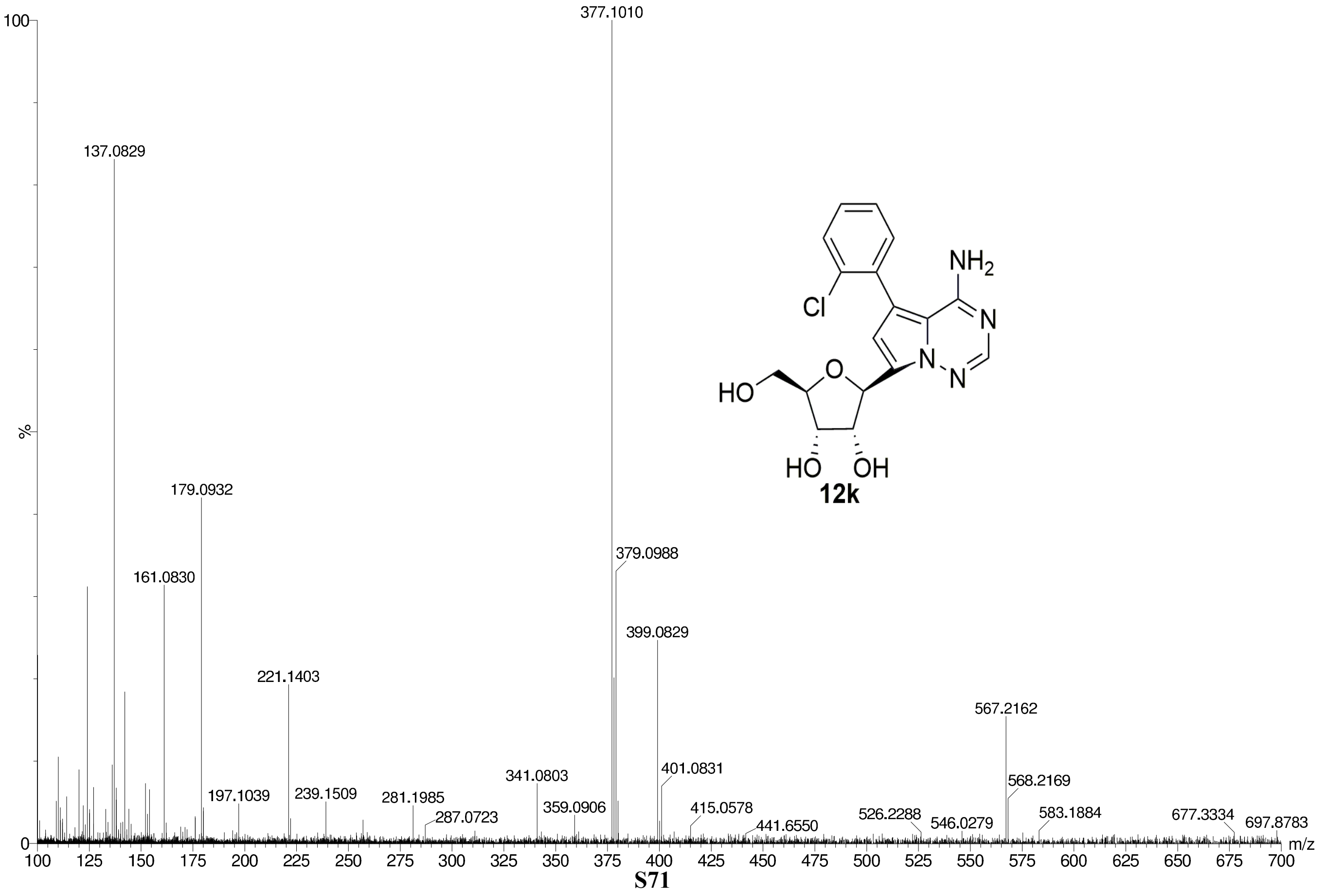

